SUPPORTING INFORMATION

\title{
Virginia Orange: A versatile, red-shifted fluorescein scaffold for single- and dual-input fluorogenic probes
}

\author{
Jonathan B. Grimm, Todd D. Gruber, Gloria Ortiz, Timothy A. Brown, and Luke D. Lavis* \\ Janelia Research Campus, Howard Hughes Medical Institute, \\ Ashburn, VA 20147
}

Email: lavis1@janelia.hhmi.org

\section{EXPERIMENTAL INFORMATION}

\begin{tabular}{ll} 
Page & Contents \\
\hline S2 & General Experimental Information for Synthesis \\
S2 & Experimentals and Characterization Data for All Compounds \\
S2 & Virginia Orange \\
S7 & Single-Input Fluorogenic Probes \\
S12 & Dual-Input Fluorogenic Probes \\
S16 & Probe 33 \\
S19 & Optical Spectroscopy and Microscopy Methods \\
S21 & Figures S1, S2 \\
S22 & References \\
S23 & NMR and HPLC/MS
\end{tabular}




\section{GENERAL EXPERIMENTAL INFORMATION FOR SYNTHESIS}

Commercial reagents were obtained from reputable suppliers and used as received. All solvents were purchased in septum-sealed bottles stored under an inert atmosphere. All reactions were sealed with septa through which a nitrogen atmosphere was introduced unless otherwise noted. Reactions were conducted in round-bottomed flasks or septum-capped crimp-top vials containing Teflon-coated magnetic stir bars. Heating of reactions was accomplished with a silicon oil bath or an aluminum reaction block on top of a stirring hotplate equipped with an electronic contact thermometer to maintain the indicated temperatures.

Reactions were monitored by thin layer chromatography (TLC) on precoated TLC glass plates (silica gel $60 \mathrm{~F}_{254}$, $250 \mu \mathrm{m}$ thickness) or by LC/MS (Phenomenex Kinetex $2.1 \mathrm{~mm} \times 30 \mathrm{~mm} 2.6 \mu \mathrm{m}$ C18 column; $5 \mu \mathrm{L}$ injection; 5$98 \% \mathrm{MeCN} / \mathrm{H}_{2} \mathrm{O}$, linear gradient, with constant $0.1 \% \mathrm{v} / \mathrm{v} \mathrm{HCO}_{2} \mathrm{H}$ additive; 6 min run; $0.5 \mathrm{~mL} / \mathrm{min}$ flow; ESI; positive ion mode). TLC chromatograms were visualized by UV illumination or developed with $p$-anisaldehyde, ceric ammonium molybdate, or $\mathrm{KMnO}_{4}$ stain. Reaction products were purified by flash chromatography on an automated purification system using pre-packed silica gel columns or by preparative HPLC (Phenomenex GeminiNX $30 \times 150 \mathrm{~mm} 5 \mu \mathrm{m} \mathrm{C18}$ column). Analytical HPLC analysis was performed with an Agilent Eclipse XDB $4.6 \times$ $150 \mathrm{~mm} 5 \mu \mathrm{m} \mathrm{C} 18$ column under the indicated conditions. High-resolution mass spectrometry was obtained by the Mass Spectrometry Center in the Department of Medicinal Chemistry at the University of Washington and the High Resolution Mass Spectrometry Facility at the University of Iowa.

NMR spectra were recorded on a $400 \mathrm{MHz}$ spectrometer. ${ }^{1} \mathrm{H}$ and ${ }^{13} \mathrm{C}$ chemical shifts ( $\delta$ ) were referenced to TMS or residual solvent peaks, ${ }^{1}$ and ${ }^{19} \mathrm{~F}$ chemical shifts $(\delta)$ were referenced to $\mathrm{CFCl}_{3}$. Data for ${ }^{1} \mathrm{H} \mathrm{NMR}$ spectra are reported as follows: chemical shift $(\delta \mathrm{ppm})$, multiplicity $(\mathrm{s}=$ singlet, $\mathrm{d}=$ doublet, $\mathrm{t}=$ triplet, $\mathrm{q}=$ quartet, $\mathrm{dd}=$ doublet of doublets, $\mathrm{m}=$ multiplet), coupling constant $(\mathrm{Hz})$, integration. Data for ${ }^{13} \mathrm{C}$ NMR spectra are reported by chemical shift ( $\delta$ ppm) with hydrogen multiplicity $\left(\mathrm{C}, \mathrm{CH}, \mathrm{CH}_{2}, \mathrm{CH}_{3}\right)$ information obtained from DEPT spectra.

\section{SYNTHESIS OF ViRginia ORANGE}

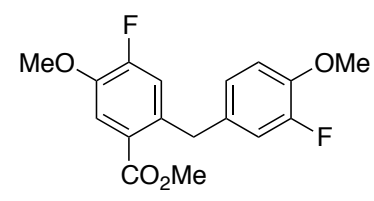

Methyl 4-fluoro-2-(3-fluoro-4-methoxybenzyl)-5-methoxybenzoate (7): A round bottom flask equipped with a reflux condenser was charged with methyl 2-bromo-4-fluoro-5-methoxybenzoate (5; $7.44 \mathrm{~g}, 28.3 \mathrm{mmol}), \mathrm{Pd}(\mathrm{OAc})_{2}$ (319 mg, $1.42 \mathrm{mmol}, 0.05 \mathrm{eq}$ ), and SPhos ( $1.16 \mathrm{~g}, 2.83 \mathrm{mmol}, 0.10 \mathrm{eq}$ ). The flask was evacuated and backfilled with nitrogen $(3 \times)$. Degassed THF ( $85 \mathrm{~mL}$ ) was added, followed by 3-fluoro-4-methoxybenzylzinc chloride (6; $0.5 \mathrm{M}$ in THF, $85.0 \mathrm{~mL}, 42.5 \mathrm{mmol}, 1.5 \mathrm{eq})$. The reaction was stirred under nitrogen in a $60{ }^{\circ} \mathrm{C}$ oil bath for $5 \mathrm{~h}$. It was subsequently cooled to room temperature, quenched with saturated $\mathrm{NH}_{4} \mathrm{Cl}$, diluted with water, and extracted with 
EtOAc (2x). The combined organic extracts were washed with brine, dried over anhydrous $\mathrm{MgSO}_{4}$, filtered, and concentrated in vacuo. Flash chromatography on silica gel (0-30\% EtOAc/hexanes, linear gradient; mixed fractions repurified with $0-20 \% \mathrm{Et}_{2} \mathrm{O} /$ hexanes, linear gradient) afforded $8.68 \mathrm{~g}(95 \%)$ of 7 as a pale yellow solid. ${ }^{1} \mathrm{H}$ NMR $\left(\mathrm{CDCl}_{3}, 400 \mathrm{MHz}\right) \delta 7.56\left(\mathrm{~d},{ }^{4} J_{\mathrm{HF}}=8.8 \mathrm{~Hz}, 1 \mathrm{H}\right), 6.91-6.81(\mathrm{~m}, 4 \mathrm{H}), 4.23(\mathrm{~s}, 2 \mathrm{H}), 3.91(\mathrm{~s}, 3 \mathrm{H}), 3.85(\mathrm{~s}, 3 \mathrm{H}), 3.85$ $(\mathrm{s}, 3 \mathrm{H}) ;{ }^{19} \mathrm{~F} \mathrm{NMR}\left(\mathrm{CDCl}_{3}, 376 \mathrm{MHz}\right) \delta-129.06\left(\mathrm{dd}, J_{\mathrm{FH}}=12.1,8.8 \mathrm{~Hz}, 1 \mathrm{~F}\right),-135.80\left(\mathrm{dd}, J_{\mathrm{FH}}=12.2,7.6 \mathrm{~Hz}, 1 \mathrm{~F}\right)$; ${ }^{13} \mathrm{C} \mathrm{NMR}\left(\mathrm{CDCl}_{3}, 101 \mathrm{MHz}\right) \delta 167.0(\mathrm{C}), 154.5\left(\mathrm{~d},{ }^{1} J_{\mathrm{CF}}=253.8 \mathrm{~Hz}, \mathrm{C}\right), 152.5\left(\mathrm{~d},{ }^{1} J_{\mathrm{CF}}=245.6 \mathrm{~Hz}, \mathrm{C}\right), 146.1\left(\mathrm{~d},{ }^{2} J_{\mathrm{CF}}\right.$ $=10.8 \mathrm{~Hz}, \mathrm{C}), 145.9\left(\mathrm{~d},{ }^{2} J_{\mathrm{CF}}=10.9 \mathrm{~Hz}, \mathrm{C}\right), 136.6\left(\mathrm{~d},{ }^{3} J_{\mathrm{CF}}=6.7 \mathrm{~Hz}, \mathrm{C}\right), 133.8\left(\mathrm{~d},{ }^{3} J_{\mathrm{CF}}=6.0 \mathrm{~Hz}, \mathrm{C}\right), 125.5\left(\mathrm{~d},{ }^{4} J_{\mathrm{CF}}=\right.$ $3.5 \mathrm{~Hz}, \mathrm{C}), 124.4\left(\mathrm{~d},{ }^{3} J_{\mathrm{CF}}=3.5 \mathrm{~Hz}, \mathrm{CH}\right), 119.1\left(\mathrm{~d},{ }^{2} J_{\mathrm{CF}}=18.9 \mathrm{~Hz}, \mathrm{CH}\right), 116.6\left(\mathrm{~d},{ }^{2} J_{\mathrm{CF}}=18.4 \mathrm{~Hz}, \mathrm{CH}\right), 116.2\left(\mathrm{~d},{ }^{3} J_{\mathrm{CF}}\right.$ $=3.3 \mathrm{~Hz}, \mathrm{CH}), 113.6\left(\mathrm{~d},{ }^{4} J_{\mathrm{CF}}=2.2 \mathrm{~Hz}, \mathrm{CH}\right), 56.6\left(\mathrm{CH}_{3}\right), 56.5\left(\mathrm{CH}_{3}\right), 52.2\left(\mathrm{CH}_{3}\right), 38.1\left(\mathrm{CH}_{2}\right)$; HRMS (EI) calcd for $\mathrm{C}_{17} \mathrm{H}_{16} \mathrm{~F}_{2} \mathrm{O}_{4}[\mathrm{M} \cdot]^{+}$322.1017, found 322.1013 .

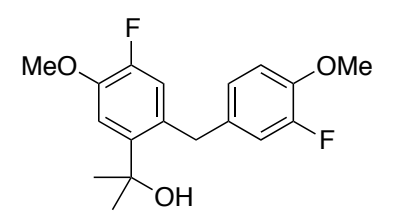

2-(4-Fluoro-2-(3-fluoro-4-methoxybenzyl)-5-methoxyphenyl)propan-2-ol (8): A solution of ester 7 (8.37 g, 26.0 $\mathrm{mmol})$ in THF $(120 \mathrm{~mL})$ was cooled to $-78^{\circ} \mathrm{C}$ under nitrogen. Methylmagnesium chloride $(3 \mathrm{M}$ in THF, $26.0 \mathrm{~mL}$, $77.9 \mathrm{mmol}, 3 \mathrm{eq}$ ) was added; the reaction was allowed to warm to room temperature and stirred overnight. It was subsequently quenched with saturated $\mathrm{NH}_{4} \mathrm{Cl}$, diluted with water, and extracted with EtOAc $(2 \times)$. The combined organic extracts were washed with brine, dried over anhydrous $\mathrm{MgSO}_{4}$, filtered, and concentrated in vacuo. The residue was purified by silica gel chromatography (0-30\% EtOAc/hexanes, linear gradient; mixed fractions repurified with $0-10 \%$ EtOAc/toluene, linear gradient) to provide 8 as a pale yellow oil (6.42 $\mathrm{g}, 77 \%)$. ${ }^{1} \mathrm{H}$ NMR $\left(\mathrm{CDCl}_{3}, 400 \mathrm{MHz}\right) \delta 7.11\left(\mathrm{~d},{ }^{4} J_{\mathrm{HF}}=8.9 \mathrm{~Hz}, 1 \mathrm{H}\right), 6.89-6.78(\mathrm{~m}, 3 \mathrm{H}), 6.76\left(\mathrm{~d},{ }^{3} J_{\mathrm{HF}}=12.6 \mathrm{~Hz}, 1 \mathrm{H}\right), 4.23(\mathrm{~s}, 2 \mathrm{H})$, $3.90(\mathrm{~s}, 3 \mathrm{H}), 3.86(\mathrm{~s}, 3 \mathrm{H}), 1.63(\mathrm{~s}, 6 \mathrm{H}) ;{ }^{19} \mathrm{~F} \mathrm{NMR}\left(\mathrm{CDCl}_{3}, 376 \mathrm{MHz}\right) \delta-135.72--135.82(\mathrm{~m}, 1 \mathrm{~F}),-138.36\left(\mathrm{dd}, J_{\mathrm{FH}}=\right.$ 12.6, 8.9 Hz, 1F); ${ }^{13} \mathrm{C} \mathrm{NMR}\left(\mathrm{CDCl}_{3}, 101 \mathrm{MHz}\right) \delta 152.5\left(\mathrm{~d},{ }^{1} J_{\mathrm{CF}}=245.6 \mathrm{~Hz}, \mathrm{C}\right), 151.1\left(\mathrm{~d},{ }^{1} J_{\mathrm{CF}}=245.5 \mathrm{~Hz}, \mathrm{C}\right), 145.9$ $\left(\mathrm{d},{ }^{2} J_{\mathrm{CF}}=10.8 \mathrm{~Hz}, \mathrm{C}\right), 145.2\left(\mathrm{~d},{ }^{2} J_{\mathrm{CF}}=10.3 \mathrm{~Hz}, \mathrm{C}\right), 142.3\left(\mathrm{~d},{ }^{4} J_{\mathrm{CF}}=3.6 \mathrm{~Hz}, \mathrm{C}\right), 135.3\left(\mathrm{~d},{ }^{3} J_{\mathrm{CF}}=5.8 \mathrm{~Hz}, \mathrm{C}\right), 131.3(\mathrm{~d}$, $\left.{ }^{3} J_{\mathrm{CF}}=5.4 \mathrm{~Hz}, \mathrm{C}\right), 124.3\left(\mathrm{~d},{ }^{3} J_{\mathrm{CF}}=3.4 \mathrm{~Hz}, \mathrm{CH}\right), 120.1\left(\mathrm{~d},{ }^{2} J_{\mathrm{CF}}=18.0 \mathrm{~Hz}, \mathrm{CH}\right), 116.6\left(\mathrm{~d},{ }^{2} J_{\mathrm{CF}}=18.4 \mathrm{~Hz}, \mathrm{CH}\right), 113.6$ $\left(\mathrm{d},{ }^{3} J_{\mathrm{CF}}=2.2 \mathrm{~Hz}, \mathrm{CH}\right), 112.2\left(\mathrm{~d},{ }^{4} J_{\mathrm{CF}}=2.2 \mathrm{~Hz}, \mathrm{CH}\right), 73.6(\mathrm{C}), 56.7\left(\mathrm{CH}_{3}\right), 56.5\left(\mathrm{CH}_{3}\right), 38.0\left(\mathrm{CH}_{2}\right), 32.0\left(\mathrm{CH}_{3}\right)$; HRMS (EI) calcd for $\mathrm{C}_{18} \mathrm{H}_{20} \mathrm{~F}_{2} \mathrm{O}_{3}[\mathrm{M} \cdot]^{+} 322.1381$, found 322.1381 .

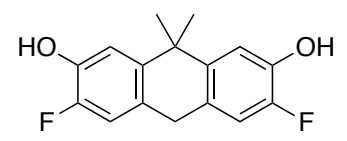

3,6-Difluoro-9,9-dimethyl-9,10-dihydroanthracene-2,7-diol (9): Alcohol 8 (6.17 g, $19.1 \mathrm{mmol})$ was taken up in $\mathrm{CH}_{2} \mathrm{Cl}_{2}(150 \mathrm{~mL})$ under nitrogen and cooled to $0{ }^{\circ} \mathrm{C} . \mathrm{BBr}_{3}\left(1.0 \mathrm{M}\right.$ in $\mathrm{CH}_{2} \mathrm{Cl}_{2}, 68.9 \mathrm{~mL}, 68.9 \mathrm{mmol}$, 3.6 eq $)$ was added dropwise. The reaction was warmed to room temperature and stirred for $2 \mathrm{~h}$. It was then carefully quenched with water $(\sim 50 \mathrm{~mL})$ and vigorously stirred for $30 \mathrm{~min}$. The mixture was neutralized (to $\mathrm{pH} \sim 7$ ) with saturated $\mathrm{NaHCO}_{3}$ and extracted with $\mathrm{CH}_{2} \mathrm{Cl}_{2}(2 \times)$ and EtOAc $(2 \times)$. The combined organics were dried over anhydrous 
$\mathrm{MgSO}_{4}$, filtered, concentrated in vacuo, and deposited onto Celite. Flash chromatography on silica gel (0-50\% EtOAc/hexanes, linear gradient; dry load with Celite) yielded $4.60 \mathrm{~g}(87 \%)$ of 9 as an air-sensitive, orange-yellow solid. ${ }^{1} \mathrm{H}$ NMR (DMSO- $\left.d_{6}, 400 \mathrm{MHz}\right) \delta 9.50(\mathrm{~s}, 2 \mathrm{H}), 7.08\left(\mathrm{~d},{ }^{4} J_{\mathrm{HF}}=8.9 \mathrm{~Hz}, 2 \mathrm{H}\right), 7.01\left(\mathrm{~d},{ }^{3} J_{\mathrm{HF}}=11.6 \mathrm{~Hz}, 2 \mathrm{H}\right), 3.80$ $(\mathrm{s}, 2 \mathrm{H}), 1.43(\mathrm{~s}, 6 \mathrm{H}) ;{ }^{19} \mathrm{~F}$ NMR (DMSO- $\left.d_{6}, 376 \mathrm{MHz}\right) \delta-140.30\left(\mathrm{dd}, J_{\mathrm{FH}}=11.3,9.1 \mathrm{~Hz}\right) ;{ }^{13} \mathrm{C}$ NMR (DMSO- $d_{6}, 101$ MHz) $\delta 149.0\left(\mathrm{~d},{ }^{1} J_{\mathrm{CF}}=239.3 \mathrm{~Hz}, \mathrm{C}\right), 142.7\left(\mathrm{~d},{ }^{2} J_{\mathrm{CF}}=12.1 \mathrm{~Hz}, \mathrm{C}\right), 140.4\left(\mathrm{~d},{ }^{4} J_{\mathrm{CF}}=3.1 \mathrm{~Hz}, \mathrm{C}\right), 126.5\left(\mathrm{~d},{ }^{3} J_{\mathrm{CF}}=6.1\right.$ $\mathrm{Hz}, \mathrm{C}), 114.7\left(\mathrm{~d},{ }^{2} J_{\mathrm{CF}}=18.0 \mathrm{~Hz}, \mathrm{CH}\right), 114.0\left(\mathrm{~d},{ }^{3} J_{\mathrm{CF}}=3.0 \mathrm{~Hz}, \mathrm{CH}\right), 38.2(\mathrm{C}), 32.7\left(\mathrm{CH}_{2}\right), 29.0\left(\mathrm{CH}_{3}\right) ; \mathrm{HRMS}(\mathrm{EI})$ calcd for $\mathrm{C}_{16} \mathrm{H}_{14} \mathrm{~F}_{2} \mathrm{O}_{2}[\mathrm{M} \cdot]^{+} 276.0962$, found 276.0968 .

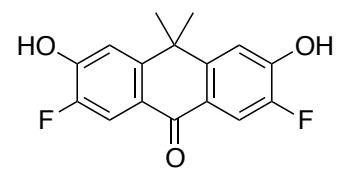

2,7-Difluoro-3,6-dihydroxy-10,10-dimethylanthracen-9(10H)-one (10): Phenol 9 (4.79 g, 17.3 mmol) was taken up in a mixture of $\mathrm{CH}_{2} \mathrm{Cl}_{2}(150 \mathrm{~mL})$ and dioxane $(75 \mathrm{~mL})$, and water $(19 \mathrm{~mL})$ was added. The mixture was cooled to $0{ }^{\circ} \mathrm{C}$, and DDQ $(11.80 \mathrm{~g}, 52.0 \mathrm{mmol}, 3 \mathrm{eq})$ was added. The reaction was warmed to room temperature and stirred overnight. The crude reaction mixture was deposited onto Celite and concentrated to dryness. Flash chromatography $\left(10-100 \%\right.$ EtOAc/hexanes, linear gradient; dry load with Celite) afforded $\mathbf{1 0}(3.19 \mathrm{~g}, 63 \%)$ as an off-white solid. ${ }^{1} \mathrm{H}$ NMR (DMSO- $\left.d_{6}, 400 \mathrm{MHz}\right) \delta 10.92(\mathrm{~s}, 2 \mathrm{H}), 7.77\left(\mathrm{~d},{ }^{3} J_{\mathrm{HF}}=11.7 \mathrm{~Hz}, 2 \mathrm{H}\right), 7.30\left(\mathrm{~d},{ }^{4} J_{\mathrm{HF}}=8.1 \mathrm{~Hz}, 2 \mathrm{H}\right), 1.60(\mathrm{~s}, 6 \mathrm{H})$; ${ }^{19} \mathrm{~F}$ NMR (DMSO- $\left.d_{6}, 376 \mathrm{MHz}\right) \delta-137.16\left(\mathrm{dd}, J_{\mathrm{FH}}=11.5,8.2 \mathrm{~Hz}\right.$ ) ${ }^{13} \mathrm{C}$ NMR (DMSO- $\left.d_{6}, 101 \mathrm{MHz}\right) \delta 179.1(\mathrm{C})$, $150.3\left(\mathrm{~d},{ }^{2} J_{\mathrm{CF}}=13.1 \mathrm{~Hz}, \mathrm{C}\right), 150.2\left(\mathrm{~d},{ }^{1} J_{\mathrm{CF}}=243.5 \mathrm{~Hz}, \mathrm{C}\right), 148.3\left(\mathrm{~d},{ }^{4} J_{\mathrm{CF}}=2.7 \mathrm{~Hz}, \mathrm{C}\right), 121.9\left(\mathrm{~d},{ }^{3} J_{\mathrm{CF}}=4.4 \mathrm{~Hz}, \mathrm{C}\right)$, $115.5\left(\mathrm{~d},{ }^{3} J_{\mathrm{CF}}=2.6 \mathrm{~Hz}, \mathrm{CH}\right), 113.1\left(\mathrm{~d},{ }^{2} J_{\mathrm{CF}}=18.3 \mathrm{~Hz}, \mathrm{CH}\right), 37.2(\mathrm{C}), 32.8\left(\mathrm{CH}_{3}\right)$; HRMS (ESI) calcd for $\mathrm{C}_{16} \mathrm{H}_{13} \mathrm{~F}_{2} \mathrm{O}_{3}[\mathrm{M}+\mathrm{H}]^{+}$291.0827, found 291.0831.

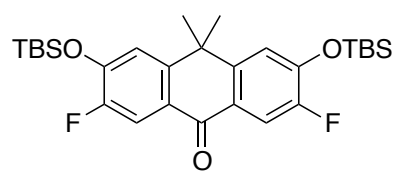

3,6-Bis((tert-butyldimethylsilyl)oxy)-2,7-difluoro-10,10-dimethylanthracen-9(10H)-one (11): To a solution of 10 (436 mg, $1.50 \mathrm{mmol})$ in DMF (10 mL) were added imidazole (307 mg, $4.51 \mathrm{mmol}, 3 \mathrm{eq})$ and TBSCl (680 mg, $4.51 \mathrm{mmol}, 3 \mathrm{eq}$ ). The reaction was stirred at room temperature for $3 \mathrm{~h}$. It was subsequently diluted with water and extracted with EtOAc (2x). The combined organic extracts were washed with water and brine, dried over anhydrous $\mathrm{MgSO}_{4}$, filtered, and concentrated in vacuo. Silica gel chromatography (0-10\% EtOAc/hexanes, linear gradient) afforded $631 \mathrm{mg}(81 \%)$ of $\mathbf{1 1}$ as a colorless solid. ${ }^{1} \mathrm{H} \mathrm{NMR}\left(\mathrm{CDCl}_{3}, 400 \mathrm{MHz}\right) \delta 7.99\left(\mathrm{~d},{ }^{3} J_{\mathrm{HF}}=11.1 \mathrm{~Hz}, 2 \mathrm{H}\right), 7.11$ $\left(\mathrm{d},{ }^{4} J_{\mathrm{HF}}=7.7 \mathrm{~Hz}, 2 \mathrm{H}\right), 1.64(\mathrm{~s}, 6 \mathrm{H}), 1.03(\mathrm{~s}, 18 \mathrm{H}), 0.27$ (s, 6H), $0.26(\mathrm{~s}, 6 \mathrm{H}) ;{ }^{19} \mathrm{~F} \mathrm{NMR}\left(\mathrm{CDCl}_{3}, 376 \mathrm{MHz}\right) \delta-133.34$ - -133.46 (m); ${ }^{13} \mathrm{C}$ NMR $\left(\mathrm{CDCl}_{3}, 101 \mathrm{MHz}\right) \delta 180.7(\mathrm{C}), 153.3\left(\mathrm{~d},{ }^{1} J_{\mathrm{CF}}=246.7 \mathrm{~Hz}, \mathrm{C}\right), 148.6\left(\mathrm{~d},{ }^{2} J_{\mathrm{CF}}=13.4 \mathrm{~Hz}, \mathrm{C}\right)$, $147.8\left(\mathrm{~d},{ }^{4} J_{\mathrm{CF}}=3.2 \mathrm{~Hz}, \mathrm{C}\right), 124.9\left(\mathrm{~d},{ }^{3} J_{\mathrm{CF}}=5.5 \mathrm{~Hz}, \mathrm{C}\right), 120.1\left(\mathrm{~d},{ }^{3} J_{\mathrm{CF}}=1.7 \mathrm{~Hz}, \mathrm{CH}\right), 114.7\left(\mathrm{~d},{ }^{2} J_{\mathrm{CF}}=19.6 \mathrm{~Hz}, \mathrm{CH}\right)$, $37.4(\mathrm{C}), 33.3\left(\mathrm{CH}_{3}\right), 25.7\left(\mathrm{CH}_{3}\right), 18.6(\mathrm{C}),-4.4\left(\mathrm{CH}_{3}\right),-4.5\left(\mathrm{CH}_{3}\right)$; HRMS (ESI) calcd for $\mathrm{C}_{28} \mathrm{H}_{41} \mathrm{~F}_{2} \mathrm{O}_{3} \mathrm{Si}_{2}[\mathrm{M}+\mathrm{H}]^{+}$ 519.2557 , found 519.2566 . 


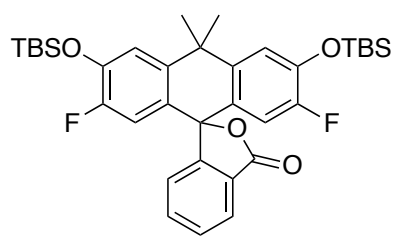

\section{3,6-Bis((tert-butyldimethylsilyl)oxy)-2,7-difluoro-10,10-dimethyl-3' $H, 10 H$-spiro[anthracene-9, 1'-}

isobenzofuran]-3'-one (14): A vial was charged with tert-butyl 2-bromobenzoate (12; $372 \mathrm{mg}, 1.45 \mathrm{mmol}, 1.5 \mathrm{eq})$, sealed, and flushed with nitrogen. After dissolving the bromide in THF $(2.5 \mathrm{~mL})$ and cooling the reaction to $-15^{\circ} \mathrm{C}$, $i$-PrMgCl-LiCl $(1.3 \mathrm{M}$ in THF, $1.11 \mathrm{~mL}, 1.45 \mathrm{mmol}, 1.5 \mathrm{eq})$ was added. The reaction was warmed to $-5{ }^{\circ} \mathrm{C}$ and stirred for $6 \mathrm{~h}$. Ketone 11 (500 mg, $0.964 \mathrm{mmol})$ in THF (2.5 mL) was then added dropwise. The reaction mixture was warmed to room temperature and stirred for $30 \mathrm{~min}$. It was subsequently quenched with saturated $\mathrm{NH}_{4} \mathrm{Cl}$, diluted with water, and extracted with EtOAc $(2 x)$. The combined organics were washed with brine, dried over anhydrous $\mathrm{MgSO}_{4}$, filtered, and evaporated. Silica gel chromatography (0-20\% Et $2 \mathrm{O} /$ hexanes, linear gradient) provided $302 \mathrm{mg}(50 \%)$ of $\mathbf{1 4}$ as a colorless foam. ${ }^{1} \mathrm{H} \mathrm{NMR}\left(\mathrm{CDCl}_{3}, 400 \mathrm{MHz}\right) \delta 8.05-8.01(\mathrm{~m}, 1 \mathrm{H}), 7.68-7.58$ $(\mathrm{m}, 2 \mathrm{H}), 7.11\left(\mathrm{~d},{ }^{4} J_{\mathrm{HF}}=8.3 \mathrm{~Hz}, 2 \mathrm{H}\right), 7.07-7.03(\mathrm{~m}, 1 \mathrm{H}), 6.38\left(\mathrm{~d},{ }^{3} J_{\mathrm{HF}}=11.4 \mathrm{~Hz}, 2 \mathrm{H}\right), 1.76(\mathrm{~s}, 3 \mathrm{H}), 1.67(\mathrm{~s}, 3 \mathrm{H})$, $1.00(\mathrm{~s}, 18 \mathrm{H}), 0.20(\mathrm{~s}, 12 \mathrm{H}) ;{ }^{19} \mathrm{~F} \mathrm{NMR}\left(\mathrm{CDCl}_{3}, 376 \mathrm{MHz}\right) \delta-133.46--133.54(\mathrm{~m}) ;{ }^{13} \mathrm{C} \mathrm{NMR}\left(\mathrm{CDCl}_{3}, 101 \mathrm{MHz}\right) \delta$ $170.1(\mathrm{C}), 154.4(\mathrm{C}), 152.7\left(\mathrm{~d},{ }^{1} J_{\mathrm{CF}}=245.5 \mathrm{~Hz}, \mathrm{C}\right), 144.5\left(\mathrm{~d},{ }^{2} J_{\mathrm{CF}}=12.7 \mathrm{~Hz}, \mathrm{C}\right), 141.7\left(\mathrm{~d},{ }^{4} J_{\mathrm{CF}}=3.4 \mathrm{~Hz}, \mathrm{C}\right), 135.2$ $(\mathrm{CH}), 129.8(\mathrm{CH}), 126.3(\mathrm{C}), 125.6(\mathrm{CH}), 125.2\left(\mathrm{~d},{ }^{3} J_{\mathrm{CF}}=5.6 \mathrm{~Hz}, \mathrm{C}\right), 123.8(\mathrm{CH}), 120.1\left(\mathrm{~d},{ }^{3} J_{\mathrm{CF}}=1.9 \mathrm{~Hz}, \mathrm{CH}\right)$, $115.1\left(\mathrm{~d},{ }^{2} J_{\mathrm{CF}}=20.1 \mathrm{~Hz}, \mathrm{CH}\right), 85.5(\mathrm{C}), 37.7(\mathrm{C}), 35.3\left(\mathrm{CH}_{3}\right), 33.1\left(\mathrm{CH}_{3}\right), 25.7\left(\mathrm{CH}_{3}\right), 18.5(\mathrm{C}),-4.49\left(\mathrm{CH}_{3}\right),-4.51$ $\left(\mathrm{CH}_{3}\right)$; HRMS (ESI) calcd for $\mathrm{C}_{35} \mathrm{H}_{45} \mathrm{~F}_{2} \mathrm{O}_{4} \mathrm{Si}_{2}[\mathrm{M}+\mathrm{H}]^{+}$623.2819, found 623.2827.

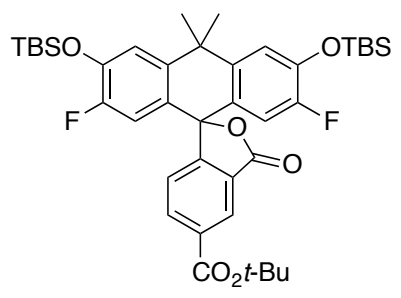

tert-Butyl 3,6-bis((tert-butyldimethylsilyl)oxy)-2,7-difluoro-10,10-dimethyl-3'-oxo-3'H,10H-spiro[anthracene9,1'-isobenzofuran]-5'-carboxylate (15): A vial was charged with di-tert-butyl 4-bromoisophthalate ${ }^{2}$ (13; $1.03 \mathrm{~g}$, $2.89 \mathrm{mmol}, 1.5 \mathrm{eq})$, sealed, and flushed with nitrogen. After dissolving the bromide in THF (5 mL) and cooling the reaction to $-15^{\circ} \mathrm{C}, i$-PrMgCl$\cdot \mathrm{LiCl}(1.3 \mathrm{M}$ in $\mathrm{THF}, 2.22 \mathrm{~mL}, 2.89 \mathrm{mmol}, 1.5 \mathrm{eq})$ was added. The reaction was warmed to $-5{ }^{\circ} \mathrm{C}$ and stirred for $5 \mathrm{~h}$. Ketone 11 (1.00 g, $\left.1.93 \mathrm{mmol}\right)$ in THF $(4 \mathrm{~mL})$ was then added dropwise. The reaction mixture was warmed to room temperature and stirred for $2 \mathrm{~h}$. It was subsequently quenched with saturated $\mathrm{NH}_{4} \mathrm{Cl}$, diluted with water, and extracted with EtOAc $(2 \times)$. The combined organics were washed with brine, dried over anhydrous $\mathrm{MgSO}_{4}$, filtered, and evaporated. Silica gel chromatography (0-10\% Et $2 \mathrm{O} /$ hexanes, linear gradient) provided $672 \mathrm{mg}(48 \%)$ of 15 as a colorless foam. ${ }^{1} \mathrm{H}$ NMR $\left(\mathrm{CDCl}_{3}, 400 \mathrm{MHz}\right) \delta 8.63(\mathrm{dd}, J=1.5,0.7 \mathrm{~Hz}, 1 \mathrm{H}), 8.28$ $(\mathrm{dd}, J=8.0,1.5 \mathrm{~Hz}, 1 \mathrm{H}), 7.13\left(\mathrm{~d},{ }^{4} J_{\mathrm{HF}}=8.3 \mathrm{~Hz}, 2 \mathrm{H}\right), 7.09(\mathrm{dd}, J=8.0,0.7 \mathrm{~Hz}, 1 \mathrm{H}), 6.37\left(\mathrm{~d},{ }^{3} J_{\mathrm{HF}}=11.3 \mathrm{~Hz}, 2 \mathrm{H}\right)$, $1.77(\mathrm{~s}, 3 \mathrm{H}), 1.68(\mathrm{~s}, 3 \mathrm{H}), 1.64(\mathrm{~s}, 9 \mathrm{H}), 1.00(\mathrm{~s}, 18 \mathrm{H}), 0.208(\mathrm{~s}, 6 \mathrm{H}), 0.206(\mathrm{~s}, 6 \mathrm{H}) ;{ }^{19} \mathrm{~F} \mathrm{NMR}\left(\mathrm{CDCl}_{3}, 376 \mathrm{MHz}\right) \delta-$ $133.11--133.18(\mathrm{~m}) ;{ }^{13} \mathrm{C} \mathrm{NMR}\left(\mathrm{CDCl}_{3}, 101 \mathrm{MHz}\right) \delta 169.3(\mathrm{C}), 164.1(\mathrm{C}), 157.9(\mathrm{C}), 152.8\left(\mathrm{~d},{ }^{1} J_{\mathrm{CF}}=246.0 \mathrm{~Hz}, \mathrm{C}\right)$, 
$144.7\left(\mathrm{~d},{ }^{2} J_{\mathrm{CF}}=12.7 \mathrm{~Hz}, \mathrm{C}\right), 141.7\left(\mathrm{~d},{ }^{4} J_{\mathrm{CF}}=3.4 \mathrm{~Hz}, \mathrm{C}\right), 136.2(\mathrm{CH}), 134.2(\mathrm{C}), 127.0(\mathrm{CH}), 126.5(\mathrm{C}), 124.4(\mathrm{~d}$, $\left.{ }^{3} J_{\mathrm{CF}}=5.5 \mathrm{~Hz}, \mathrm{C}\right), 123.8(\mathrm{CH}), 120.3\left(\mathrm{~d},{ }^{3} J_{\mathrm{CF}}=1.8 \mathrm{~Hz}, \mathrm{CH}\right), 115.0\left(\mathrm{~d},{ }^{2} J_{\mathrm{CF}}=20.2 \mathrm{~Hz}, \mathrm{CH}\right), 85.6(\mathrm{C}), 82.5(\mathrm{C}), 37.7$ (C), $35.2\left(\mathrm{CH}_{3}\right), 33.3\left(\mathrm{CH}_{3}\right), 28.3\left(\mathrm{CH}_{3}\right), 25.7\left(\mathrm{CH}_{3}\right), 18.5(\mathrm{C}),-4.49\left(\mathrm{CH}_{3}\right),-4.51\left(\mathrm{CH}_{3}\right)$; HRMS (ESI) calcd for $\mathrm{C}_{40} \mathrm{H}_{53} \mathrm{~F}_{2} \mathrm{O}_{6} \mathrm{Si}_{2}[\mathrm{M}+\mathrm{H}]^{+}$723.3343, found 723.3349 .

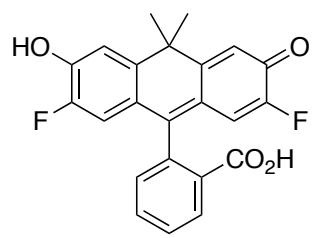

Virginia Orange ("VO," 4): To a solution of silyl ether 14 (295 mg, $0.474 \mathrm{mmol})$ was added TBAF (1.0 M in THF, $1.89 \mathrm{~mL}, 1.89 \mathrm{mmol}, 4 \mathrm{eq}$ ). The reaction was stirred at room temperature for $30 \mathrm{~min}$. It was subsequently acidified with $1 \mathrm{~N} \mathrm{HCl}$, diluted with water, and extracted with EtOAc $(2 \times)$. The organic extracts were dried over anhydrous $\mathrm{MgSO}_{4}$, filtered, and concentrated in vacuo. Flash chromatography (20-100\% EtOAc/hexanes, linear gradient) yielded 4 (182 mg, 97\%) as a pale yellow solid. ${ }^{1} \mathrm{H}$ NMR (DMSO- $\left.d_{6}, 400 \mathrm{MHz}\right) \delta 10.23(\mathrm{~s}, 2 \mathrm{H}), 8.03-7.97$ (m, $1 \mathrm{H}), 7.75(\mathrm{td}, J=7.5,1.3 \mathrm{~Hz}, 1 \mathrm{H}), 7.69(\mathrm{td}, J=7.4,1.0 \mathrm{~Hz}, 1 \mathrm{H}), 7.27\left(\mathrm{~d},{ }^{4} J_{\mathrm{HF}}=8.8 \mathrm{~Hz}, 2 \mathrm{H}\right), 7.15-7.10(\mathrm{~m}, 1 \mathrm{H})$, $6.31\left(\mathrm{~d},{ }^{3} J_{\mathrm{HF}}=12.0 \mathrm{~Hz}, 2 \mathrm{H}\right), 1.72(\mathrm{~s}, 3 \mathrm{H}), 1.62(\mathrm{~s}, 3 \mathrm{H}) ;{ }^{19} \mathrm{~F}$ NMR (DMSO- $\left.d_{6}, 376 \mathrm{MHz}\right) \delta-136.98\left(\mathrm{dd}, J_{\mathrm{FH}}=11.9\right.$, $8.8 \mathrm{~Hz}$ ); ${ }^{13} \mathrm{C}$ NMR (DMSO- $\left.d_{6}, 101 \mathrm{MHz}\right) \delta 169.2(\mathrm{C}), 154.0(\mathrm{C}), 149.7\left(\mathrm{~d},{ }^{1} J_{\mathrm{CF}}=242.4 \mathrm{~Hz}, \mathrm{C}\right), 145.9\left(\mathrm{~d},{ }^{2} J_{\mathrm{CF}}=12.5\right.$ $\mathrm{Hz}, \mathrm{C}), 141.6\left(\mathrm{~d},{ }^{4} J_{\mathrm{CF}}=3.0 \mathrm{~Hz}, \mathrm{C}\right), 135.7(\mathrm{CH}), 129.9(\mathrm{CH}), 125.14(\mathrm{C}), 125.11(\mathrm{CH}), 123.4(\mathrm{CH}), 122.1\left(\mathrm{~d},{ }^{3} J_{\mathrm{CF}}=\right.$ $5.2 \mathrm{~Hz}, \mathrm{C}), 115.5\left(\mathrm{~d},{ }^{3} J_{\mathrm{CF}}=2.8 \mathrm{~Hz}, \mathrm{CH}\right), 113.7\left(\mathrm{~d},{ }^{2} J_{\mathrm{CF}}=18.9 \mathrm{~Hz}, \mathrm{CH}\right), 84.8(\mathrm{C}), 37.2(\mathrm{C}), 34.5\left(\mathrm{CH}_{3}\right), 33.2\left(\mathrm{CH}_{3}\right)$; Analytical HPLC: $t_{R}=12.7 \mathrm{~min},>99 \%$ purity $\left(5 \mu \mathrm{L}\right.$ injection; $10-95 \% \mathrm{MeCN} / \mathrm{H}_{2} \mathrm{O}$, linear gradient, with constant $0.1 \% \mathrm{v} / \mathrm{v}$ TFA additive; $20 \mathrm{~min}$ run; $1 \mathrm{~mL} / \mathrm{min}$ flow; ESI; positive ion mode; UV detection at $254 \mathrm{~nm}$ ); HRMS (ESI) calcd for $\mathrm{C}_{23} \mathrm{H}_{17} \mathrm{~F}_{2} \mathrm{O}_{4}[\mathrm{M}+\mathrm{H}]^{+}$395.1089, found 395.1091.

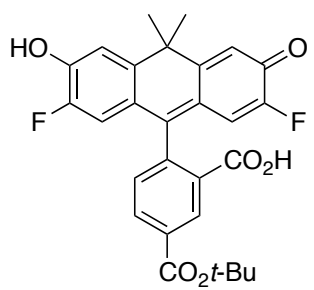

5-(tert-Butoxycarbonyl)-Virginia Orange (16): To a solution of silyl ether 15 (610 mg, $0.844 \mathrm{mmol})$ in THF (10 $\mathrm{mL}$ ) was added TBAF (1.0 M in THF, $3.37 \mathrm{~mL}, 3.37 \mathrm{mmol}, 4 \mathrm{eq})$. The reaction was stirred at room temperature for 45 min. It was subsequently acidified with $1 \mathrm{~N} \mathrm{HCl}$, diluted with water, and extracted with EtOAc $(2 \times)$. The organic extracts were dried over anhydrous $\mathrm{MgSO}_{4}$, filtered, and evaporated. Flash chromatography (0-40\% EtOAc/toluene, linear gradient) afforded 16 as a yellow-orange solid (401 mg, 96\%). ${ }^{1} \mathrm{H}$ NMR (DMSO- $\left.d_{6}, 400 \mathrm{MHz}\right) \delta 10.26$ (s, $2 \mathrm{H}), 8.37(\mathrm{dd}, J=1.4,0.6 \mathrm{~Hz}, 1 \mathrm{H}), 8.21(\mathrm{dd}, J=8.1,1.5 \mathrm{~Hz}, 1 \mathrm{H}), 7.28\left(\mathrm{~d},{ }^{4} J_{\mathrm{HF}}=8.8 \mathrm{~Hz}, 2 \mathrm{H}\right), 7.24(\mathrm{dd}, J=8.1,0.5$ $\mathrm{Hz}, 1 \mathrm{H}), 6.42\left(\mathrm{~d},{ }^{3} J_{\mathrm{HF}}=11.9 \mathrm{~Hz}, 2 \mathrm{H}\right), 1.73$ (s, 3H), $1.62(\mathrm{~s}, 3 \mathrm{H}), 1.59$ (s, 9H); ${ }^{19} \mathrm{~F}$ NMR (DMSO- $\left.d_{6}, 376 \mathrm{MHz}\right) \delta$ $136.86\left(\mathrm{dd}, J_{\mathrm{FH}}=11.8,8.9 \mathrm{~Hz}\right) ;{ }^{13} \mathrm{C} \mathrm{NMR}\left(\mathrm{DMSO}-d_{6}, 101 \mathrm{MHz}\right) \delta 168.4(\mathrm{C}), 163.6(\mathrm{C}), 157.5(\mathrm{C}), 149.8\left(\mathrm{~d},{ }^{1} J_{\mathrm{CF}}=\right.$ $242.5 \mathrm{~Hz}, \mathrm{C}), 146.1\left(\mathrm{~d},{ }^{2} J_{\mathrm{CF}}=12.5 \mathrm{~Hz}, \mathrm{C}\right), 141.6\left(\mathrm{~d},{ }^{4} J_{\mathrm{CF}}=3.0 \mathrm{~Hz}, \mathrm{C}\right), 135.9(\mathrm{CH}), 133.0(\mathrm{C}), 125.9(\mathrm{CH}), 124.0$ 
$(\mathrm{CH}), 121.3\left(\mathrm{~d},{ }^{3} J_{\mathrm{CF}}=5.3 \mathrm{~Hz}, \mathrm{C}\right), 115.5\left(\mathrm{~d},{ }^{3} J_{\mathrm{CF}}=2.7 \mathrm{~Hz}, \mathrm{CH}\right), 114.1\left(\mathrm{~d},{ }^{2} J_{\mathrm{CF}}=19.0 \mathrm{~Hz}, \mathrm{CH}\right), 85.1(\mathrm{C}), 81.8(\mathrm{C})$, 37.2 (C), $34.5\left(\mathrm{CH}_{3}\right), 33.2\left(\mathrm{CH}_{3}\right), 27.7\left(\mathrm{CH}_{3}\right)$; HRMS (ESI) calcd for $\mathrm{C}_{28} \mathrm{H}_{25} \mathrm{~F}_{2} \mathrm{O}_{6}[\mathrm{M}+\mathrm{H}]^{+}$495.1614, found 495.1595 .

\section{Synthesis of Single-InPut Fluorogenic Probes}

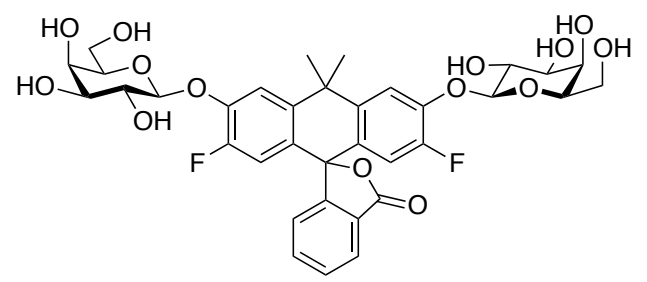

$\mathbf{G a l}_{2}-\mathbf{V O}$ (20): Virginia Orange (4; $\left.50 \mathrm{mg}, 0.127 \mathrm{mmol}\right)$ and acetobromo- $\alpha$-D-galactose $(\mathbf{1 7} ; 209 \mathrm{mg}, 0.507 \mathrm{mmol}$, 4 eq) were combined in $\mathrm{MeCN}(3 \mathrm{~mL})$ under nitrogen, and $\mathrm{Ag}_{2} \mathrm{O}$ (118 mg, $\left.0.507 \mathrm{mmol}, 4 \mathrm{eq}\right)$ was added. The resulting mixture was stirred at $50{ }^{\circ} \mathrm{C}$ for $3 \mathrm{~h}$. The reaction was then cooled to room temperature, filtered through Celite with $\mathrm{MeCN}$, and evaporated. The crude residue was purified by reverse phase HPLC ( $40-95 \% \mathrm{MeCN} / \mathrm{H}_{2} \mathrm{O}$, linear gradient, with constant $0.1 \% \mathrm{v} / \mathrm{v}$ TFA additive) to provide $75 \mathrm{mg}(56 \%)$ of the octaacetate as a white solid.

The octaacetate $(75 \mathrm{mg}, 71.1 \mu \mathrm{mol})$ was subsequently dissolved in $1: 1 \mathrm{MeOH} / \mathrm{MeCN}(5.7 \mathrm{~mL})$, and $1 \mathrm{M}$ $\mathrm{Na}_{2} \mathrm{CO}_{3}$ (aq, $1.42 \mathrm{~mL}, 1.42 \mathrm{mmol}, 20 \mathrm{eq}$ ) was added. The reaction was stirred at room temperature for $2 \mathrm{~h}$. It was then neutralized with $1 \mathrm{~N} \mathrm{HCl}(2.85 \mathrm{~mL})$, and the resulting solution was directly purified by reverse phase HPLC (10-95\% MeCN/ $\mathrm{H}_{2} \mathrm{O}$, linear gradient, with constant $0.1 \%$ v/v TFA additive) to afford 20 (49 $\mathrm{mg}, 96 \%$ ) as a white solid. ${ }^{1} \mathrm{H}$ NMR $\left(\mathrm{CD}_{3} \mathrm{OD}, 400 \mathrm{MHz}\right) \delta 8.04$ (ddd, $\left.J=7.3,1.3,0.8 \mathrm{~Hz}, 1 \mathrm{H}\right), 7.74(\mathrm{td}, J=7.4,1.4 \mathrm{~Hz}, 1 \mathrm{H}), 7.69(\operatorname{td}, J$ $=7.4,1.1 \mathrm{~Hz}, 1 \mathrm{H}), 7.65\left(\mathrm{~d},{ }^{4} J_{\mathrm{HF}}=8.2 \mathrm{~Hz}, 1 \mathrm{H}\right), 7.64\left(\mathrm{~d},{ }^{4} J_{\mathrm{HF}}=8.2 \mathrm{~Hz}, 1 \mathrm{H}\right), 7.05(\mathrm{dt}, J=7.7,1.0 \mathrm{~Hz}, 1 \mathrm{H}), 6.40(\mathrm{~d}$, $\left.{ }^{3} J_{\mathrm{HF}}=11.7 \mathrm{~Hz}, 1 \mathrm{H}\right), 6.39\left(\mathrm{~d},{ }^{3} J_{\mathrm{HF}}=11.8 \mathrm{~Hz}, 1 \mathrm{H}\right), 5.03(\mathrm{~d}, J=7.8 \mathrm{~Hz}, 1 \mathrm{H}), 4.99(\mathrm{~d}, J=7.8 \mathrm{~Hz}, 1 \mathrm{H}), 3.95-3.90(\mathrm{~m}$, 2H), $3.90-3.74(\mathrm{~m}, 8 \mathrm{H}), 3.65-3.59(\mathrm{~m}, 2 \mathrm{H}), 1.87(\mathrm{~s}, 3 \mathrm{H}), 1.77(\mathrm{~s}, 3 \mathrm{H}) ;{ }^{19} \mathrm{~F}$ NMR $\left(\mathrm{CD}_{3} \mathrm{OD}, 376 \mathrm{MHz}\right) \delta-134.52$ $\left(\mathrm{dd}, J_{\mathrm{FH}}=11.3,8.2 \mathrm{~Hz}, 1 \mathrm{~F}\right),-134.55\left(\mathrm{dd}, J_{\mathrm{FH}}=11.5,8.2 \mathrm{~Hz}, 1 \mathrm{~F}\right) ;{ }^{13} \mathrm{C} \mathrm{NMR}\left(\mathrm{CD}_{3} \mathrm{OD}, 101 \mathrm{MHz}\right) \delta 171.9(\mathrm{C}), 156.1$ (C), $152.62\left(\mathrm{~d},{ }^{1} J_{\mathrm{CF}}=247.4 \mathrm{~Hz}, \mathrm{C}\right), 152.59\left(\mathrm{~d},{ }^{1} J_{\mathrm{CF}}=247.3 \mathrm{~Hz}, \mathrm{C}\right), 147.5\left(\mathrm{~d},{ }^{2} J_{\mathrm{CF}}=11.0 \mathrm{~Hz}, \mathrm{C}\right), 143.1\left(\mathrm{~d},{ }^{4} J_{\mathrm{CF}}=3.5\right.$ $\mathrm{Hz}, \mathrm{C}), 143.0\left(\mathrm{~d},{ }^{4} J_{\mathrm{CF}}=3.5 \mathrm{~Hz}, \mathrm{C}\right), 136.8(\mathrm{CH}), 131.2(\mathrm{CH}), 126.65(\mathrm{C}), 126.61\left(\mathrm{~d},{ }^{3} J_{\mathrm{CF}}=5.7 \mathrm{~Hz}, \mathrm{C}\right), 126.57\left(\mathrm{~d},{ }^{3} J_{\mathrm{CF}}\right.$ $=5.4 \mathrm{~Hz}, \mathrm{C}), 126.4(\mathrm{CH}), 124.6(\mathrm{CH}), 117.6(\mathrm{CH}), 117.5(\mathrm{CH}), 115.1\left(\mathrm{~d},{ }^{2} J_{\mathrm{CF}}=19.1 \mathrm{~Hz}, \mathrm{CH}\right), 103.2(\mathrm{CH}), 103.0$ $(\mathrm{CH}), 86.4(\mathrm{C}), 77.5(\mathrm{CH}), 77.4(\mathrm{CH}), 74.9(\mathrm{CH}), 72.1(\mathrm{CH}), 72.0(\mathrm{CH}), 70.3(\mathrm{CH}), 62.5\left(\mathrm{CH}_{2}\right), 39.3(\mathrm{C}), 35.0$ $\left(\mathrm{CH}_{3}\right), 34.0\left(\mathrm{CH}_{3}\right)$; Analytical HPLC: $\mathrm{t}_{\mathrm{R}}=8.0 \mathrm{~min},>99 \%$ purity $\left(5 \mu \mathrm{L}\right.$ injection; $10-95 \% \mathrm{MeCN} / \mathrm{H}_{2} \mathrm{O}$, linear gradient, with constant $0.1 \% \mathrm{v} / \mathrm{v}$ TFA additive; $20 \mathrm{~min}$ run; $1 \mathrm{~mL} / \mathrm{min}$ flow; ESI; positive ion mode; UV detection at $254 \mathrm{~nm}$ ); HRMS (ESI) calcd for $\mathrm{C}_{35} \mathrm{H}_{36} \mathrm{~F}_{2} \mathrm{O}_{14} \mathrm{Na}[\mathrm{M}+\mathrm{Na}]^{+}$741.1965, found 741.1928. 


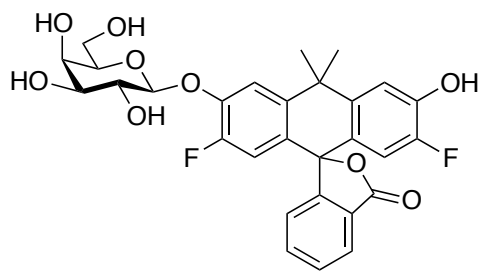

Gal-VO (21): Virginia Orange (4; $14 \mathrm{mg}, 0.0355 \mathrm{mmol})$ and acetobromo- $\alpha$-D-galactose (17; $146 \mathrm{mg}, 0.355 \mathrm{mmol}$, 10 eq) were combined in $\mathrm{MeCN}(4 \mathrm{~mL})$ under nitrogen, and $\mathrm{Et}_{3} \mathrm{~N}(495 \mu \mathrm{L}, 3.55 \mathrm{mmol}, 100 \mathrm{eq})$ was added. The resulting solution was stirred at $50{ }^{\circ} \mathrm{C}$ for $24 \mathrm{~h}$. After cooling the reaction to room temperature, it was concentrated in vacuo and directly purified by reverse phase HPLC $\left(30-95 \% \mathrm{MeCN} / \mathrm{H}_{2} \mathrm{O}\right.$, linear gradient, with constant $0.1 \% \mathrm{v} / \mathrm{v}$ TFA additive) to give $9.5 \mathrm{mg}$ (37\%) of the galactoside tetraacetate as a white solid.

The tetraacetate $(9.5 \mathrm{mg}, 13.1 \mu \mathrm{mol})$ was subsequently dissolved in $1: 1 \mathrm{MeOH} / \mathrm{MeCN}(524 \mu \mathrm{L})$, and $1 \mathrm{M}$ $\mathrm{Na}_{2} \mathrm{CO}_{3}$ (aq, $131 \mu \mathrm{L}, 131 \mu \mathrm{mol}, 10 \mathrm{eq}$ ) was added. The reaction was stirred at room temperature for $2 \mathrm{~h}$. It was then diluted with $\mathrm{MeOH}(1 \mathrm{~mL})$ and neutralized through the addition of $1 \mathrm{~N} \mathrm{HCl}(262 \mu \mathrm{L})$. Reverse phase HPLC of the crude reaction (10-95\% $\mathrm{MeCN} / \mathrm{H}_{2} \mathrm{O}$, linear gradient, with constant $0.1 \% \mathrm{v} / \mathrm{v}$ TFA additive) afforded 21 (6.8 mg, 93\%, diastereomeric mixture) as a white solid. ${ }^{1} \mathrm{H}$ NMR $\left(\mathrm{CD}_{3} \mathrm{OD}, 400 \mathrm{MHz}\right) \delta 8.05-8.01(\mathrm{~m}, 1 \mathrm{H}), 7.77-7.72(\mathrm{~m}$, $1 \mathrm{H}), 7.72-7.66(\mathrm{~m}, 1 \mathrm{H}), 7.64(\mathrm{~d}, J=8.2 \mathrm{~Hz}, 0.45 \mathrm{H}), 7.63(\mathrm{~d}, J=8.2 \mathrm{~Hz}, 0.55 \mathrm{H}), 7.24\left(\mathrm{~d},{ }^{4} J_{\mathrm{HF}}=8.7 \mathrm{~Hz}, 1 \mathrm{H}\right), 7.10$ $-7.05(\mathrm{~m}, 1 \mathrm{H}), 6.373\left(\mathrm{~d},{ }^{3} J_{\mathrm{HF}}=11.8 \mathrm{~Hz}, 0.55 \mathrm{H}\right), 6.368\left(\mathrm{~d},{ }^{3} J_{\mathrm{HF}}=11.8 \mathrm{~Hz}, 0.45 \mathrm{H}\right), 6.313\left(\mathrm{~d},{ }^{3} J_{\mathrm{HF}}=11.9 \mathrm{~Hz}, 0.55 \mathrm{H}\right)$, $6.306\left(\mathrm{~d},{ }^{3} J_{\mathrm{HF}}=11.9 \mathrm{~Hz}, 0.45 \mathrm{H}\right), 5.02(\mathrm{~d}, J=7.8 \mathrm{~Hz}, 0.55 \mathrm{H}), 4.98(\mathrm{~d}, J=7.8 \mathrm{~Hz}, 0.45 \mathrm{H}), 3.94-3.74(\mathrm{~m}, 5 \mathrm{H}), 3.65$ - $3.59(\mathrm{~m}, 1 \mathrm{H}), 1.83(\mathrm{~s}, 3 \mathrm{H}), 1.73(\mathrm{~s}, 3 \mathrm{H}) ;{ }^{19} \mathrm{~F}$ NMR $\left(\mathrm{CD}_{3} \mathrm{OD}, 376 \mathrm{MHz}\right) \delta \delta-134.66$ - -134.75 (m, $\left.1 \mathrm{~F}\right),-138.47$ - $138.59(\mathrm{~m}, 1 \mathrm{~F})$; Analytical HPLC: $\mathrm{t}_{\mathrm{R}}=9.8 \mathrm{~min},>99 \%$ purity (diastereomeric mixture; $5 \mu \mathrm{L}$ injection; $10-95 \%$ $\mathrm{MeCN} / \mathrm{H}_{2} \mathrm{O}$, linear gradient, with constant $0.1 \% \mathrm{v} / \mathrm{v}$ TFA additive; $20 \mathrm{~min}$ run; $1 \mathrm{~mL} / \mathrm{min}$ flow; ESI; positive ion mode; UV detection at $254 \mathrm{~nm}$ ); HRMS (ESI) calcd for $\mathrm{C}_{29} \mathrm{H}_{26} \mathrm{~F}_{2} \mathrm{O}_{9} \mathrm{Na}[\mathrm{M}+\mathrm{Na}]^{+}$579.1437, found 579.1433.

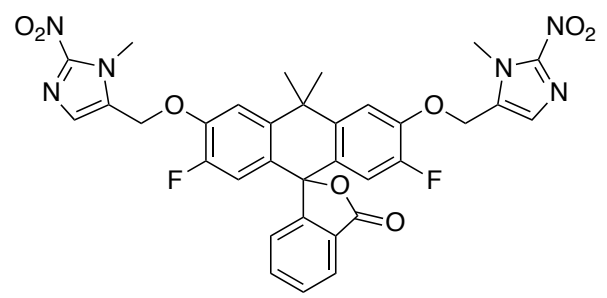

$\mathbf{N M}_{2}-$ VO (22): To a solution of Virginia Orange (4; $\left.40 \mathrm{mg}, 0.101 \mathrm{mmol}\right)$ and 5-(bromomethyl)-1-methyl-2-nitro$1 H$-imidazole (18; $89 \mathrm{mg}, 0.406 \mathrm{mmol}, 4 \mathrm{eq})$ in $\mathrm{MeCN}(3.5 \mathrm{~mL})$ was added $\mathrm{Ag}_{2} \mathrm{O}$ (94 mg, $\left.0.406 \mathrm{mmol}, 4 \mathrm{eq}\right)$, and the resulting mixture was stirred at $60{ }^{\circ} \mathrm{C}$ for $90 \mathrm{~min}$. The reaction was then cooled to room temperature, filtered through Celite with $\mathrm{MeCN}$, and evaporated. The crude residue was purified by silica gel chromatography ( $0-50 \%$ $\mathrm{MeCN} / \mathrm{CH}_{2} \mathrm{Cl}_{2}$, linear gradient) to afford $22(64 \mathrm{mg}, 94 \%)$ as an off-white solid. ${ }^{1} \mathrm{H}$ NMR $\left(\mathrm{CDCl}_{3}, 400 \mathrm{MHz}\right) \delta 8.08$ $-8.04(\mathrm{~m}, 1 \mathrm{H}), 7.70-7.63(\mathrm{~m}, 2 \mathrm{H}), 7.26\left(\mathrm{~d},{ }^{4} J_{\mathrm{HF}}=8.0 \mathrm{~Hz}, 2 \mathrm{H}\right), 7.23(\mathrm{~s}, 2 \mathrm{H}), 7.04-7.01(\mathrm{~m}, 1 \mathrm{H}), 6.47\left(\mathrm{~d},{ }^{3} J_{\mathrm{HF}}=\right.$ $11.8 \mathrm{~Hz}, 2 \mathrm{H}), 5.21(\mathrm{~s}, 4 \mathrm{H}), 4.11(\mathrm{~s}, 6 \mathrm{H}), 1.82(\mathrm{~s}, 3 \mathrm{H}), 1.73(\mathrm{~s}, 3 \mathrm{H}) ;{ }^{19} \mathrm{~F} \mathrm{NMR}\left(\mathrm{CDCl}_{3}, 376 \mathrm{MHz}\right) \delta-133.81\left(\mathrm{dd}, J_{\mathrm{FH}}=\right.$ 11.8, 8.0 Hz); ${ }^{13} \mathrm{C}$ NMR $\left(\mathrm{CDCl}_{3}, 101 \mathrm{MHz}\right) \delta 169.7$ (C), $153.8(\mathrm{C}), 151.9\left(\mathrm{~d},{ }^{1} J_{\mathrm{CF}}=248.2 \mathrm{~Hz}, \mathrm{C}\right), 146.7(\mathrm{C}), 146.2$ $\left(\mathrm{d},{ }^{2} J_{\mathrm{CF}}=11.3 \mathrm{~Hz}, \mathrm{C}\right), 141.7\left(\mathrm{~d},{ }^{4} J_{\mathrm{CF}}=3.5 \mathrm{~Hz}, \mathrm{C}\right), 135.5(\mathrm{CH}), 132.0(\mathrm{C}), 130.2(\mathrm{CH}), 129.5(\mathrm{CH}), 126.5\left(\mathrm{~d},{ }^{3} J_{\mathrm{CF}}=\right.$ 
$5.7 \mathrm{~Hz}, \mathrm{C}), 126.0(\mathrm{C}), 125.9(\mathrm{CH}), 123.6(\mathrm{CH}), 115.6\left(\mathrm{~d},{ }^{2} J_{\mathrm{CF}}=19.5 \mathrm{~Hz}, \mathrm{CH}\right), 115.0\left(\mathrm{~d},{ }^{3} J_{\mathrm{CF}}=1.1 \mathrm{~Hz}, \mathrm{CH}\right), 84.6$ (C), $61.8\left(\mathrm{CH}_{2}\right), 38.3(\mathrm{C}), 35.3\left(\mathrm{CH}_{3}\right), 34.7\left(\mathrm{CH}_{3}\right), 33.4\left(\mathrm{CH}_{3}\right)$; HRMS (ESI) calcd for $\mathrm{C}_{33} \mathrm{H}_{26} \mathrm{~F}_{2} \mathrm{~N}_{6} \mathrm{O}_{8} \mathrm{Na}[\mathrm{M}+\mathrm{Na}]^{+}$ 695.1672 , found 695.1659 .

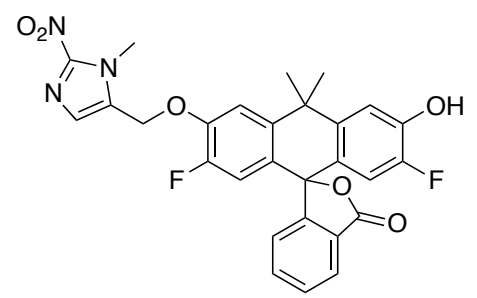

NM-VO (23): To a solution of Virginia Orange (4; $140 \mathrm{mg}, 0.355 \mathrm{mmol}$ ) and 5-(bromomethyl)-1-methyl-2-nitro$1 \mathrm{H}$-imidazole (18; $78 \mathrm{mg}, 0.355 \mathrm{mmol}, 1 \mathrm{eq})$ in $\mathrm{MeCN}(8 \mathrm{~mL})$ was added $\mathrm{Ag}_{2} \mathrm{O}$ (82 $\left.\mathrm{mg}, 0.355 \mathrm{mmol}, 1 \mathrm{eq}\right)$, and the resulting mixture was stirred at $60^{\circ} \mathrm{C}$ for $90 \mathrm{~min}$. After cooling the reaction to room temperature, $1 \mathrm{~N} \mathrm{HCl}(20 \mathrm{~mL})$ and EtOAc $(20 \mathrm{~mL})$ were added. The gray suspension was filtered through Celite; the filtrate was diluted with water and extracted with EtOAc $(2 \times)$. The combined organic extracts were washed with brine, dried over anhydrous $\mathrm{MgSO}_{4}$, filtered, and concentrated in vacuo. Purification by flash chromatography on silica gel (0-50\% EtOAc/ $\mathrm{CH}_{2} \mathrm{Cl}_{2}$, linear gradient) yielded $82 \mathrm{mg}(43 \%)$ of 23 as a pale yellow solid. ${ }^{1} \mathrm{H}$ NMR $\left(\mathrm{CDCl}_{3}, 400 \mathrm{MHz}\right) \delta$ $8.05-8.01(\mathrm{~m}, 1 \mathrm{H}), 7.69-7.61(\mathrm{~m}, 2 \mathrm{H}), 7.29-7.21(\mathrm{~m}, 3 \mathrm{H}), 7.06-7.02(\mathrm{~m}, 1 \mathrm{H}), 6.65(\mathrm{~s}, 1 \mathrm{H}), 6.44\left(\mathrm{~d},{ }^{3} J_{\mathrm{HF}}=11.9\right.$ $\mathrm{Hz}, 1 \mathrm{H}), 6.38\left(\mathrm{~d},{ }^{3} J_{\mathrm{HF}}=11.4 \mathrm{~Hz}, 1 \mathrm{H}\right), 5.22\left(\mathrm{AB}\right.$ quartet, $\left.v_{\mathrm{A}}=2089.8 \mathrm{~Hz}, v_{\mathrm{B}}=2084.8 \mathrm{~Hz}, J_{\mathrm{AB}}=13.1 \mathrm{~Hz}, 2 \mathrm{H}\right), 4.10$ $(\mathrm{s}, 3 \mathrm{H}), 1.77$ (s, 3H), $1.64(\mathrm{~s}, 3 \mathrm{H}) ;{ }^{19} \mathrm{~F} \mathrm{NMR}\left(\mathrm{CDCl}_{3}, 376 \mathrm{MHz}\right) \delta-134.35\left(\mathrm{dd}, J_{\mathrm{FH}}=11.8,8.1 \mathrm{~Hz}, 1 \mathrm{~F}\right),-141.70(\mathrm{dd}$, $\left.J_{\mathrm{FH}}=11.0,8.9 \mathrm{~Hz}, 1 \mathrm{~F}\right) ;{ }^{13} \mathrm{C} \mathrm{NMR}\left(\mathrm{CDCl}_{3}, 101 \mathrm{MHz}\right) \delta 170.3(\mathrm{C}), 154.1(\mathrm{C}), 151.7\left(\mathrm{~d},{ }^{1} J_{\mathrm{CF}}=247.7 \mathrm{~Hz}, \mathrm{C}\right), 150.0(\mathrm{~d}$, $\left.{ }^{1} J_{\mathrm{CF}}=240.3 \mathrm{~Hz}, \mathrm{C}\right), 146.5(\mathrm{C}), 146.1\left(\mathrm{~d},{ }^{2} J_{\mathrm{CF}}=11.3 \mathrm{~Hz}, \mathrm{C}\right), 145.2\left(\mathrm{~d},{ }^{2} J_{\mathrm{CF}}=14.2 \mathrm{~Hz}, \mathrm{C}\right), 142.2\left(\mathrm{~d},{ }^{4} J_{\mathrm{CF}}=3.5 \mathrm{~Hz}, \mathrm{C}\right)$, $141.9\left(\mathrm{~d},{ }^{4} J_{\mathrm{CF}}=3.2 \mathrm{~Hz}, \mathrm{C}\right), 135.5(\mathrm{CH}), 132.1(\mathrm{C}), 130.1(\mathrm{CH}), 129.3(\mathrm{CH}), 126.6\left(\mathrm{~d},{ }^{3} J_{\mathrm{CF}}=5.6 \mathrm{~Hz}, \mathrm{C}\right), 126.0(\mathrm{C})$, $125.7(\mathrm{CH}), 123.7(\mathrm{CH}), 123.4\left(\mathrm{~d},{ }^{3} J_{\mathrm{CF}}=5.3 \mathrm{~Hz}, \mathrm{C}\right), 115.473\left(\mathrm{~d},{ }^{3} J_{\mathrm{CF}}=2.0 \mathrm{~Hz}, \mathrm{CH}\right), 115.472\left(\mathrm{~d},{ }^{2} J_{\mathrm{CF}}=19.4 \mathrm{~Hz}\right.$, $\mathrm{CH}), 114.9(\mathrm{CH}), 114.4\left(\mathrm{~d},{ }^{2} J_{\mathrm{CF}}=19.2 \mathrm{~Hz}, \mathrm{CH}\right), 85.4(\mathrm{C}), 61.7\left(\mathrm{CH}_{2}\right), 38.1(\mathrm{C}), 35.2\left(\mathrm{CH}_{3}\right), 34.7\left(\mathrm{CH}_{3}\right), 33.2\left(\mathrm{CH}_{3}\right)$; HRMS (ESI) calcd for $\mathrm{C}_{28} \mathrm{H}_{21} \mathrm{~F}_{2} \mathrm{~N}_{3} \mathrm{O}_{6} \mathrm{Na}[\mathrm{M}+\mathrm{Na}]^{+}$556.1291, found 556.1266.

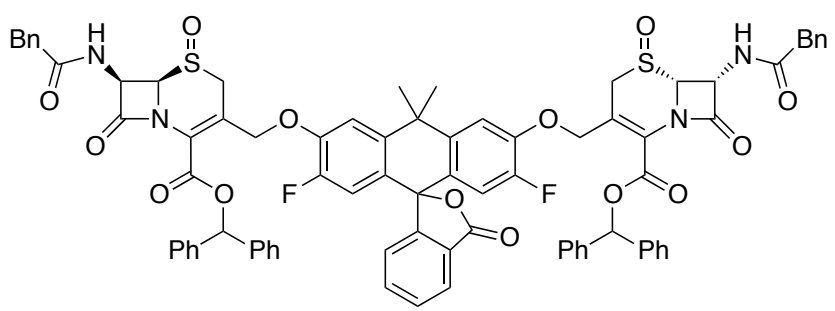

[Ceph(Bzh) $]_{2}-$ VO (S1): Virginia Orange (4; $\left.100 \mathrm{mg}, 0.254 \mathrm{mmol}\right),(6 R, 7 R)$-benzhydryl 3-(chloromethyl)-8-oxo-7(2-phenylacetamido)-5-thia-1-azabicyclo[4.2.0]oct-2-ene-2-carboxylate (19; $541 \mathrm{mg}, 1.01 \mathrm{mmol}, 4 \mathrm{eq}), \mathrm{K}_{2} \mathrm{CO}_{3}(140$ $\mathrm{mg}, 1.01 \mathrm{mmol}, 4 \mathrm{eq})$, and $\mathrm{NaI}(76 \mathrm{mg}, 0.507 \mathrm{mmol}, 2 \mathrm{eq})$ were combined in $\mathrm{MeCN}(10 \mathrm{~mL})$ and stirred at room temperature for $7 \mathrm{~h}$. The reaction was subsequently diluted with water and extracted with EtOAc $(2 \times)$. The combined organics were washed with brine, dried over anhydrous $\mathrm{MgSO}_{4}$, filtered, and evaporated. Silica gel 
chromatography ( $0-50 \%$ EtOAc/toluene, linear gradient) provided the bis-alkylated product as a mixture of isomers (274 mg).

The isomeric mixture $(274 \mathrm{mg})$ was dissolved in $\mathrm{CH}_{2} \mathrm{Cl}_{2}(5 \mathrm{~mL})$ and cooled to $0{ }^{\circ} \mathrm{C} . m$-Chloroperoxybenzoic acid $(77 \%, 106 \mathrm{mg}, 0.474 \mathrm{mmol}, 2.4 \mathrm{eq})$ was added, and the reaction was stirred at $0{ }^{\circ} \mathrm{C}$ for $30 \mathrm{~min}$. It was then diluted with saturated $\mathrm{NaHCO}_{3}$ and extracted with $\mathrm{CH}_{2} \mathrm{Cl}_{2}(2 \times)$. The organics were washed with brine, dried over anhydrous $\mathrm{MgSO}_{4}$, filtered, and evaporated. Flash chromatography $\left(0-50 \% \mathrm{EtOAc} / \mathrm{CH}_{2} \mathrm{Cl}_{2}\right.$, linear gradient $)$ afforded $125 \mathrm{mg}\left(35 \%, 2\right.$ steps) of $\mathbf{S} \mathbf{1}$ as a pale yellow solid. ${ }^{1} \mathrm{H}$ NMR $\left(\mathrm{CDCl}_{3}, 400 \mathrm{MHz}\right) \delta 8.06-7.99(\mathrm{~m}, 1 \mathrm{H})$, $7.66-7.58(\mathrm{~m}, 2 \mathrm{H}), 7.54-7.46(\mathrm{~m}, 4 \mathrm{H}), 7.41-7.26(\mathrm{~m}, 26 \mathrm{H}), 7.06\left(\mathrm{~d},{ }^{4} J_{\mathrm{HF}}=8.1 \mathrm{~Hz}, 2 \mathrm{H}\right), 6.97-6.93(\mathrm{~m}, 1 \mathrm{H})$, $6.93(\mathrm{~s}, 1 \mathrm{H}), 6.91(\mathrm{~s}, 1 \mathrm{H}), 6.77-6.70(\mathrm{~m}, 2 \mathrm{H}), 6.391\left(\mathrm{~d},{ }^{3} J_{\mathrm{HF}}=11.7 \mathrm{~Hz}, 1 \mathrm{H}\right), 6.390\left(\mathrm{~d},{ }^{3} J_{\mathrm{HF}}=11.7 \mathrm{~Hz}, 1 \mathrm{H}\right), 6.16-$ $6.10(\mathrm{~m}, 2 \mathrm{H}), 5.39(\mathrm{~d}, J=14.0 \mathrm{~Hz}, 1 \mathrm{H}), 5.38(\mathrm{~d}, J=13.8 \mathrm{~Hz}, 1 \mathrm{H}), 4.91(\mathrm{~d}, J=14.0 \mathrm{~Hz}, 1 \mathrm{H}), 4.88(\mathrm{~d}, J=13.8 \mathrm{~Hz}$, $1 \mathrm{H}), 4.50-4.47(\mathrm{~m}, 2 \mathrm{H}), 4.02(\mathrm{~d}, J=19.1 \mathrm{~Hz}, 2 \mathrm{H}), 3.63\left(\mathrm{AB}\right.$ quartet, $v_{\mathrm{A}}=1459.1 \mathrm{~Hz}, v_{\mathrm{B}}=1446.0 \mathrm{~Hz}, J_{\mathrm{AB}}=15.7$ $\mathrm{Hz}, 4 \mathrm{H}), 3.36(\mathrm{~d}, J=19.1 \mathrm{~Hz}, 1 \mathrm{H}), 3.34(\mathrm{~d}, J=19.2 \mathrm{~Hz}, 1 \mathrm{H}), 1.62(\mathrm{~s}, 3 \mathrm{H}), 1.53(\mathrm{~s}, 3 \mathrm{H}) ;{ }^{19} \mathrm{~F} \mathrm{NMR}\left(\mathrm{CDCl}_{3}, 376\right.$ $\mathrm{MHz}) \delta-135.57\left(\mathrm{dd}, J_{\mathrm{FH}}=11.7,8.2 \mathrm{~Hz}, 1 \mathrm{~F}\right),-135.77\left(\mathrm{dd}, J_{\mathrm{FH}}=11.6,8.2 \mathrm{~Hz}, 1 \mathrm{~F}\right) ;{ }^{13} \mathrm{C} \mathrm{NMR}\left(\mathrm{CDCl}_{3}, 101 \mathrm{MHz}\right) \delta$ 171.5 (C), 171.4 (C), 169.9 (C), 164.5 (C), 160.13 (C), 160.11 (C), 154.3 (C), 151.32 (d, $\left.{ }^{1} J_{\mathrm{CF}}=247.6, \mathrm{C}\right), 151.26$ (d, $\left.{ }^{1} J_{\mathrm{CF}}=247.5 \mathrm{~Hz}, \mathrm{C}\right), 146.73\left(\mathrm{~d},{ }^{2} J_{\mathrm{CF}}=11.3 \mathrm{~Hz}, \mathrm{C}\right), 146.71\left(\mathrm{~d},{ }^{2} J_{\mathrm{CF}}=11.1 \mathrm{~Hz}, \mathrm{C}\right), 141.7\left(\mathrm{~d},{ }^{4} J_{\mathrm{CF}}=3.2 \mathrm{~Hz}, \mathrm{C}\right), 139.13$ (C), $139.07(\mathrm{C}), 139.06(\mathrm{C}), 139.03(\mathrm{C}), 135.4(\mathrm{CH}), 133.8(\mathrm{C}), 130.0(\mathrm{CH}), 129.50(\mathrm{CH}), 129.49(\mathrm{CH}), 129.2(\mathrm{CH})$, $128.9(\mathrm{CH}), 128.8(\mathrm{CH}), 128.7(\mathrm{CH}), 128.5(\mathrm{CH}), 128.4(\mathrm{CH}), 127.7(\mathrm{CH}), 127.4(\mathrm{CH}), 127.19(\mathrm{CH}), 127.17(\mathrm{CH})$, $125.8(\mathrm{C}), 125.7(\mathrm{CH}), 125.2\left(\mathrm{~d},{ }^{3} J_{\mathrm{CF}}=5.4 \mathrm{~Hz}, \mathrm{C}\right), 125.1\left(\mathrm{~d},{ }^{3} J_{\mathrm{CF}}=5.8 \mathrm{~Hz}, \mathrm{C}\right), 124.5(\mathrm{C}), 124.4(\mathrm{C}), 123.8(\mathrm{C})$, $123.5(\mathrm{CH}), 115.0\left(\mathrm{~d},{ }^{2} J_{\mathrm{CF}}=19.1 \mathrm{~Hz}, \mathrm{CH}\right), 113.6(\mathrm{CH}), 113.3(\mathrm{CH}), 84.8(\mathrm{C}), 80.9(\mathrm{CH}), 80.8(\mathrm{CH}), 68.7\left(\mathrm{CH}_{2}\right)$, $68.5\left(\mathrm{CH}_{2}\right), 67.0(\mathrm{CH}), 66.9(\mathrm{CH}), 59.1(\mathrm{CH}), 45.44\left(\mathrm{CH}_{2}\right), 45.36\left(\mathrm{CH}_{2}\right), 43.49\left(\mathrm{CH}_{2}\right), 43.48\left(\mathrm{CH}_{2}\right), 38.2(\mathrm{C}), 34.8$ $\left(\mathrm{CH}_{3}\right), 33.6\left(\mathrm{CH}_{3}\right)$; Analytical HPLC: $\mathrm{t}_{\mathrm{R}}=11.3 \mathrm{~min}, 97.1 \%$ purity $\left(5 \mu \mathrm{L}\right.$ injection; $65-95 \% \mathrm{MeCN} / \mathrm{H}_{2} \mathrm{O}$, linear gradient, with constant $0.1 \% \mathrm{v} / \mathrm{v}$ TFA additive; $20 \mathrm{~min}$ run; $1 \mathrm{~mL} / \mathrm{min}$ flow; ESI; positive ion mode; UV detection at $254 \mathrm{~nm}$ ); HRMS (ESI) calcd for $\mathrm{C}_{81} \mathrm{H}_{64} \mathrm{~F}_{2} \mathrm{~N}_{4} \mathrm{O}_{14} \mathrm{~S}_{2} \mathrm{Na}[\mathrm{M}+\mathrm{Na}]^{+}$1441.3721, found 1441.3735.

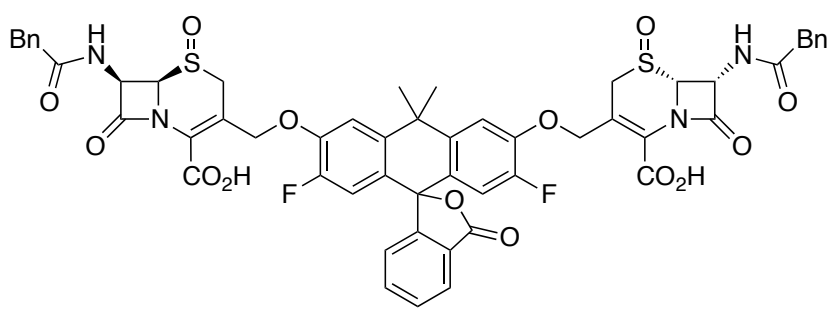

Ceph $\mathbf{C}_{2}$-VO (24): Diester S1 (45 mg, $\left.31.7 \mu \mathrm{mol}\right)$ was taken up in $\mathrm{CH}_{2} \mathrm{Cl}_{2}(4 \mathrm{~mL})$ and cooled to $0{ }^{\circ} \mathrm{C}$. Anisole (200 $\mu \mathrm{L})$ and TFA $(400 \mu \mathrm{L})$ were added, and the reaction was stirred at $0{ }^{\circ} \mathrm{C}$ for $2 \mathrm{~h}$. Toluene $(4 \mathrm{~mL})$ was added, and the reaction mixture was concentrated to dryness. Reverse phase HPLC (10-95\% $\mathrm{MeCN} / \mathrm{H}_{2} \mathrm{O}$, linear gradient, with constant $0.1 \% \mathrm{v} / \mathrm{v}$ TFA additive) afforded $24(27 \mathrm{mg}, 79 \%)$ as a white solid. ${ }^{1} \mathrm{H}$ NMR (DMSO- $\left.d_{6}, 400 \mathrm{MHz}\right) \delta$ 13.99 (s, 2H), 8.42 (d, $J=8.7 \mathrm{~Hz}, 1 \mathrm{H}), 8.39$ (d, $J=8.7 \mathrm{~Hz}, 1 \mathrm{H}), 8.05-7.97(\mathrm{~m}, 1 \mathrm{H}), 7.73$ (td, $J=7.5,1.5 \mathrm{~Hz}, 1 \mathrm{H})$, $7.69(\mathrm{td}, J=7.5,1.3 \mathrm{~Hz}, 1 \mathrm{H}), 7.54\left(\mathrm{~d},{ }^{4} J_{\mathrm{HF}}=8.6 \mathrm{~Hz}, 1 \mathrm{H}\right), 7.52\left(\mathrm{~d},{ }^{4} J_{\mathrm{HF}}=8.6 \mathrm{~Hz}, 1 \mathrm{H}\right), 7.34-7.18(\mathrm{~m}, 10 \mathrm{H}), 7.09-$ $7.04(\mathrm{~m}, 1 \mathrm{H}), 6.43\left(\mathrm{~d},{ }^{3} J_{\mathrm{HF}}=11.9 \mathrm{~Hz}, 2 \mathrm{H}\right), 5.87-5.77(\mathrm{~m}, 2 \mathrm{H}), 5.22(\mathrm{~d}, J=12.1 \mathrm{~Hz}, 1 \mathrm{H}), 5.19(\mathrm{~d}, J=11.9 \mathrm{~Hz}, 1 \mathrm{H})$, $5.06(\mathrm{~d}, J=11.8 \mathrm{~Hz}, 1 \mathrm{H}), 5.03(\mathrm{~d}, J=11.8 \mathrm{~Hz}, 1 \mathrm{H}), 4.94-4.88(\mathrm{~m}, 2 \mathrm{H}), 3.98(\mathrm{~d}, J=18.5 \mathrm{~Hz}, 2 \mathrm{H}), 3.70(\mathrm{~d}, J=14.1$ 
$\mathrm{Hz}, 2 \mathrm{H}), 3.67-3.61(\mathrm{~m}, 2 \mathrm{H}), 3.55(\mathrm{~d}, J=14.0 \mathrm{~Hz}, 1 \mathrm{H}), 3.54(\mathrm{~d}, J=14.1 \mathrm{H}, 1 \mathrm{H}), 1.81(\mathrm{~s}, 3 \mathrm{H}), 1.71(\mathrm{~s}, 3 \mathrm{H}) ;{ }^{19} \mathrm{~F}$ NMR (DMSO- $\left.d_{6}, 376 \mathrm{MHz}\right) \delta-135.00--135.11(\mathrm{~m}) ;{ }^{13} \mathrm{C}$ NMR (DMSO- $\left.d_{6}, 101 \mathrm{MHz}\right) \delta 171.06(\mathrm{C}), 171.05(\mathrm{C})$, 169.2 (C), 164.30 (C), 164.29 (C), 162.3 (C), 154.1 (C), 150.5 (d, $\left.{ }^{1} J_{\mathrm{CF}}=245.7 \mathrm{~Hz}, \mathrm{C}\right), 146.7$ (d, $\left.{ }^{2} J_{\mathrm{CF}}=11.0 \mathrm{~Hz}, \mathrm{C}\right)$, $141.6(\mathrm{C}), 135.82(\mathrm{CH}), 135.81(\mathrm{CH}), 130.1(\mathrm{CH}), 129.1(\mathrm{CH}), 128.3(\mathrm{CH}), 126.6(\mathrm{CH}), 126.2(\mathrm{C}), 126.1(\mathrm{C}), 125.4$ $(\mathrm{CH}), 124.8(\mathrm{C}), 123.74\left(\mathrm{~d},{ }^{3} J_{\mathrm{CF}}=5.4 \mathrm{~Hz}, \mathrm{C}\right), 123.72\left(\mathrm{~d},{ }^{3} J_{\mathrm{CF}}=5.7 \mathrm{~Hz}, \mathrm{C}\right), 123.3(\mathrm{CH}), 118.8(\mathrm{C}), 113.9(\mathrm{CH})$, $113.8(\mathrm{CH}), 113.6\left(\mathrm{~d},{ }^{2} J_{\mathrm{CF}}=20.0 \mathrm{~Hz}, \mathrm{CH}\right), 84.1(\mathrm{C}), 68.2\left(\mathrm{CH}_{2}\right), 66.3(\mathrm{CH}), 58.3(\mathrm{CH}), 45.2\left(\mathrm{CH}_{2}\right), 41.5\left(\mathrm{CH}_{2}\right), 38.0$ (C), $33.8\left(\mathrm{CH}_{3}\right), 33.6\left(\mathrm{CH}_{3}\right)$; Analytical HPLC: $\mathrm{t}_{\mathrm{R}}=14.0 \mathrm{~min},>99 \%$ purity $\left(5 \mu \mathrm{L}\right.$ injection; $10-95 \% \mathrm{MeCN} / \mathrm{H}_{2} \mathrm{O}$, linear gradient, with constant $0.1 \% \mathrm{v} / \mathrm{v}$ TFA additive; $20 \mathrm{~min}$ run; $1 \mathrm{~mL} / \mathrm{min}$ flow; ESI; positive ion mode; UV detection at $254 \mathrm{~nm}$ ); HRMS (ESI) calcd for $\mathrm{C}_{55} \mathrm{H}_{44} \mathrm{~F}_{2} \mathrm{~N}_{4} \mathrm{O}_{14} \mathrm{~S}_{2} \mathrm{Na}[\mathrm{M}+\mathrm{Na}]^{+}$1109.2156, found 1109.2164.

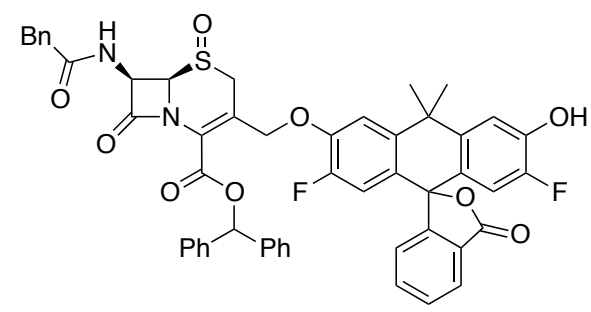

Ceph(Bzh)-VO (S2): Virginia Orange (4; $200 \mathrm{mg}, 0.507 \mathrm{mmol}),(6 R, 7 R)$-benzhydryl 3-(chloromethyl)-8-oxo-7-(2phenylacetamido)-5-thia-1-azabicyclo[4.2.0]oct-2-ene-2-carboxylate (19; $270 \mathrm{mg}, 0.507 \mathrm{mmol}, 1 \mathrm{eq}), \mathrm{K}_{2} \mathrm{CO}_{3}(105$ $\mathrm{mg}, 0.761 \mathrm{mmol}, 1.5 \mathrm{eq})$, and $\mathrm{NaI}(76 \mathrm{mg}, 0.507 \mathrm{mmol}, 1 \mathrm{eq})$ were combined in $\mathrm{MeCN}(7 \mathrm{~mL})$ and stirred at room temperature for $7 \mathrm{~h}$. The reaction was subsequently diluted with water and extracted with EtOAc $(2 \times)$. The combined organics were washed with brine, dried over anhydrous $\mathrm{MgSO}_{4}$, filtered, and evaporated. Silica gel chromatography $(0-50 \%$ EtOAc/toluene, linear gradient) provided the mono-alkylated product as a mixture of isomers (323 mg).

The isomeric mixture $(323 \mathrm{mg})$ was dissolved in $\mathrm{CH}_{2} \mathrm{Cl}_{2}(10 \mathrm{~mL})$ and cooled to $0{ }^{\circ} \mathrm{C} . \mathrm{m}$-Chloroperoxybenzoic acid $(77 \%, 98 \mathrm{mg}, 0.363 \mathrm{mmol}, 1.2 \mathrm{eq})$ was added, and the reaction was stirred at $0{ }^{\circ} \mathrm{C}$ for $30 \mathrm{~min}$. It was then diluted with saturated $\mathrm{NaHCO}_{3}$ and extracted with $\mathrm{CH}_{2} \mathrm{Cl}_{2}(2 \times)$. The organics were washed with brine, dried over anhydrous $\mathrm{MgSO}_{4}$, filtered, and evaporated. Flash chromatography $\left(0-40 \% \mathrm{EtOAc} / \mathrm{CH}_{2} \mathrm{Cl}_{2}\right.$, linear gradient) afforded $128 \mathrm{mg}$ (28\%, 2 steps, diastereomeric mixture) of $\mathbf{S 2}$ as an off-white solid. ${ }^{1} \mathrm{H}$ NMR $\left(\mathrm{CDCl}_{3}, 400 \mathrm{MHz}\right) \delta$ $8.06-8.01(\mathrm{~m}, 1 \mathrm{H}), 7.68-7.59(\mathrm{~m}, 2 \mathrm{H}), 7.53-7.46(\mathrm{~m}, 2 \mathrm{H}), 7.40-7.27(\mathrm{~m}, 13 \mathrm{H}), 7.21\left(\mathrm{~d},{ }^{4} J_{\mathrm{HF}}=8.6 \mathrm{~Hz}, 0.4 \mathrm{H}\right)$, $7.20\left(\mathrm{~d},{ }^{4} J_{\mathrm{HF}}=8.6 \mathrm{~Hz}, 0.6 \mathrm{H}\right), 7.11-7.05(\mathrm{~m}, 1 \mathrm{H}), 7.03-6.97(\mathrm{~m}, 1 \mathrm{H}), 6.92(\mathrm{~s}, 0.6 \mathrm{~F}), 6.90(\mathrm{~s}, 0.4 \mathrm{~F}), 6.77-6.69(\mathrm{~m}$, $1 \mathrm{H}), 6.41\left(\mathrm{~d},{ }^{3} J_{\mathrm{HF}}=11.2 \mathrm{~Hz}, 1.2 \mathrm{H}\right), 6.39\left(\mathrm{~d},{ }^{3} J_{\mathrm{HF}}=11.7 \mathrm{~Hz}, 0.8 \mathrm{H}\right), 6.17-6.09(\mathrm{~m}, 1 \mathrm{H}), 5.57-5.52(\mathrm{~m}, 1 \mathrm{H}), 5.40$ $(\mathrm{d}, J=14.0 \mathrm{~Hz}, 0.6 \mathrm{H}), 5.39(\mathrm{~d}, J=13.8 \mathrm{~Hz}, 0.4 \mathrm{H}), 4.88(\mathrm{~d}, J=13.9 \mathrm{~Hz}, 0.6 \mathrm{H}), 4.85(\mathrm{~d}, J=13.7 \mathrm{~Hz}, 0.4 \mathrm{H}), 4.50-$ $4.45(\mathrm{~m}, 1 \mathrm{H}), 4.024$ (d, $J=19.3 \mathrm{~Hz}, 0.6 \mathrm{H}), 4.017$ (d, $J=19.2 \mathrm{~Hz}, 0.4 \mathrm{H}), 3.70-3.58$ (m, 2H), 3.36 (d, $J=18.8 \mathrm{~Hz}$, $0.4 \mathrm{H}), 3.34(\mathrm{~d}, J=19.1 \mathrm{~Hz}, 0.6 \mathrm{H}), 1.70(\mathrm{~s}, 1.2 \mathrm{~F}), 1.69(\mathrm{~s}, 1.8 \mathrm{~F}), 1.62(\mathrm{~s}, 1.2 \mathrm{~F}), 1.59(\mathrm{~s}, 1.8 \mathrm{~F}) ;{ }^{19} \mathrm{~F} \mathrm{NMR}\left(\mathrm{CDCl}_{3}, 376\right.$ $\mathrm{MHz}) \delta 135.69\left(\mathrm{dd}, J_{\mathrm{FH}}=11.9,8.2 \mathrm{~Hz}, 0.4 \mathrm{~F}\right),-135.90\left(\mathrm{dd}, J_{\mathrm{FH}}=11.7,8.2 \mathrm{~Hz}, 0.6 \mathrm{~F}\right),-141.79--141.93(\mathrm{~m}, 1 \mathrm{~F})$; Analytical HPLC: $\mathrm{t}_{\mathrm{R}}=10.7 \mathrm{~min}, 96.2 \%$ purity (diastereomeric mixture; $5 \mu \mathrm{L}$ injection; $50-95 \% \mathrm{MeCN} / \mathrm{H}_{2} \mathrm{O}$, linear gradient, with constant $0.1 \% \mathrm{v} / \mathrm{v}$ TFA additive; $20 \mathrm{~min}$ run; $1 \mathrm{~mL} / \mathrm{min}$ flow; ESI; positive ion mode; UV detection at $254 \mathrm{~nm}$ ); HRMS (ESI) calcd for $\mathrm{C}_{52} \mathrm{H}_{40} \mathrm{~F}_{2} \mathrm{~N}_{2} \mathrm{O}_{9} \mathrm{SNa}[\mathrm{M}+\mathrm{Na}]^{+}$929.2315, found 929.2323. 


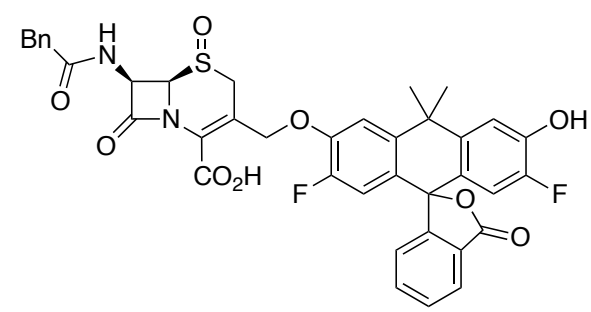

Ceph-VO (25): Ester S2 $(29 \mathrm{mg}, 32.0 \mu \mathrm{mol})$ was taken up in $\mathrm{CH}_{2} \mathrm{Cl}_{2}(3 \mathrm{~mL})$ and cooled to $0{ }^{\circ} \mathrm{C}$. Anisole $(150 \mu \mathrm{L})$ and TFA $(300 \mu \mathrm{L})$ were added, and the reaction was stirred at $0{ }^{\circ} \mathrm{C}$ for $2 \mathrm{~h}$. Toluene $(4 \mathrm{~mL})$ was added, and the reaction mixture was concentrated to dryness. Reverse phase HPLC (10-95\% MeCN/ $\mathrm{H}_{2} \mathrm{O}$, linear gradient, with constant $0.1 \% \mathrm{v} / \mathrm{v}$ TFA additive) afforded $25\left(17 \mathrm{mg}, 71 \%\right.$, diastereomeric mixture) as a white solid. ${ }^{1} \mathrm{H}$ NMR (DMSO- $\left.d_{6}, 400 \mathrm{MHz}\right) \delta 10.25(\mathrm{~s}, 1 \mathrm{H}), 8.41(\mathrm{~d}, J=8.5 \mathrm{~Hz}, 0.4 \mathrm{H}), 8.39(\mathrm{~d}, J=8.4 \mathrm{~Hz}, 0.6 \mathrm{H}), 8.02-7.98(\mathrm{~m}, 1 \mathrm{H})$, $7.77-7.72(\mathrm{~m}, 1 \mathrm{H}), 7.72-7.66(\mathrm{~m}, 1 \mathrm{H}), 7.51\left(\mathrm{~d},{ }^{4} J_{\mathrm{HF}}=8.5 \mathrm{~Hz}, 0.4 \mathrm{H}\right), 7.48\left(\mathrm{~d},{ }^{4} J_{\mathrm{HF}}=8.6 \mathrm{~Hz}, 0.6 \mathrm{H}\right), 7.33-7.19$ $(\mathrm{m}, 6 \mathrm{H}), 7.12-7.07(\mathrm{~m}, 1 \mathrm{H}), 6.41\left(\mathrm{~d},{ }^{3} J_{\mathrm{HF}}=12.0 \mathrm{~Hz}, 1 \mathrm{H}\right), 6.33\left(\mathrm{~d},{ }^{3} J_{\mathrm{HF}}=11.9 \mathrm{~Hz}, 1 \mathrm{H}\right), 5.85-5.79(\mathrm{~m}, 1 \mathrm{H}), 5.27-$ $5.18(\mathrm{~m}, 1 \mathrm{H}), 5.07-4.98(\mathrm{~m}, 1 \mathrm{H}), 4.93-4.89(\mathrm{~m}, 1 \mathrm{H}), 3.98(\mathrm{~d}, J=18.5 \mathrm{~Hz}, 1 \mathrm{H}), 3.69(\mathrm{~d}, J=14.1 \mathrm{~Hz}, 1 \mathrm{H}), 3.67-$ $3.60(\mathrm{~m}, 1 \mathrm{H}), 3.55(\mathrm{~d}, J=14.1 \mathrm{~Hz}, 1 \mathrm{H}), 1.76(\mathrm{~s}, 3 \mathrm{H}), 1.66(\mathrm{~s}, 3 \mathrm{H}) ;{ }^{19} \mathrm{~F}$ NMR (DMSO- $\left.d_{6}, 376 \mathrm{MHz}\right) \delta-135.06-$ $135.19(\mathrm{~m}, 1 \mathrm{~F}),-136.75--136.89(\mathrm{~m}, 1 \mathrm{~F})$; Analytical HPLC: $\mathrm{t}_{\mathrm{R}}=13.4 \mathrm{~min}, 13.5 \mathrm{~min},>99 \%$ purity (diastereomeric mixture; $5 \mu \mathrm{L}$ injection; $10-95 \% \mathrm{MeCN} / \mathrm{H}_{2} \mathrm{O}$, linear gradient, with constant $0.1 \% \mathrm{v} / \mathrm{v}$ TFA additive; 20 min run; 1 $\mathrm{mL} / \mathrm{min}$ flow; ESI; positive ion mode; UV detection at $254 \mathrm{~nm}$ ); HRMS (ESI) calcd for $\mathrm{C}_{39} \mathrm{H}_{31} \mathrm{~F}_{2} \mathrm{~N}_{2} \mathrm{O}_{9} \mathrm{~S}[\mathrm{M}+\mathrm{H}]^{+}$ 741.1713 , found 741.1727 .

\section{Synthesis of Dual-InPUt Fluorogenic Probes}

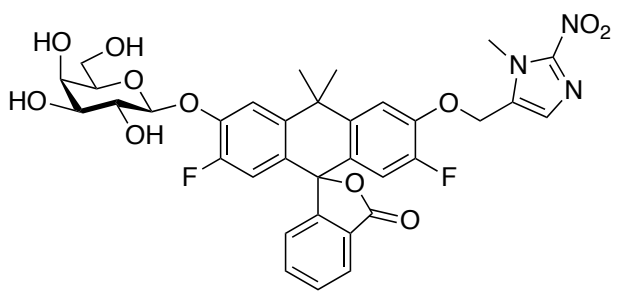

Gal-VO-NM (26): Imidazole 23 (60 mg, $0.112 \mathrm{mmol}$ ) and acetobromo- $\alpha$-D-galactose (17; $185 \mathrm{mg}, 0.450 \mathrm{mmol}, 4$ eq) were combined in $\mathrm{MeCN}(4 \mathrm{~mL})$ under nitrogen, and $\mathrm{Ag}_{2} \mathrm{O}$ (104 mg, $\left.0.450 \mathrm{mmol}, 4 \mathrm{eq}\right)$ was added. The resulting mixture was stirred at $50{ }^{\circ} \mathrm{C}$ for $2 \mathrm{~h}$. The reaction was then cooled to room temperature, filtered through Celite with $\mathrm{MeCN}$, and concentrated in vacuo. The crude residue was purified by flash chromatography on silica gel ( $0-40 \% \mathrm{MeCN} / \mathrm{CH}_{2} \mathrm{Cl}_{2}$, linear gradient) to provide $82 \mathrm{mg}(84 \%)$ of the galactoside tetraacetate as a white solid.

The tetraacetate $(82 \mathrm{mg}, 0.0949 \mathrm{mmol})$ was subsequently dissolved in $1: 1 \mathrm{MeOH} / \mathrm{MeCN}(4 \mathrm{~mL})$, and $1 \mathrm{M}$ $\mathrm{Na}_{2} \mathrm{CO}_{3}$ (aq, $949 \mu \mathrm{L}, 0.949 \mathrm{mmol}, 10 \mathrm{eq}$ ) was added. The reaction was stirred at room temperature for $2 \mathrm{~h}$. It was then neutralized with $1 \mathrm{~N} \mathrm{HCl}(2 \mathrm{~mL})$, and the resulting solution was directly purified by reverse phase HPLC (10$95 \% \mathrm{MeCN} / \mathrm{H}_{2} \mathrm{O}$, linear gradient, with constant $0.1 \% \mathrm{v} / \mathrm{v}$ TFA additive) to yield $57 \mathrm{mg}(86 \%$, diastereomeric mixture) of 26 as a white solid. ${ }^{1} \mathrm{H}$ NMR $\left(\mathrm{CD}_{3} \mathrm{OD}, 400 \mathrm{MHz}\right) \delta 8.05-8.02(\mathrm{~m}, 1 \mathrm{H}), 7.76-7.71(\mathrm{~m}, 1 \mathrm{H}), 7.71-$ 
$7.66(\mathrm{~m}, 1 \mathrm{H}), 7.66\left(\mathrm{~d},{ }^{4} J_{\mathrm{HF}}=8.2 \mathrm{~Hz}, 0.5 \mathrm{H}\right), 7.65\left(\mathrm{~d},{ }^{4} J_{\mathrm{HF}}=8.2 \mathrm{~Hz}, 0.5 \mathrm{H}\right), 7.57\left(\mathrm{~d},{ }^{4} J_{\mathrm{HF}}=8.2 \mathrm{~Hz}, 1 \mathrm{H}\right), 7.30(\mathrm{~s}, 1 \mathrm{H})$, $7.06-7.02(\mathrm{~m}, 1 \mathrm{H}), 6.42\left(\mathrm{~d},{ }^{3} J_{\mathrm{HF}}=11.9 \mathrm{~Hz}, 0.5 \mathrm{H}\right), 6.42\left(\mathrm{~d},{ }^{3} J_{\mathrm{HF}}=11.8 \mathrm{~Hz}, 0.5 \mathrm{H}\right), 6.39\left(\mathrm{~d},{ }^{3} J_{\mathrm{HF}}=11.8 \mathrm{~Hz}, 0.5 \mathrm{H}\right)$, $6.39\left(\mathrm{~d},{ }^{3} J_{\mathrm{HF}}=11.7 \mathrm{~Hz}, 0.5 \mathrm{H}\right), 5.40(\mathrm{~s}, 2 \mathrm{H}), 5.05-4.97(\mathrm{~m}, 1 \mathrm{H}), 4.08(\mathrm{~s}, 3 \mathrm{H}), 3.93-3.75(\mathrm{~m}, 5 \mathrm{H}), 3.65-3.59(\mathrm{~m}$, $1 \mathrm{H}), 1.89(\mathrm{~s}, 3 \mathrm{H}), 1.79(\mathrm{~s}, 3 \mathrm{H}) ;{ }^{19} \mathrm{~F}$ NMR $\left(\mathrm{CD}_{3} \mathrm{OD}, 376 \mathrm{MHz}\right) \delta-134.41\left(\mathrm{dd}, J_{\mathrm{FH}}=11.7,7.7 \mathrm{~Hz}, 0.5 \mathrm{~F}\right),-134.43(\mathrm{dd}$, $\left.J_{\mathrm{FH}}=11.8,7.8 \mathrm{~Hz}, 0.5 \mathrm{~F}\right),-135.31\left(\mathrm{dd}, J_{\mathrm{FH}}=11.8,8.4 \mathrm{~Hz}, 0.5 \mathrm{~F}\right),-135.32\left(\mathrm{dd}, J_{\mathrm{FH}}=11.9,8.1 \mathrm{~Hz}, 0.5 \mathrm{~F}\right)$; Analytical HPLC: $t_{R}=11.4 \mathrm{~min},>99 \%$ purity (diastereomeric mixture; $5 \mu \mathrm{L}$ injection; $10-95 \% \mathrm{MeCN} / \mathrm{H}_{2} \mathrm{O}$, linear gradient, with constant $0.1 \% \mathrm{v} / \mathrm{v}$ TFA additive; $20 \mathrm{~min}$ run; $1 \mathrm{~mL} / \mathrm{min}$ flow; ESI; positive ion mode; UV detection at 254 $\mathrm{nm}$ ); HRMS (ESI) calcd for $\mathrm{C}_{34} \mathrm{H}_{31} \mathrm{~F}_{2} \mathrm{~N}_{3} \mathrm{O}_{11} \mathrm{Na}[\mathrm{M}+\mathrm{Na}]^{+} 718.1819$, found 718.1789.

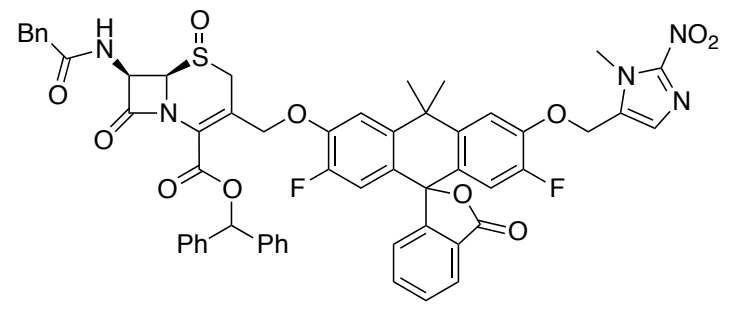

Ceph(Bzh)-VO-NM (S3): Imidazole 23 (161 mg, 0.302 mmol), (6R,7R)-benzhydryl 3-(chloromethyl)-8-oxo-7-(2phenylacetamido)-5-thia-1-azabicyclo[4.2.0]oct-2-ene-2-carboxylate (19; $483 \mathrm{mg}, 0.905 \mathrm{mmol}, 3 \mathrm{eq}), \mathrm{K}_{2} \mathrm{CO}_{3}(125$ $\mathrm{mg}, 0.905 \mathrm{mmol}, 3 \mathrm{eq})$, and $\mathrm{NaI}(68 \mathrm{mg}, 0.453 \mathrm{mmol}, 1.5 \mathrm{eq})$ were combined in $\mathrm{MeCN}(12 \mathrm{~mL})$ and stirred at room temperature for $7 \mathrm{~h}$. The reaction was subsequently diluted with water and extracted with EtOAc $(2 \times)$. The combined organics were washed with brine, dried over anhydrous $\mathrm{MgSO}_{4}$, filtered, and evaporated. Silica gel chromatography $\left(0-40 \% \mathrm{EtOAc} / \mathrm{CH}_{2} \mathrm{Cl}_{2}\right.$, linear gradient) provided the alkylated product as a mixture of isomers (260 mg).

The isomeric mixture $(260 \mathrm{mg})$ was dissolved in $\mathrm{CH}_{2} \mathrm{Cl}_{2}(10 \mathrm{~mL})$ and cooled to $0{ }^{\circ} \mathrm{C} . m$-Chloroperoxybenzoic acid $(77 \%, 68 \mathrm{mg}, 0.303 \mathrm{mmol}, 1.2 \mathrm{eq})$ was added, and the reaction was stirred at $0{ }^{\circ} \mathrm{C}$ for $30 \mathrm{~min}$. It was then diluted with saturated $\mathrm{NaHCO}_{3}$ and extracted with $\mathrm{CH}_{2} \mathrm{Cl}_{2}(2 \times)$. The organics were washed with brine, dried over anhydrous $\mathrm{MgSO}_{4}$, filtered, and evaporated. Flash chromatography $\left(0-50 \%\right.$ EtOAc/ $\mathrm{CH}_{2} \mathrm{Cl}_{2}$, linear gradient) afforded $181 \mathrm{mg}\left(57 \%, 2\right.$ steps, diastereomeric mixture) of $\mathbf{S 3}$ as a pale yellow solid. ${ }^{1} \mathrm{H}$ NMR $\left(\mathrm{CDCl}_{3}, 400 \mathrm{MHz}\right) \delta$ $8.07-8.02(\mathrm{~m}, 1 \mathrm{H}), 7.69-7.60(\mathrm{~m}, 2 \mathrm{H}), 7.52-7.46(\mathrm{~m}, 2 \mathrm{H}), 7.40-7.27(\mathrm{~m}, 13 \mathrm{H}), 7.233\left(\mathrm{~d},{ }^{4} J_{\mathrm{HF}}=8.0 \mathrm{~Hz}, 0.5 \mathrm{H}\right)$, $7.230(\mathrm{~s}, 1 \mathrm{H}), 7.224\left(\mathrm{~d},{ }^{4} J_{\mathrm{HF}}=7.8 \mathrm{~Hz}, 0.5 \mathrm{H}\right), 7.11\left(\mathrm{~d},{ }^{4} J_{\mathrm{HF}}=8.1 \mathrm{~Hz}, 0.5 \mathrm{H}\right), 7.10\left(\mathrm{~d},{ }^{4} J_{\mathrm{HF}}=8.1 \mathrm{~Hz}, 0.5 \mathrm{H}\right), 7.02-6.96$ $(\mathrm{m}, 1 \mathrm{H}), 6.92(\mathrm{~s}, 0.5 \mathrm{H}), 6.91(\mathrm{~s}, 0.5 \mathrm{H}), 6.75-6.67(\mathrm{~m}, 1 \mathrm{H}), 6.46\left(\mathrm{~d},{ }^{3} J_{\mathrm{HF}}=11.8 \mathrm{~Hz}, 1 \mathrm{H}\right), 6.41\left(\mathrm{~d},{ }^{3} J_{\mathrm{HF}}=11.7 \mathrm{~Hz}\right.$, $0.5 \mathrm{H}), 6.40\left(\mathrm{~d},{ }^{3} J_{\mathrm{HF}}=11.7 \mathrm{~Hz}, 0.5 \mathrm{H}\right), 6.17-6.10(\mathrm{~m}, 1 \mathrm{H}), 5.380(\mathrm{~d}, J=14.0 \mathrm{~Hz}, 0.5 \mathrm{H}), 5.376(\mathrm{~d}, J=13.7 \mathrm{~Hz}$, $0.5 \mathrm{H}), 5.19(\mathrm{~s}, 2 \mathrm{H}), 4.90(\mathrm{~d}, J=13.6 \mathrm{~Hz}, 0.5 \mathrm{H}), 4.88(\mathrm{~d}, J=13.5 \mathrm{~Hz}, 0.5 \mathrm{H}), 4.52-4.47(\mathrm{~m}, 1 \mathrm{H}), 4.11(\mathrm{~s}, 3 \mathrm{H}), 4.02$ $(\mathrm{d}, J=19.1 \mathrm{~Hz}, 1 \mathrm{H}), 3.70-3.57(\mathrm{~m}, 2 \mathrm{H}), 3.37(\mathrm{~d}, J=19.2 \mathrm{~Hz}, 0.5 \mathrm{H}), 3.36(\mathrm{~d}, J=19.3 \mathrm{~Hz}, 0.5 \mathrm{H}), 1.74(\mathrm{~s}, 1.5 \mathrm{H})$, $1.73(\mathrm{~s}, 1.5 \mathrm{H}), 1.66(\mathrm{~s}, 1.5 \mathrm{H}), 1.63(\mathrm{~s}, 1.5 \mathrm{H}) ;{ }^{19} \mathrm{~F} \mathrm{NMR}\left(\mathrm{CDCl}_{3}, 376 \mathrm{MHz}\right) \delta-134.09\left(\mathrm{dd}, J_{\mathrm{FH}}=11.8,8.0 \mathrm{~Hz}, 0.5 \mathrm{~F}\right),-$ $134.10\left(\mathrm{dd}, J_{\mathrm{FH}}=11.8,7.9 \mathrm{~Hz}, 0.5 \mathrm{~F}\right),-135.26\left(\mathrm{dd}, J_{\mathrm{FH}}=11.7,8.1 \mathrm{~Hz}, 0.5 \mathrm{~F}\right),-135.47\left(\mathrm{dd}, J_{\mathrm{FH}}=11.6,8.1 \mathrm{~Hz}, 0.5 \mathrm{~F}\right)$; Analytical HPLC: $t_{\mathrm{R}}=12.3 \mathrm{~min},>99 \%$ purity (diastereomeric mixture; $5 \mu \mathrm{L}$ injection; $50-95 \% \mathrm{MeCN} / \mathrm{H}_{2} \mathrm{O}$, linear gradient, with constant $0.1 \% \mathrm{v} / \mathrm{v}$ TFA additive; $20 \mathrm{~min}$ run; $1 \mathrm{~mL} / \mathrm{min}$ flow; ESI; positive ion mode; UV detection at $254 \mathrm{~nm}$ ); HRMS (ESI) calcd for $\mathrm{C}_{57} \mathrm{H}_{45} \mathrm{~F}_{2} \mathrm{~N}_{5} \mathrm{O}_{11} \mathrm{SNa}[\mathrm{M}+\mathrm{Na}]^{+}$1068.2697, found 1068.2709. 


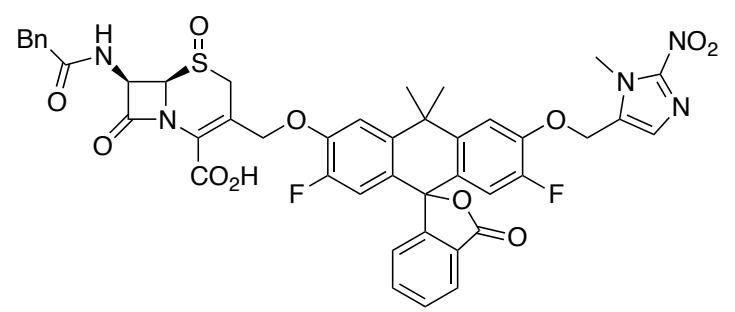

Ceph-VO-NM (27): Ester $\mathbf{S 3}$ (60 mg, $57.4 \mu \mathrm{mol})$ was taken up in $\mathrm{CH}_{2} \mathrm{Cl}_{2}(4 \mathrm{~mL})$ and cooled to $0{ }^{\circ} \mathrm{C}$. Anisole (200 $\mu \mathrm{L})$ and TFA $(400 \mu \mathrm{L})$ were added, and the reaction was stirred at $0{ }^{\circ} \mathrm{C}$ for $3 \mathrm{~h}$. Toluene $(5 \mathrm{~mL})$ was added, and the reaction mixture was concentrated to dryness. Reverse phase HPLC (10-95\% $\mathrm{MeCN} / \mathrm{H}_{2} \mathrm{O}$, linear gradient, with constant $0.1 \% \mathrm{v} / \mathrm{v}$ TFA additive) afforded 27 as a white solid (TFA salt, $38 \mathrm{mg}, 67 \%$, diastereomeric mixture). ${ }^{1} \mathrm{H}$ NMR (DMSO- $\left.d_{6}, 400 \mathrm{MHz}\right) \delta 14.01(\mathrm{~s}, 1 \mathrm{H}), 8.44-8.37(\mathrm{~m}, 1 \mathrm{H}), 8.03-7.98(\mathrm{~m}, 1 \mathrm{H}), 7.77-7.65(\mathrm{~m}, 3 \mathrm{H}), 7.56(\mathrm{~d}$, $\left.{ }^{4} J_{\mathrm{HF}}=8.5 \mathrm{~Hz}, 0.5 \mathrm{H}\right), 7.53\left(\mathrm{~d},{ }^{4} J_{\mathrm{HF}}=8.4 \mathrm{~Hz}, 0.5 \mathrm{H}\right), 7.39(\mathrm{~s}, 1 \mathrm{H}), 7.34-7.27(\mathrm{~m}, 4 \mathrm{H}), 7.27-7.20(\mathrm{~m}, 1 \mathrm{H}), 7.09-$ $7.03(\mathrm{~m}, 1 \mathrm{H}), 6.45\left(\mathrm{~d},{ }^{3} J_{\mathrm{HF}}=11.9 \mathrm{~Hz}, 1 \mathrm{H}\right), 6.44\left(\mathrm{~d},{ }^{3} J_{\mathrm{HF}}=11.9 \mathrm{~Hz}, 1 \mathrm{H}\right), 5.86-5.80(\mathrm{~m}, 1 \mathrm{H}), 5.50(\mathrm{~s}, 2 \mathrm{H}), 5.27-$ $5.17(\mathrm{~m}, 1 \mathrm{H}), 5.10-5.00(\mathrm{~m}, 1 \mathrm{H}), 4.94-4.90(\mathrm{~m}, 1 \mathrm{H}), 3.98(\mathrm{~d}, J=18.2 \mathrm{~Hz}, 1 \mathrm{H}), 3.97$ (s, 3H), $3.70(\mathrm{~d}, J=14.1 \mathrm{~Hz}$, $1 \mathrm{H}), 3.69-3.61(\mathrm{~m}, 1 \mathrm{H}), 3.551(\mathrm{~d}, J=14.0 \mathrm{~Hz}, 0.5 \mathrm{H}), 3.548(\mathrm{~d}, J=14.1 \mathrm{~Hz}, 0.5 \mathrm{H}), 1.862(\mathrm{~s}, 1.5 \mathrm{H}), 1.857(\mathrm{~s}$, $1.5 \mathrm{H}$ ), $1.77(\mathrm{~s}, 3 \mathrm{H}) ;{ }^{19} \mathrm{~F}$ NMR (DMSO- $\left.d_{6}, 376 \mathrm{MHz}\right) \delta-134.95--135.07$ (m, 1F), -135.24 - -135.34 (m, 1F); Analytical HPLC: $t_{R}=12.1 \mathrm{~min}, 12.2 \mathrm{~min},>99 \%$ purity (diastereomeric mixture; $5 \mu \mathrm{L}$ injection; 30-95\% $\mathrm{MeCN} / \mathrm{H}_{2} \mathrm{O}$, linear gradient, with constant $0.1 \% \mathrm{v} / \mathrm{v}$ TFA additive; $20 \mathrm{~min}$ run; $1 \mathrm{~mL} / \mathrm{min}$ flow; ESI; positive ion mode; UV detection at $254 \mathrm{~nm}$ ); HRMS (ESI) calcd for $\mathrm{C}_{44} \mathrm{H}_{35} \mathrm{~F}_{2} \mathrm{~N}_{5} \mathrm{O}_{11} \mathrm{SNa}[\mathrm{M}+\mathrm{Na}]^{+}$902.1914, found 902.1906.

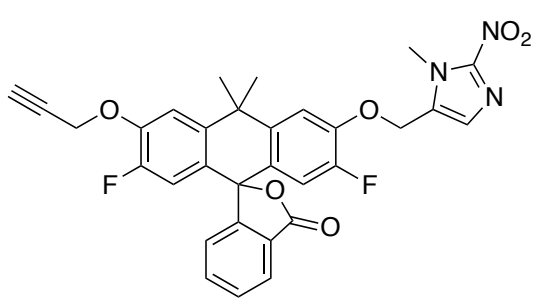

NM-VO-Prg (28): To a mixture of imidazole 23 (40 mg, $75.0 \mu \mathrm{mol})$ and $\mathrm{K}_{2} \mathrm{CO}_{3}(41 \mathrm{mg}, 0.300 \mathrm{mmol}, 4 \mathrm{eq})$ in DMF $(2 \mathrm{~mL})$ was added propargyl bromide $(80 \% \mathrm{w} / \mathrm{w}$ in toluene, $33 \mu \mathrm{L}, 0.300 \mathrm{mmol}, 4 \mathrm{eq})$, and the reaction was stirred at room temperature for $18 \mathrm{~h}$. It was subsequently diluted with water and extracted with EtOAc (2x). The combined organics were washed with brine, dried over anhydrous $\mathrm{MgSO}_{4}$, filtered, and evaporated. Silica gel chromatography (10-100\% EtOAc/hexanes, linear gradient, with constant $40 \% \mathrm{v} / \mathrm{v} \mathrm{CH}_{2} \mathrm{Cl}_{2}$ additive) provided $\mathbf{2 8}$ as a yellow solid (39 mg, 91\%). ${ }^{1} \mathrm{H} \mathrm{NMR}\left(\mathrm{CDCl}_{3}, 400 \mathrm{MHz}\right) \delta 8.07-8.03(\mathrm{~m}, 1 \mathrm{H}), 7.66(\mathrm{td}, J=7.3,1.6 \mathrm{~Hz}, 1 \mathrm{H}), 7.63$ $(\mathrm{td}, J=7.3,1.3 \mathrm{~Hz}, 1 \mathrm{H}), 7.34\left(\mathrm{~d},{ }^{4} J_{\mathrm{HF}}=8.1 \mathrm{~Hz}, 1 \mathrm{H}\right), 7.26\left(\mathrm{~d},{ }^{4} J_{\mathrm{HF}}=8.0 \mathrm{~Hz}, 1 \mathrm{H}\right), 7.23(\mathrm{~s}, 1 \mathrm{H}), 7.05-7.01(\mathrm{~m}, 1 \mathrm{H})$, $6.48\left(\mathrm{~d},{ }^{3} J_{\mathrm{HF}}=11.9 \mathrm{~Hz}, 1 \mathrm{H}\right), 6.44\left(\mathrm{~d},{ }^{3} J_{\mathrm{HF}}=11.8 \mathrm{~Hz}, 1 \mathrm{H}\right), 5.20(\mathrm{~s}, 2 \mathrm{H}), 4.83(\mathrm{~d}, J=2.2 \mathrm{~Hz}, 2 \mathrm{H}), 4.11(\mathrm{~s}, 3 \mathrm{H}), 2.60$ $(\mathrm{t}, J=2.4 \mathrm{~Hz}, 1 \mathrm{H}), 1.83(\mathrm{~s}, 3 \mathrm{H}), 1.74(\mathrm{~s}, 3 \mathrm{H}) ;{ }^{19} \mathrm{~F} \mathrm{NMR}\left(\mathrm{CDCl}_{3}, 376 \mathrm{MHz}\right) \delta-134.11\left(\mathrm{dd}, J_{\mathrm{FH}}=11.9,8.0 \mathrm{~Hz}, 1 \mathrm{~F}\right),-$ $134.95\left(\mathrm{dd}, J_{\mathrm{FH}}=11.8,8.1 \mathrm{~Hz}, 1 \mathrm{~F}\right) ;{ }^{13} \mathrm{C} \mathrm{NMR}\left(\mathrm{CDCl}_{3}, 101 \mathrm{MHz}\right) \delta 169.8(\mathrm{C}), 154.0(\mathrm{C}), 151.8\left(\mathrm{~d},{ }^{1} J_{\mathrm{CF}}=247.9 \mathrm{~Hz}\right.$, C), $151.6\left(\mathrm{~d},{ }^{1} J_{\mathrm{CF}}=248.0 \mathrm{~Hz}, \mathrm{C}\right), 146.7(\mathrm{C}), 146.4\left(\mathrm{~d},{ }^{2} J_{\mathrm{CF}}=11.1 \mathrm{~Hz}, \mathrm{C}\right), 146.1\left(\mathrm{~d},{ }^{2} J_{\mathrm{CF}}=11.3 \mathrm{~Hz}, \mathrm{C}\right), 142.0\left(\mathrm{~d},{ }^{4} J_{\mathrm{CF}}\right.$ $=3.5 \mathrm{~Hz}, \mathrm{C}), 141.1\left(\mathrm{~d},{ }^{4} J_{\mathrm{CF}}=3.5 \mathrm{~Hz}, \mathrm{C}\right), 135.4(\mathrm{CH}), 132.0(\mathrm{C}), 130.1(\mathrm{CH}), 129.5(\mathrm{CH}), 126.7\left(\mathrm{~d},{ }^{3} J_{\mathrm{CF}}=5.7 \mathrm{~Hz}\right.$, 
C), $126.0(\mathrm{C}), 125.8(\mathrm{CH}), 125.1\left(\mathrm{~d},{ }^{3} J_{\mathrm{CF}}=5.7 \mathrm{~Hz}, \mathrm{C}\right), 123.6(\mathrm{CH}), 115.58\left(\mathrm{~d},{ }^{2} J_{\mathrm{CF}}=19.5 \mathrm{~Hz}, \mathrm{CH}\right), 115.10\left(\mathrm{~d},{ }^{3} J_{\mathrm{CF}}=\right.$ $1.4 \mathrm{~Hz}, \mathrm{CH}), 115.06\left(\mathrm{~d},{ }^{2} J_{\mathrm{CF}}=19.4 \mathrm{~Hz}, \mathrm{CH}\right), 114.17\left(\mathrm{~d},{ }^{3} J_{\mathrm{CF}}=1.4 \mathrm{~Hz}, \mathrm{CH}\right), 84.8(\mathrm{C}), 77.8(\mathrm{C}), 76.9(\mathrm{CH}), 61.8(\mathrm{~d}$, $\left.{ }^{4} J_{\mathrm{CF}}=1.8 \mathrm{~Hz}, \mathrm{CH}_{2}\right), 57.4\left(\mathrm{CH}_{2}\right), 38.2(\mathrm{C}), 35.1\left(\mathrm{CH}_{3}\right), 34.7\left(\mathrm{CH}_{3}\right), 33.4\left(\mathrm{CH}_{3}\right)$; HRMS (ESI) calcd for $\mathrm{C}_{31} \mathrm{H}_{24} \mathrm{~F}_{2} \mathrm{~N}_{3} \mathrm{O}_{6}$ $[\mathrm{M}+\mathrm{H}]^{+}$572.1628, found 572.1636.

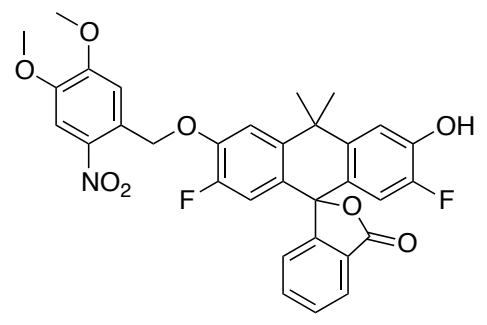

NV-VO (29): To a solution of Virginia Orange $(4 ; 300 \mathrm{mg}, 0.761 \mathrm{mmol})$ and 4,5-dimethoxy-2-nitrobenzyl bromide (210 mg, $0.761 \mathrm{mmol}, 1 \mathrm{eq})$ in $\mathrm{MeCN}(15 \mathrm{~mL})$ was added $\mathrm{Ag}_{2} \mathrm{O}$ (176 mg, $\left.0.761 \mathrm{mmol}, 1 \mathrm{eq}\right)$, and the resulting mixture was stirred at $60{ }^{\circ} \mathrm{C}$ for $1 \mathrm{~h}$. After cooling the reaction to room temperature, $1 \mathrm{~N} \mathrm{HCl}(40 \mathrm{~mL})$ and EtOAc $(40 \mathrm{~mL})$ were added. The gray suspension was filtered through Celite, and the filtrate was extracted with EtOAc $(2 \times)$. The combined organic extracts were washed with brine, dried over anhydrous $\mathrm{MgSO}_{4}$, filtered, and concentrated in vacuo. Purification by flash chromatography on silica gel (0-40\% EtOAc/hexanes, linear gradient, with constant $40 \% \mathrm{v} / \mathrm{v} \mathrm{CH}_{2} \mathrm{Cl}_{2}$ additive) yielded $133 \mathrm{mg}$ (30\%) of $\mathbf{2 9}$ as a pale yellow solid. ${ }^{1} \mathrm{H} \mathrm{NMR}\left(\mathrm{CDCl}_{3}, 400\right.$ MHz) $\delta 8.07-8.03(\mathrm{~m}, 1 \mathrm{H}), 7.78(\mathrm{~s}, 1 \mathrm{H}), 7.66(\mathrm{td}, J=7.4,1.5 \mathrm{~Hz}, 1 \mathrm{H}), 7.63(\mathrm{td}, J=7.4,1.2 \mathrm{~Hz}, 1 \mathrm{H}), 7.45(\mathrm{~s}, 1 \mathrm{H})$, $7.28\left(\mathrm{~d},{ }^{4} J_{\mathrm{HF}}=8.1 \mathrm{~Hz}, 1 \mathrm{H}\right), 7.26\left(\mathrm{~d},{ }^{4} J_{\mathrm{HF}}=8.6 \mathrm{~Hz}, 1 \mathrm{H}\right), 7.06-7.02(\mathrm{~m}, 1 \mathrm{H}), 6.47\left(\mathrm{~d},{ }^{3} J_{\mathrm{HF}}=11.8 \mathrm{~Hz}, 1 \mathrm{H}\right), 6.43(\mathrm{~d}$, $\left.{ }^{3} J_{\mathrm{HF}}=11.3 \mathrm{~Hz}, 1 \mathrm{H}\right), 5.60(\mathrm{~s}, 2 \mathrm{H}), 5.41\left(\mathrm{~d},{ }^{4} J_{\mathrm{HF}}=3.5 \mathrm{~Hz}, 1 \mathrm{H}\right), 3.98(\mathrm{~s}, 3 \mathrm{H}), 3.98(\mathrm{~s}, 3 \mathrm{H}), 1.81(\mathrm{~s}, 3 \mathrm{H}), 1.70(\mathrm{~s}, 3 \mathrm{H})$; ${ }^{19} \mathrm{~F}$ NMR $\left(\mathrm{CDCl}_{3}, 376 \mathrm{MHz}\right) \delta-135.81\left(\mathrm{dd}, J_{\mathrm{FH}}=11.8,8.1 \mathrm{~Hz}, 1 \mathrm{~F}\right),-142.19\left(\mathrm{ddd}, J_{\mathrm{FH}}=11.6,8.7,3.8 \mathrm{~Hz}, 1 \mathrm{~F}\right) ;{ }^{13} \mathrm{C}$ $\operatorname{NMR}\left(\mathrm{CDCl}_{3}, 101 \mathrm{MHz}\right) \delta 170.3(\mathrm{C}), 154.4(\mathrm{C}), 154.3(\mathrm{C}), 151.6\left(\mathrm{~d},{ }^{1} J_{\mathrm{CF}}=247.2 \mathrm{~Hz}, \mathrm{C}\right), 149.9\left(\mathrm{~d},{ }^{1} J_{\mathrm{CF}}=149.9 \mathrm{~Hz}\right.$, C), $148.2(\mathrm{C}), 147.25\left(\mathrm{~d},{ }^{2} J_{\mathrm{CF}}=11.1 \mathrm{~Hz}, \mathrm{C}\right), 144.84\left(\mathrm{~d},{ }^{2} J_{\mathrm{CF}}=14.4 \mathrm{~Hz}, \mathrm{C}\right), 142.22\left(\mathrm{~d},{ }^{4} J_{\mathrm{CF}}=3.3 \mathrm{~Hz}, \mathrm{C}\right), 142.02(\mathrm{~d}$, $\left.{ }^{4} J_{\mathrm{CF}}=3.5 \mathrm{~Hz}, \mathrm{C}\right), 139.1(\mathrm{C}), 135.4(\mathrm{CH}), 130.0(\mathrm{CH}), 128.6(\mathrm{C}), 126.1(\mathrm{C}), 125.7(\mathrm{CH}), 125.29\left(\mathrm{~d},{ }^{3} J_{\mathrm{CF}}=5.6 \mathrm{~Hz}\right.$, C), $123.81\left(\mathrm{~d},{ }^{3} J_{\mathrm{CF}}=5.4 \mathrm{~Hz}, \mathrm{C}\right), 123.7(\mathrm{CH}), 115.3\left(\mathrm{~d},{ }^{3} J_{\mathrm{CF}}=1.6 \mathrm{~Hz}, \mathrm{CH}\right), 115.04\left(\mathrm{~d},{ }^{2} J_{\mathrm{CF}}=19.2 \mathrm{~Hz}, \mathrm{CH}\right), 114.32$ $\left(\mathrm{d},{ }^{2} J_{\mathrm{CF}}=19.1 \mathrm{~Hz}, \mathrm{CH}\right), 113.7\left(\mathrm{~d},{ }^{3} J_{\mathrm{CF}}=1.0 \mathrm{~Hz}, \mathrm{CH}\right), 109.6(\mathrm{CH}), 108.1(\mathrm{CH}), 85.5(\mathrm{C}), 68.5\left(\mathrm{CH}_{2}\right), 56.62\left(\mathrm{CH}_{3}\right)$, $56.57\left(\mathrm{CH}_{3}\right), 38.2(\mathrm{C}), 35.2\left(\mathrm{CH}_{3}\right), 33.4\left(\mathrm{CH}_{3}\right)$; HRMS (ESI) calcd for $\mathrm{C}_{32} \mathrm{H}_{26} \mathrm{~F}_{2} \mathrm{NO}_{8}[\mathrm{M}+\mathrm{H}]^{+}$590.1621, found 590.1630.

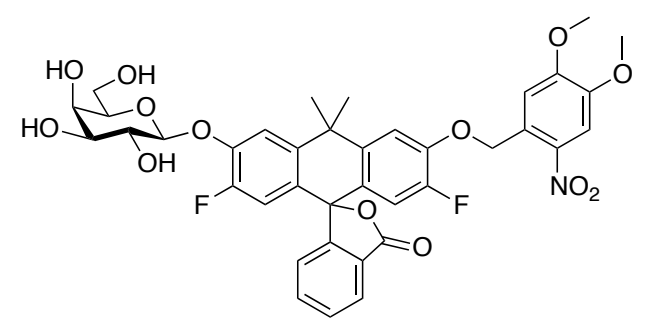

Gal-VO-NV (30): Phenol 29 (50 mg, $84.8 \mu \mathrm{mol})$ and acetobromo- $\alpha$-D-galactose (17; $140 \mathrm{mg}, 0.339 \mathrm{mmol}, 4 \mathrm{eq})$ were combined in $\mathrm{MeCN}(4 \mathrm{~mL})$ under nitrogen, and $\mathrm{Ag}_{2} \mathrm{O}$ ( $\left.79 \mathrm{mg}, 0.339 \mathrm{mmol}, 4 \mathrm{eq}\right)$ was added. The resulting 
mixture was stirred at $50{ }^{\circ} \mathrm{C}$ for $90 \mathrm{~min}$. The reaction was then cooled to room temperature, filtered through Celite with $\mathrm{MeCN}$, and concentrated in vacuo. The crude residue was purified by flash chromatography on silica gel ( $0-$ $50 \% \mathrm{EtOAc} / \mathrm{hexanes}$, linear gradient, with constant $40 \% \mathrm{v} / \mathrm{v} \mathrm{CH}_{2} \mathrm{Cl}_{2}$ additive) to provide $54 \mathrm{mg}(69 \%)$ of the galactoside tetraacetate as a white solid.

The tetraacetate $(54 \mathrm{mg}, 58.2 \mu \mathrm{mol})$ was subsequently dissolved in $1: 1 \mathrm{MeOH} / \mathrm{MeCN}(2.4 \mathrm{~mL})$, and $1 \mathrm{M}$ $\mathrm{Na}_{2} \mathrm{CO}_{3}$ (aq, $582 \mu \mathrm{L}, 0.582 \mathrm{mmol}, 10 \mathrm{eq}$ ) was added. The reaction was stirred at room temperature for $2 \mathrm{~h}$. It was then neutralized with $1 \mathrm{~N} \mathrm{HCl}(1.2 \mathrm{~mL})$, diluted with water, and extracted with $\mathrm{CH}_{2} \mathrm{Cl}_{2}(2 \times)$. The combined organic extracts were dried over anhydrous $\mathrm{MgSO}_{4}$, filtered, and concentrated in vacuo. The residue was purified by reverse phase HPLC (10-75\% MeCN/ $\mathrm{H}_{2} \mathrm{O}$, linear gradient) to yield $27 \mathrm{mg}(62 \%$, diastereomeric mixture) of $\mathbf{3 0}$ as a white solid. ${ }^{1} \mathrm{H}$ NMR $\left(\mathrm{CD}_{3} \mathrm{OD}, 400 \mathrm{MHz}\right) \delta 8.07-8.03(\mathrm{~m}, 1 \mathrm{H}), 7.78(\mathrm{~s}, 1 \mathrm{H}), 7.77-7.72(\mathrm{~m}, 1 \mathrm{H}), 7.72-7.67(\mathrm{~m}, 1 \mathrm{H})$, $7.65\left(\mathrm{~d},{ }^{4} J_{\mathrm{HF}}=8.2 \mathrm{~Hz}, 0.6 \mathrm{H}\right), 7.64\left(\mathrm{~d},{ }^{4} J_{\mathrm{HF}}=8.2 \mathrm{~Hz}, 0.4 \mathrm{H}\right), 7.43\left(\mathrm{~d},{ }^{4} J_{\mathrm{HF}}=8.2 \mathrm{~Hz}, 1 \mathrm{H}\right), 7.38(\mathrm{~s}, 1 \mathrm{H}), 7.08-7.04(\mathrm{~m}$, $1 \mathrm{H}), 6.44\left(\mathrm{~d},{ }^{3} J_{H F}=11.9 \mathrm{~Hz}, 0.4 \mathrm{H}\right), 6.43\left(\mathrm{~d},{ }^{3} J_{H F}=11.9 \mathrm{~Hz}, 0.6 \mathrm{H}\right), 6.40\left(\mathrm{~d},{ }^{3} J_{H F}=11.8 \mathrm{~Hz}, 0.4 \mathrm{H}\right), 6.39\left(\mathrm{~d},{ }^{3} J_{H F}=\right.$ $11.8 \mathrm{~Hz}, 0.6 \mathrm{H}), 5.61(\mathrm{~s}, 2 \mathrm{H}), 5.03(\mathrm{~d}, J=7.8 \mathrm{~Hz}, 0.4 \mathrm{H}), 4.99(\mathrm{~d}, J=7.8 \mathrm{~Hz}, 0.6 \mathrm{H}), 3.93(\mathrm{~s}, 3 \mathrm{H}), 3.91(\mathrm{~s}, 3 \mathrm{H}), 3.94-$ $3.74(\mathrm{~m}, 5 \mathrm{H}), 3.65-3.59(\mathrm{~m}, 1 \mathrm{H}), 1.85(\mathrm{~s}, 3 \mathrm{H}), 1.74(\mathrm{~s}, 3 \mathrm{H}) ;{ }^{19} \mathrm{~F}$ NMR $\left(\mathrm{CD}_{3} \mathrm{OD}, 376 \mathrm{MHz}\right) \delta-134.44--134.55(\mathrm{~m}$, $1 \mathrm{~F}),-135.59--135.69(\mathrm{~m}, 1 \mathrm{~F})$; Analytical HPLC: $\mathrm{t}_{\mathrm{R}}=13.1 \mathrm{~min},>99 \%$ purity (diastereomeric mixture; $5 \mu \mathrm{L}$ injection; $10-95 \% \mathrm{MeCN} / \mathrm{H}_{2} \mathrm{O}$, linear gradient, with constant $0.1 \% \mathrm{v} / \mathrm{v}$ TFA additive; $20 \mathrm{~min} \mathrm{run} ; 1 \mathrm{~mL} / \mathrm{min}$ flow; ESI; positive ion mode; UV detection at $254 \mathrm{~nm}$ ); HRMS (ESI) calcd for $\mathrm{C}_{38} \mathrm{H}_{35} \mathrm{~F}_{2} \mathrm{NO}_{13} \mathrm{Na}[\mathrm{M}+\mathrm{Na}]^{+} 774.1969$, found 774.1983 .

\section{SYNTHESIS OF PROBE 33}

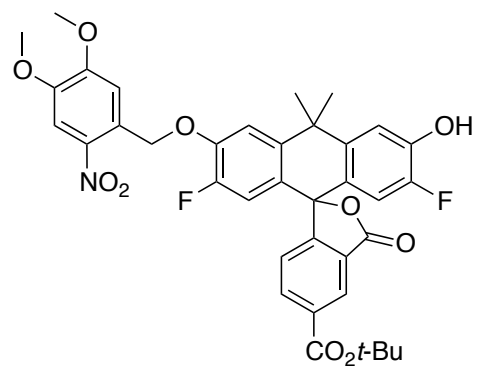

NV-VO(5-CO $\mathbf{C}_{2}$-Bu) (31): To a solution of 5-(tert-butoxycarbonyl)-Virginia Orange (16; $\left.260 \mathrm{mg}, 0.526 \mathrm{mmol}\right)$ and 4,5-dimethoxy-2-nitrobenzyl bromide (145 mg, $0.526 \mathrm{mmol}, 1 \mathrm{eq})$ in $\mathrm{MeCN}(10 \mathrm{~mL})$ was added $\mathrm{Ag}_{2} \mathrm{O}(122 \mathrm{mg}$, $0.526 \mathrm{mmol}, 1 \mathrm{eq}$ ), and the resulting mixture was stirred at $60{ }^{\circ} \mathrm{C}$ for $90 \mathrm{~min}$. After cooling the reaction to room temperature, $1 \mathrm{~N} \mathrm{HCl}(30 \mathrm{~mL})$ and EtOAc $(30 \mathrm{~mL})$ were added. The gray suspension was filtered through Celite; the filtrate was diluted with water and extracted with EtOAc $(2 \times)$. The combined organic extracts were washed with brine, dried over anhydrous $\mathrm{MgSO}_{4}$, filtered, and concentrated in vacuo. Silica gel chromatography was performed twice (0-25\% EtOAc/toluene, linear gradient; then, 5-50\% EtOAc/hexanes, linear gradient) to yield $85 \mathrm{mg}(23 \%)$ of 31 as a pale yellow solid. ${ }^{1} \mathrm{H} \mathrm{NMR}\left(\mathrm{CDCl}_{3}, 400 \mathrm{MHz}\right) \delta 8.64(\mathrm{dd}, J=1.5,0.7 \mathrm{~Hz}, 1 \mathrm{H}), 8.29(\mathrm{dd}, J=8.0,1.5 \mathrm{~Hz}$, $1 \mathrm{H}), 7.78(\mathrm{~s}, 1 \mathrm{H}), 7.45(\mathrm{~s}, 1 \mathrm{H}), 7.29\left(\mathrm{~d},{ }^{4} J_{\mathrm{HF}}=8.2 \mathrm{~Hz}, 1 \mathrm{H}\right), 7.27\left(\mathrm{~d},{ }^{4} J_{\mathrm{HF}}=8.2 \mathrm{~Hz}, 1 \mathrm{H}\right), 7.08(\mathrm{dd}, J=8.0,0.7 \mathrm{~Hz}$, $1 \mathrm{H}), 6.45\left(\mathrm{~d},{ }^{3} J_{\mathrm{HF}}=11.7 \mathrm{~Hz}, 1 \mathrm{H}\right), 6.41\left(\mathrm{~d},{ }^{3} J_{\mathrm{HF}}=11.1 \mathrm{~Hz}, 1 \mathrm{H}\right), 5.60(\mathrm{~s}, 2 \mathrm{H}), 5.31\left(\mathrm{~d},{ }^{4} J_{\mathrm{HF}}=3.6 \mathrm{~Hz}, 1 \mathrm{H}\right), 3.99(\mathrm{~s}$, 
3H), $3.98(\mathrm{~s}, 3 \mathrm{H}), 1.82(\mathrm{~s}, 3 \mathrm{H}), 1.71(\mathrm{~s}, 3 \mathrm{H}), 1.64(\mathrm{~s}, 9 \mathrm{H}) ;{ }^{19} \mathrm{~F} \mathrm{NMR}\left(\mathrm{CDCl}_{3}, 376 \mathrm{MHz}\right) \delta-135.52\left(\mathrm{dd}, J_{\mathrm{FH}}=11.6,8.1\right.$ $\mathrm{Hz}, 1 \mathrm{~F}),-141.97\left(\mathrm{ddd}, J_{\mathrm{FH}}=11.5,8.8,3.6 \mathrm{~Hz}, 1 \mathrm{~F}\right) ;{ }^{13} \mathrm{C} \mathrm{NMR}\left(\mathrm{CDCl}_{3}, 101 \mathrm{MHz}\right) \delta 169.4$ (C) 164.1 (C), 157.8 (C), $154.3(\mathrm{C}), 151.6\left(\mathrm{~d},{ }^{1} J_{\mathrm{CF}}=247.7 \mathrm{~Hz}, \mathrm{C}\right), 149.9\left(\mathrm{~d},{ }^{1} J_{\mathrm{CF}}=239.8 \mathrm{~Hz}, \mathrm{C}\right), 148.3(\mathrm{C}), 147.4\left(\mathrm{~d},{ }^{2} J_{\mathrm{CF}}=11.0 \mathrm{~Hz}, \mathrm{C}\right), 145.0$ $\left(\mathrm{d},{ }^{2} J_{\mathrm{CF}}=14.5 \mathrm{~Hz}, \mathrm{C}\right), 142.3\left(\mathrm{~d},{ }^{4} J_{\mathrm{CF}}=3.3 \mathrm{~Hz}, \mathrm{C}\right), 142.0\left(\mathrm{~d},{ }^{4} J_{\mathrm{CF}}=3.4 \mathrm{~Hz}, \mathrm{C}\right), 139.1(\mathrm{C}), 136.4(\mathrm{CH}), 134.4(\mathrm{C})$, $128.5(\mathrm{C}), 127.1(\mathrm{CH}), 126.3(\mathrm{C}), 124.55\left(\mathrm{~d},{ }^{3} J_{\mathrm{CF}}=5.5 \mathrm{~Hz}, \mathrm{C}\right), 123.7(\mathrm{CH}), 123.14\left(\mathrm{~d},{ }^{3} J_{\mathrm{CF}}=5.2 \mathrm{~Hz}, \mathrm{C}\right), 115.5(\mathrm{~d}$, $\left.{ }^{3} J_{\mathrm{CF}}=1.7 \mathrm{~Hz}, \mathrm{CH}\right), 114.9\left(\mathrm{~d},{ }^{2} J_{\mathrm{CF}}=19.3 \mathrm{~Hz}, \mathrm{CH}\right), 114.2\left(\mathrm{~d},{ }^{2} J_{\mathrm{CF}}=19.2 \mathrm{~Hz}, \mathrm{CH}\right), 113.7\left(\mathrm{~d},{ }^{3} J_{\mathrm{CF}}=0.8 \mathrm{~Hz}, \mathrm{CH}\right)$, 109.6 (CH), $108.1(\mathrm{CH}), 85.5(\mathrm{C}), 82.7(\mathrm{C}), 68.5\left(\mathrm{CH}_{2}\right), 56.63\left(\mathrm{CH}_{3}\right), 56.57\left(\mathrm{CH}_{3}\right), 38.2(\mathrm{C}), 35.2\left(\mathrm{CH}_{3}\right), 33.5\left(\mathrm{CH}_{3}\right)$, $28.3\left(\mathrm{CH}_{3}\right)$; HRMS (ESI) calcd for $\mathrm{C}_{37} \mathrm{H}_{34} \mathrm{~F}_{2} \mathrm{NO}_{10}[\mathrm{M}+\mathrm{H}]^{+}$690.2145, found 690.2153.

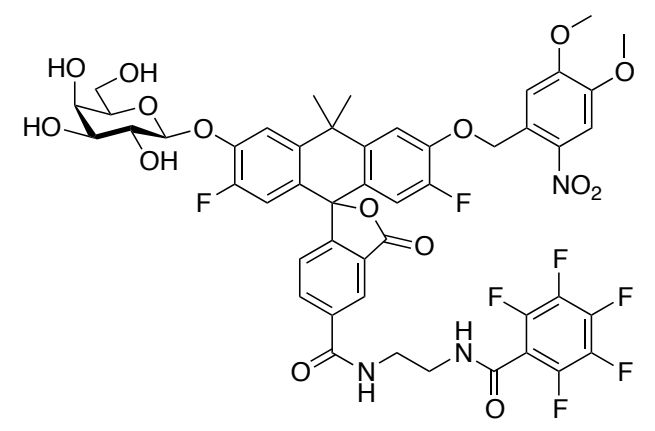

Gal-VO(5-PFB)-NV (33): Phenol 31 (68 mg, $98.6 \mu \mathrm{mol})$ and acetobromo- $\alpha$-D-galactose (17; $162 \mathrm{mg}, 0.394$ mmol, 4 eq) were combined in $\mathrm{MeCN}(5 \mathrm{~mL})$ under nitrogen, and $\mathrm{Ag}_{2} \mathrm{O}$ ( $\left.91 \mathrm{mg}, 0.394 \mathrm{mmol}, 4 \mathrm{eq}\right)$ was added. The resulting mixture was stirred at $50{ }^{\circ} \mathrm{C}$ for $90 \mathrm{~min}$. The reaction was then cooled to room temperature, filtered through Celite with $\mathrm{MeCN}$, and concentrated in vacuo. The crude residue was purified by flash chromatography on silica gel (5-40\% EtOAc/toluene, linear gradient) to afford $71 \mathrm{mg}(70 \%)$ of the galactoside tetraacetate as a white solid.

The tetracetate-t-butyl-ester $(60 \mathrm{mg}, 58.8 \mu \mathrm{mol})$ was taken up in $\mathrm{CH}_{2} \mathrm{Cl}_{2}(2.5 \mathrm{~mL})$, and trifluoroacetic acid $(0.5$ $\mathrm{mL})$ was added. The reaction was stirred at room temperature for $5 \mathrm{~h}$. Toluene $(3 \mathrm{~mL})$ was added; the reaction mixture was concentrated to dryness and then azeotroped with $\mathrm{MeOH}$ three times to provide the deprotected carboxylic acid as an off-white solid (54 mg, 95\%).

The tetraacetate-acid $(54 \mathrm{mg}, 56.0 \mu \mathrm{mol})$ was combined with HATU (43 mg, $0.112 \mathrm{mmol}, 2 \mathrm{eq}$ ) in DMF (3 $\mathrm{mL})$. After adding DIEA $(29 \mu \mathrm{L}, 0.168 \mathrm{mmol}, 3 \mathrm{eq})$, the reaction was stirred at room temperature for $15 \mathrm{~min}$. A solution of $\mathrm{N}$-(2-aminoethyl)-2,3,4,5,6-pentafluorobenzamide trifluoroacetate ${ }^{3}$ (32; $\left.41 \mathrm{mg}, 0.112 \mathrm{mmol}, 2 \mathrm{eq}\right)$ in DMF $(300 \mu \mathrm{L})$ was then added, and the reaction was stirred for an additional $2 \mathrm{~h}$ at room temperature. It was subsequently diluted with water and extracted with EtOAc $(2 x)$. The combined organic layers were washed with brine, dried over anhydrous $\mathrm{MgSO}_{4}$, filtered, and concentrated in vacuo. Flash chromatography on silica gel (5$100 \% \mathrm{EtOAc} / \mathrm{CH}_{2} \mathrm{Cl}_{2}$, linear gradient) afforded $54 \mathrm{mg}(80 \%)$ of the amide as an off-white solid.

The tetraacetate-amide $(54 \mathrm{mg}, 45.1 \mu \mathrm{mol})$ was subsequently dissolved in 1:1 $\mathrm{MeOH} / \mathrm{MeCN}(2 \mathrm{~mL})$, and $1 \mathrm{M}$ $\mathrm{Na}_{2} \mathrm{CO}_{3}$ (aq, $451 \mu \mathrm{L}, 0.451 \mathrm{mmol}, 10 \mathrm{eq}$ ) was added. The reaction was stirred at room temperature for $2 \mathrm{~h}$. It was then neutralized with $1 \mathrm{~N} \mathrm{HCl}(910 \mu \mathrm{L})$ and directly purified by reverse phase HPLC (30-95\% $\mathrm{MeCN} / \mathrm{H}_{2} \mathrm{O}$, linear gradient) to yield $35 \mathrm{mg}\left(75 \%\right.$, diastereomeric mixture) of $\mathbf{3 3}$ as a white solid. ${ }^{1} \mathrm{H} \mathrm{NMR}\left(\mathrm{CD}_{3} \mathrm{OD}, 400 \mathrm{MHz}\right) \delta 8.47$ 
$(\mathrm{dd}, J=1.6,0.7 \mathrm{~Hz}, 1 \mathrm{H}), 8.17(\mathrm{dt}, J=8.1,1.4 \mathrm{~Hz}, 1 \mathrm{H}), 7.78(\mathrm{~s}, 1 \mathrm{H}), 7.66\left(\mathrm{~d},{ }^{4} J_{\mathrm{HF}}=8.1 \mathrm{~Hz}, 0.5 \mathrm{H}\right), 7.65\left(\mathrm{~d},{ }^{4} J_{\mathrm{HF}}=\right.$ $8.2 \mathrm{~Hz}, 0.5 \mathrm{H}), 7.44\left(\mathrm{~d},{ }^{4} J_{\mathrm{HF}}=8.1 \mathrm{~Hz}, 1 \mathrm{H}\right), 7.38(\mathrm{~s}, 1 \mathrm{H}), 7.152(\mathrm{dd}, J=8.1,0.7 \mathrm{~Hz}, 0.5 \mathrm{H}), 7.146(\mathrm{dd}, J=8.1,0.7 \mathrm{~Hz}$, $0.5 \mathrm{H}), 6.47\left(\mathrm{~d},{ }^{3} J_{\mathrm{HF}}=11.8 \mathrm{~Hz}, 0.5 \mathrm{H}\right), 6.46\left(\mathrm{~d},{ }^{3} J_{\mathrm{HF}}=11.8 \mathrm{~Hz}, 0.5 \mathrm{H}\right), 6.43\left(\mathrm{~d},{ }^{3} J_{\mathrm{HF}}=11.7 \mathrm{~Hz}, 0.5 \mathrm{H}\right), 6.42\left(\mathrm{~d},{ }^{3} J_{\mathrm{HF}}=\right.$ $11.7 \mathrm{~Hz}, 0.5 \mathrm{H}), 5.61(\mathrm{~s}, 2 \mathrm{H}), 5.03(\mathrm{~d}, J=7.7 \mathrm{~Hz}, 0.5 \mathrm{H}), 5.00(\mathrm{~d}, J=7.7 \mathrm{~Hz}, 0.5 \mathrm{H}), 3.94-3.74(\mathrm{~m}, 5 \mathrm{H}), 3.93(\mathrm{~s}$, $3 \mathrm{H}), 3.91(\mathrm{~s}, 3 \mathrm{H}), 3.71-3.59(\mathrm{~m}, 5 \mathrm{H}), 1.85(\mathrm{~s}, 3 \mathrm{H}), 1.75(\mathrm{~s}, 3 \mathrm{H}) ;{ }^{19} \mathrm{~F}$ NMR $\left(\mathrm{CD}_{3} \mathrm{OD}, 376 \mathrm{MHz}\right) \delta-134.26--134.37$ (m, 1F), -135.39- -135.49 (m, 1F), -141.83 - -141.97 (m, 2F), -153.53 (tt, $J=19.7,2.2 \mathrm{~Hz}, 1 \mathrm{~F}),-162.01--162.19$ $(\mathrm{m}, 2 \mathrm{~F})$; Analytical HPLC: $\mathrm{t}_{\mathrm{R}}=10.3 \mathrm{~min},>99 \%$ purity (diastereomeric mixture; $5 \mu \mathrm{L}$ injection; $30-95 \%$ $\mathrm{MeCN} / \mathrm{H}_{2} \mathrm{O}$, linear gradient, with constant $0.1 \% \mathrm{v} / \mathrm{v}$ TFA additive; $20 \mathrm{~min}$ run; $1 \mathrm{~mL} / \mathrm{min}$ flow; ESI; positive ion mode; $\mathrm{UV}$ detection at $254 \mathrm{~nm}$ ); HRMS (ESI) calcd for $\mathrm{C}_{48} \mathrm{H}_{41} \mathrm{~F}_{7} \mathrm{~N}_{3} \mathrm{O}_{15}[\mathrm{M}+\mathrm{H}]^{+} 1032.2420$, found 1032.2422. 


\section{OPTICAL SPECTROSCOPY AND MICROSCOPY METHODS}

General. Fluorescent and fluorogenic molecules were prepared as stock solutions in DMSO and diluted such that the final DMSO concentration did not exceed 1\% v/v. Enzymes were obtained from Sigma-Aldrich ( $\beta$-galactosidase from Escherichia coli, G4155; nitroreductase from Escherichia coli, N9284) and ThermoFisher (TEM-1 $\beta$ lactamase, PV3575).

UV-Vis and Fluorescence Spectroscopy. Spectroscopy was performed using 1-cm path length, 3.5-mL quartz cuvettes from Starna Cells. All measurements were taken at ambient temperature $\left(22 \pm 2{ }^{\circ} \mathrm{C}\right)$, and spectra are uncorrected. Absorption spectra were recorded on a Cary Model 100 spectrometer (Varian), and fluorescence spectra were recorded on a Cary Eclipse fluorometer (Varian; slit widths at $5 \mathrm{~nm}$ ). The spectra, maximum absorption wavelength $\left(\lambda_{\max }\right)$, and extinction coefficient $(\varepsilon)$ of 4 were taken in $0.1 \mathrm{M} \mathrm{NaOH}$; the reported value for $\varepsilon$ is an average $(n=3)$.

Quantum Yield Determination. Absolute quantum yields $(\Phi)$ were measured using a Quantaurus-QY spectrometer (model C11374) from Hamamatsu. This instrument uses an integrating sphere to determine photons absorbed and emitted by a sample. Measurements were carried out using dilute samples $(\mathrm{A}<0.1)$ and self-absorption corrections were performed using the instrument software. ${ }^{4}$

$\mathbf{p} K_{\mathrm{a}}$ Determination (Figure 2d). The $\mathrm{p} K_{\mathrm{a}}$ values for compounds $\mathbf{1}, \mathbf{2}$ and $\mathbf{4}$ were determined in buffers containing $150 \mathrm{mM} \mathrm{NaCl}$ and $10 \mathrm{mM}$ buffer. The following buffer systems were used: citrate (pH 4.0-6.2); phosphate (pH 5.88.0); tris ( $\mathrm{pH} 7.8-9.0$ ); carbonate ( $\mathrm{pH} 9.2-10.0$ ). Buffer solutions containing $250 \mathrm{nM}$ fluorophore were placed in a black, clear-bottom 96-well microplate with a non-binding surface coating (Corning, product \#3651). Fluorescence values were read on FlexStation 3 platereader (Molecular Devices) using $\lambda_{\mathrm{ex}} / \lambda_{\mathrm{em}}=490 \mathrm{~nm} / 520 \mathrm{~nm}$ or $550 \mathrm{~nm} / 580$ $\mathrm{nm}(\mathrm{n}=3)$ and plotted using GraphPad Prism software. The points were fitted to a sigmoidal dose response curve with a variable slope to determine the Hill coefficient $(h)$. We observed $h$ values of $0.97,1.65$, and 1.46 for compounds $\mathbf{1}, \mathbf{2}$ and $\mathbf{4}$, respectively. ${ }^{5}$

Enzyme Kinetics (Figure S2). The initial velocity of fluorescence release of mono- and bis-masked VO substrates (eight two-fold dilutions, $10 \mu \mathrm{M}$ to $0.078 \mu \mathrm{M}$ ) was measured in triplicate on a FlexStation 3 platereader (Molecular Devices) in $10 \mathrm{mM}$ HEPES pH 7.3, 0.1\% DMSO (plus $100 \mu \mathrm{M}$ NADH for nitroreductase reactions). Data were fit using GraphPad Prism software to the Michaelis-Menten equation for nitroreductase ( $8.3 \mathrm{nM}$ enzyme), or the Michaelis-Menten equation at low substrate concentration $\left(v_{0}=V_{\max }[\mathrm{S}] / K_{\mathrm{M}}\right)$ for $\beta$-galactosidase $(17 \mathrm{nM})$ and TEM$1 \beta$-lactamase $(19 \mathrm{nM})$.

Activation of Fluorogenic Virginia Orange Derivatives. All measurements of fluorescence accumulation upon activation of the fluorogenic probes were determined in quartz cuvettes (1-cm path length, $3.5-\mathrm{mL})$ with $3.0 \mathrm{~mL} 10$ 
$\mathrm{mM}$ HEPES $\mathrm{pH}$ 7.3, 0.1\% DMSO (and $100 \mu \mathrm{M}$ NADH for nitroreductase reactions). The same settings were used for all measurements of fluorescence $\left(\lambda_{\mathrm{ex}}=555 \mathrm{~nm}, \lambda_{\mathrm{em}}=582 \mathrm{~nm}, 5 \mathrm{~nm}\right.$ slit widths, PMT voltage $\left.500 \mathrm{~V}\right)$. The final concentration for each enzyme was kept the same across all assays unless noted otherwise: $17 \mathrm{nM}(\sim 1.5 \mathrm{U} / \mathrm{mL})$ for $\beta$-galactosidase; $113 \mathrm{nM}(\sim 1.5 \mathrm{U} / \mathrm{mL})$ for nitroreductase; and $57 \mathrm{nM}$ for TEM-1 $\beta$-lactamase $(\sim 1.8 \mathrm{U} / \mathrm{mL})$.

(a) To demonstrate the relative rates of unmasking for the mono- and bis-masked single-enzyme substrates (Figure $3 b-d)$, cuvettes were first charged with buffer $(t=0)$. Fluorescence was recorded for $10 \mathrm{~min}$, with the addition of probe $(1 \mu \mathrm{M})$ at $\mathrm{t}=0.5 \mathrm{~min}$ and enzyme at $\mathrm{t}=2 \mathrm{~min}$.

(b) The contrast ratios (fluorescence increase, $\mathrm{F}_{\text {post }} / \mathrm{F}_{\text {pre }}$ ) for probes 20-25 were determined by first measuring the fluorescence of $1 \mu \mathrm{M}$ probe prior to addition of enzyme $\left(F_{\text {pre }}, t=0 \mathrm{~h}, \mathrm{n}=3\right)$. Enzyme was then added, and the samples were aged until no further increase in fluorescence was seen $(4 \mathrm{~h})$. Fluorescence was recorded at $2 \mathrm{~h}$ and $4 \mathrm{~h}\left(\mathrm{~F}_{\text {post }}, \mathrm{t}=4 \mathrm{~h}, \mathrm{n}=3\right)$ to calculate the contrast values (Figure $\left.\mathrm{S} 1\right)$.

(c) The sequential unmasking of $\mathbf{2 6}$ (Figure $4 \mathrm{~b}, \mathrm{c}$ ) was accomplished by first charging a cuvette with buffer $(\mathrm{t}=0)$. Fluorescence was recorded for $10 \mathrm{~min}$, with the addition of probe $(1 \mu \mathrm{M})$ at $\mathrm{t}=0.5 \mathrm{~min}$, the first enzyme at $\mathrm{t}=2$ min, and the second enzyme at $\mathrm{t}=4 \mathrm{~min}$.

(d) The contrast ratios of the dual-input bis-masked probes (26-28, 30; Figure 5) were determined by measuring the accumulated fluorescence after aging/activating each probe $(1 \mu \mathrm{M})$ with no input ("blank"), each input alone, or both inputs ( $\mathrm{n}=3$ for each condition). For 26 ( $\beta$-gal/NTR) and 27 (Blac/NTR), the samples were incubated for $20 \mathrm{~min}$; in the case of the two-input samples, both enzymes were added at $\mathrm{t}=0 \mathrm{~min}$. The $\beta$-gal $/ \mathrm{h} v \mathrm{compound} 30$ was aged with $\beta$-galactosidase alone, irradiated in the absence of enzyme (Luzchem LZC 4V photoreactor, 365 $\mathrm{nm}$ lamps), or irradiated in the presence of $\beta$-galactosidase (20 min for all conditions). For 28 (NTR/Pd), the single-input samples were incubated with nitroreductase or $[\mathrm{PdCl}(\text { allyl })]_{2}(10 \mu \mathrm{M})$ for $3 \mathrm{~h}$. The two-input condition was performed by aging the probe with nitroreductase for $20 \mathrm{~min}$, then adding $\left[\mathrm{PdCl}(\operatorname{allyl})_{2}\right]$ and recording the fluorescence after $3 \mathrm{~h}$ total.

Cell Staining and Imaging. COS-7 cells were grown in DMEM with 10\% FBS and Glutamax (Gibco) at 37 ${ }^{\circ} \mathrm{C} / 10 \% \mathrm{CO}_{2}$. Cells seeded in $35 \mathrm{~mm}$ glass bottom dishes (MatTek) were transiently transfected with a $\beta$ galactosidase expression vector (pCMVSport- $\beta$ gal) using Lipofectamine 2000 (Thermo Fisher Scientific) at an efficiency of $65 \%$. After 24 hours of recovery, 33 was added at a final concentration of $20 \mu \mathrm{M}$ in the presence of $0.2 \%$ Pluronic F-127. The dye was allowed to load for 24 hours prior to imaging. Cells were imaged with a Zeiss LSM 710 with a $20 \times / 0.8$ NA Plan-Apochromat objective. The sample was excited with a $561 \mathrm{~nm}$ source at $10 \%$ power, and 566-685 nm BP filter emission from a single plane of $3.5 \mu \mathrm{m}$. Activation of the dye was done with a $405 \mathrm{~nm}$ diode at $100 \%$ power with a single scan at $1024 \times 1024 \mathrm{p}$. Fluorescence image analysis was done using the Fiji package. ${ }^{6}$ 

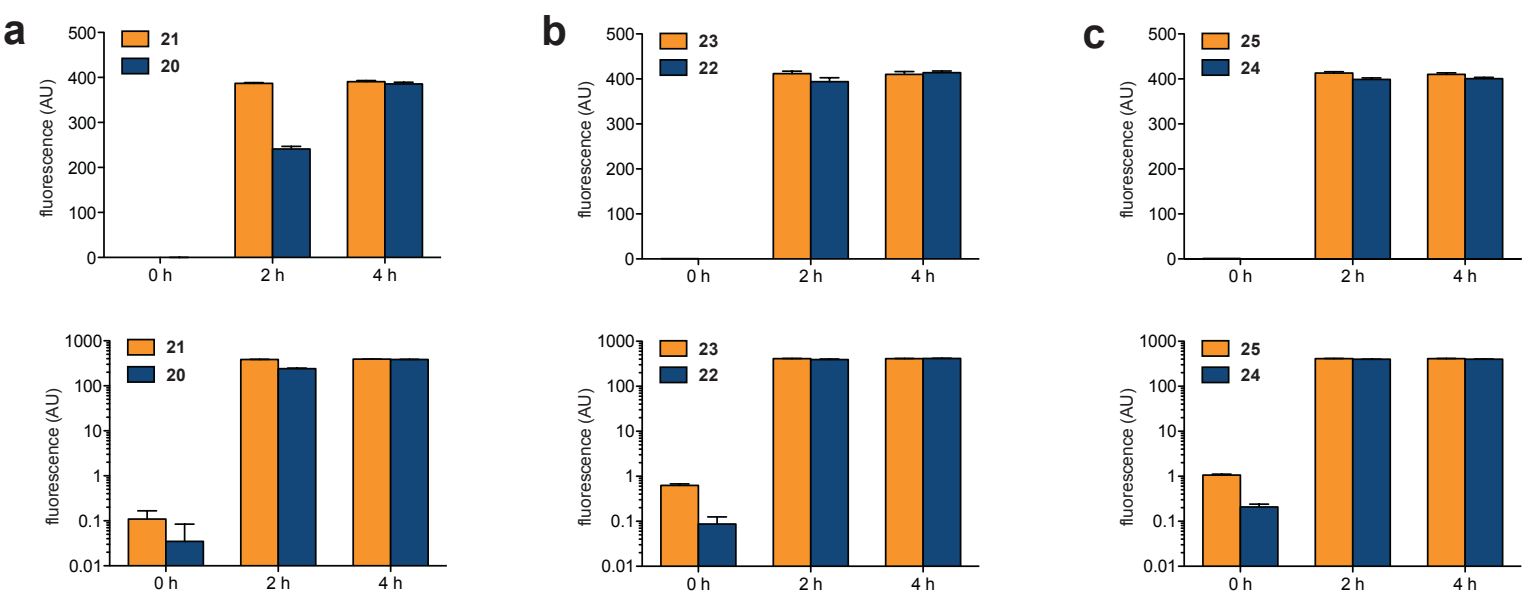

Figure S1. Determination of contrast for Virginia Orange probes by comparison of fluorescence intensity pre-activation ( $0 \mathrm{~h})$ to fluorescence $2 \mathrm{~h}$ and $4 \mathrm{~h}$ post-activation (addition of enzyme); linear plots (top panels) and logarithmic plots (bottom panels) shown (mean $\pm \mathrm{SD}, \mathrm{n}=3$ ). (a) Pre- and post-activation fluorescence of $20\left(\mathrm{Gal}_{2}-\mathrm{VO}\right)$ and 21 (Gal-VO) when unmasked with $\beta$ galactosidase. (b) Pre- and post-activation fluorescence of $22\left(\mathrm{NM}_{2}-\mathrm{VO}\right)$ and $\mathbf{2 3}$ (NM-VO) when unmasked with nitroreductase. (c) Pre- and post-activation fluorescence of $\mathbf{2 4}\left(\mathrm{Ceph}_{2}-\mathrm{VO}\right)$ and $\mathbf{2 5}$ (Ceph-VO) when unmasked with TEM-1 $\beta$-lactamase.
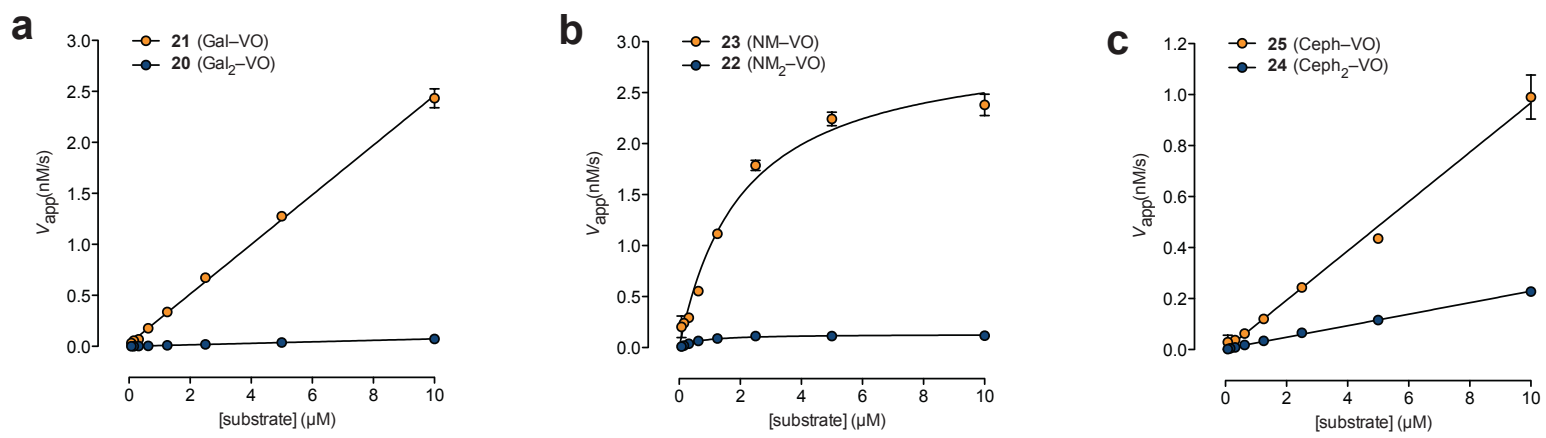

Figure S2. Apparent rate of fluorescence release versus substrate concentration for Virginia Orange enzyme substrates (mean \pm $\mathrm{SD}, \mathrm{n}=3$ ). (a) Rate plot for $\beta$-galactosidase substrates 20 ( $\mathrm{Gal}_{2}-\mathrm{VO}$ ) and $\mathbf{2 1}$ (Gal-VO); saturation was not achieved (high $K_{\mathrm{M}}$ ), so the Michaelis-Menten equation at low substrate concentration (linear regression) was used to determine $V_{\max } / K_{\mathrm{M}}$ from the slope. (b) Rate plot for nitroreductase substrates $22\left(\mathrm{NM}_{2}-\mathrm{VO}\right)$ and 23 (NM-VO); fit with Michaelis-Menten equation. (c) Rate plot for TEM-1 $\beta$-lactamase substrates $24\left(\mathrm{Ceph}_{2}-\mathrm{VO}\right)$ and 25 (Ceph-VO); saturation was not achieved (high $K_{\mathrm{M}}$ ), so the Michaelis-Menten equation at low substrate concentration (linear regression) was used to determine $V_{\max } / K_{\mathrm{M}}$ from the slope. 


\section{REFERENCES}

(1) Fulmer, G. R., Miller, A. J. M., Sherden, N. H., Gottlieb, H. E., Nudelman, A., Stoltz, B. M., Bercaw, J. E., and Goldberg, K. I. (2010) NMR chemical shifts of trace impurities: common laboratory solvents, organics, and gases in deuterated solvents relevant to the organometallic chemist. Organometallics 29, 2176-2179.

(2) Grimm, J. B., Sung, A. J., Legant, W. R., Hulamm, P., Matlosz, S. M., Betzig, E., and Lavis, L. D. (2013) Carbofluoresceins and carborhodamines as scaffolds for high-contrast fluorogenic probes. ACS Chem. Biol. 8, 1303-1310.

(3) Diwu, Z., and Haugland, R. P. Assay for glutathiane transferase using polyhaloaryl-substituted reporter molecules. U.S. Patent 5,773,236, June 30, 1998.

(4) Suzuki, K., Kobayashi, A., Kaneko, S., Takehira, K., Yoshihara, T., Ishida, H., Shiina, Y., Oishi, S., and Tobita, S. (2009) Reevaluation of absolute luminescence quantum yields of standard solutions using a spectrometer with an integrating sphere and a back-thinned CCD detector. Phys. Chem. Chem. Phys. 11, 9850-9860.

(5) Lavis, L. D., Rutkoski, T. J., and Raines, R. T. (2007) Tuning the $\mathrm{p} K_{\mathrm{a}}$ of fluorescein to optimize binding assays. Anal. Chem. 79, 6775-6782.

(6) Schindelin, J., Arganda-Carreras, I., Frise, E., Kaynig, V., Longair, M., Pietzsch, T., Preibisch, S., Rueden, C., Saalfeld, S., Schmid, B., et al. (2012) Fiji: an open-source platform for biological-image analysis. Nat. Methods 9, 676-682. 


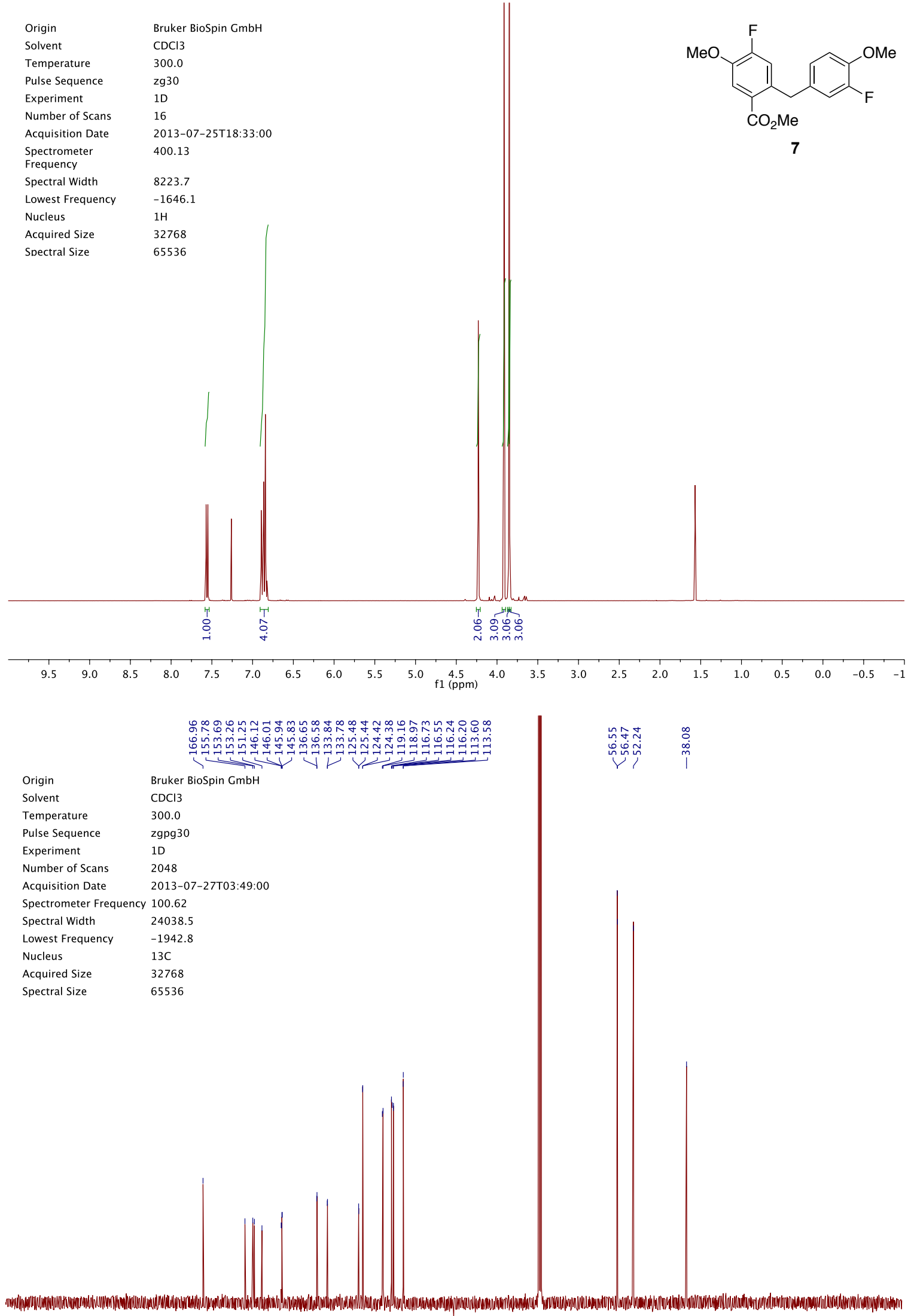

$\begin{array}{lllllllllllllllllllllllll}210 & 200 & 190 & 180 & 170 & 160 & 150 & 140 & 130 & 120 & 110 & \begin{array}{l}100 \\ \mathrm{fpm})\end{array} & 90 & 80 & 70 & 60 & 50 & 40 & 30 & 20 & 10 & 0 & -10\end{array}$ 


$\begin{array}{ll}\text { Origin } & \text { Bruker BioSpin } \mathrm{CmbH} \\ \text { Solvent } & \mathrm{CDCl} 3 \\ \text { Temperature } & 300.0 \\ \text { Pulse Sequence } & \mathrm{zg} 30 \\ \text { Experiment } & 1 \mathrm{D} \\ \text { Number of Scans } & 16 \\ \text { Acquisition Date } & 2013-08-14 \mathrm{~T} 03: 37: 00 \\ \text { Spectrometer Frequency } & 400.13 \\ \text { Spectral Width } & 8223.7 \\ \text { Lowest Frequency } & -1645.1 \\ \text { Nucleus } & 1 \mathrm{H} \\ \text { Acquired Size } & 32768 \\ \text { Spectral Size } & 65536\end{array}$
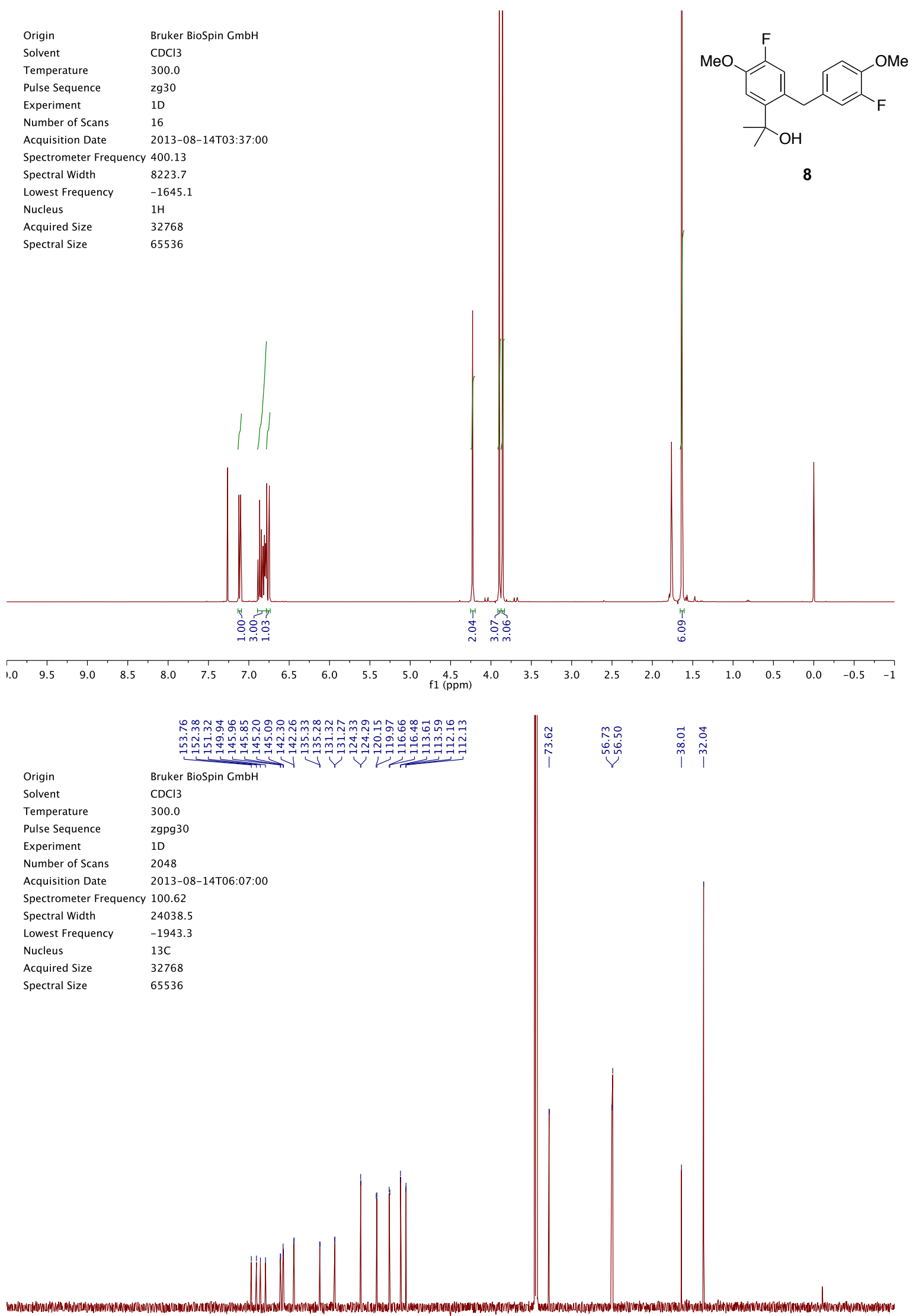

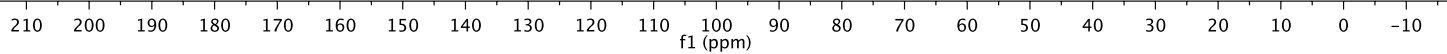




\begin{tabular}{|c|c|}
\hline Origin & Bruker BioSpin GmbH \\
\hline Solvent & DMSO \\
\hline Temperature & 300.0 \\
\hline Pulse Sequence & $\mathrm{zg} 30$ \\
\hline Experiment & $1 \mathrm{D}$ \\
\hline Number of Scans & 16 \\
\hline Acquisition Date & 2013-10-16Т09:49:00 \\
\hline \multicolumn{2}{|c|}{ Spectrometer Frequency 400.13} \\
\hline Spectral Width & 8223.7 \\
\hline Lowest Frequency & -1638.4 \\
\hline Nucleus & $1 \mathrm{H}$ \\
\hline Acquired Size & 32768 \\
\hline Spectral Size & 65536 \\
\hline
\end{tabular}

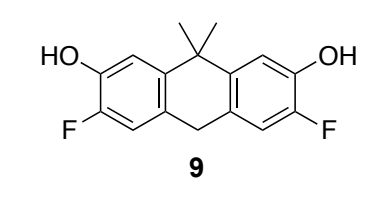

rang

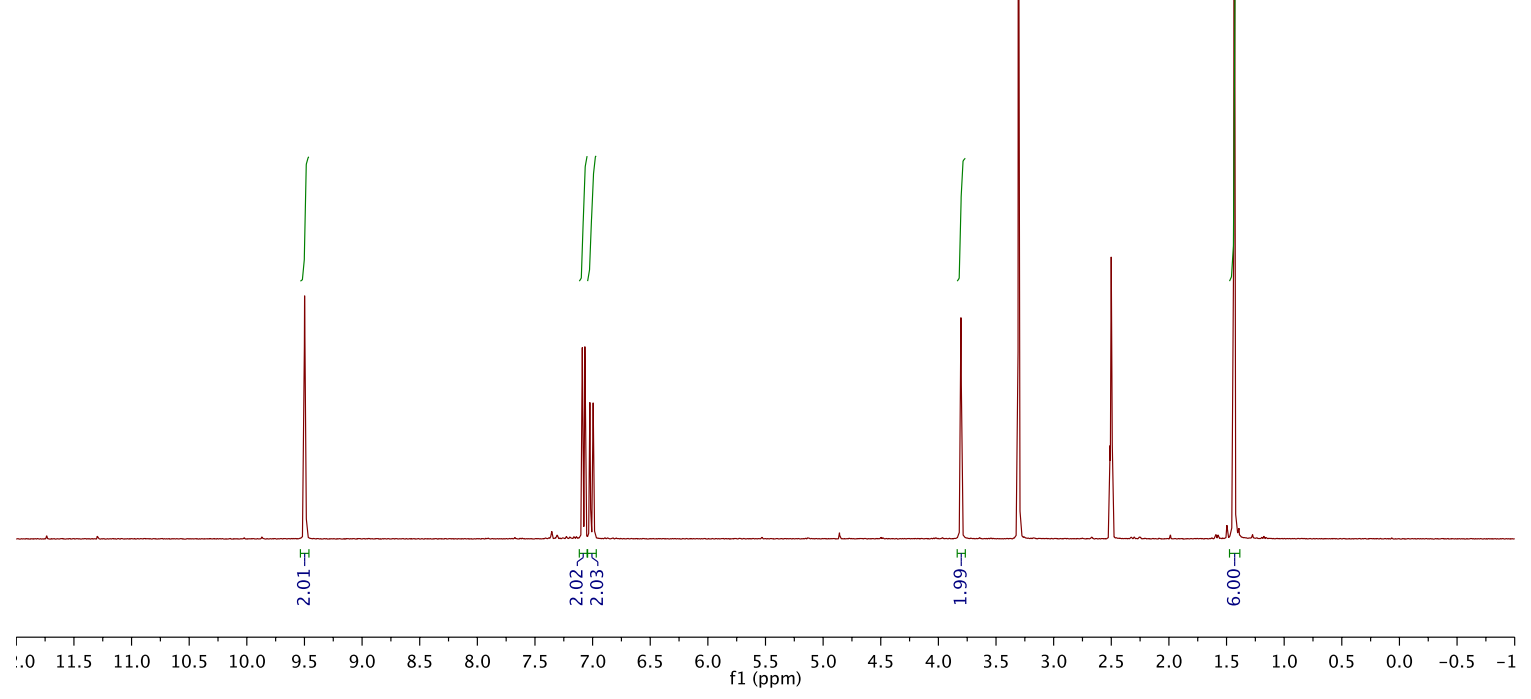

$\begin{array}{ll}\text { Origin } & \text { Bruker BioSpin } \mathrm{GmbH} \\ \text { Solvent } & \text { DMSO } \\ \text { Temperature } & 300.0 \\ \text { Pulse Sequence } & \text { zgpg30 } \\ \text { Experiment } & 1 \mathrm{D} \\ \text { Number of Scans } & 1024 \\ \text { Acquisition Date } & 2013-10-16 \mathrm{~T} 11: 54: 00 \\ \text { Spectrometer Frequency } & 100.62 \\ \text { Spectral Width } & 24038.5 \\ \text { Lowest Frequency } & -2004.2 \\ \text { Nucleus } & 13 \mathrm{C} \\ \text { Acquired Size } & 32768 \\ \text { Spectral Size } & 65536\end{array}$

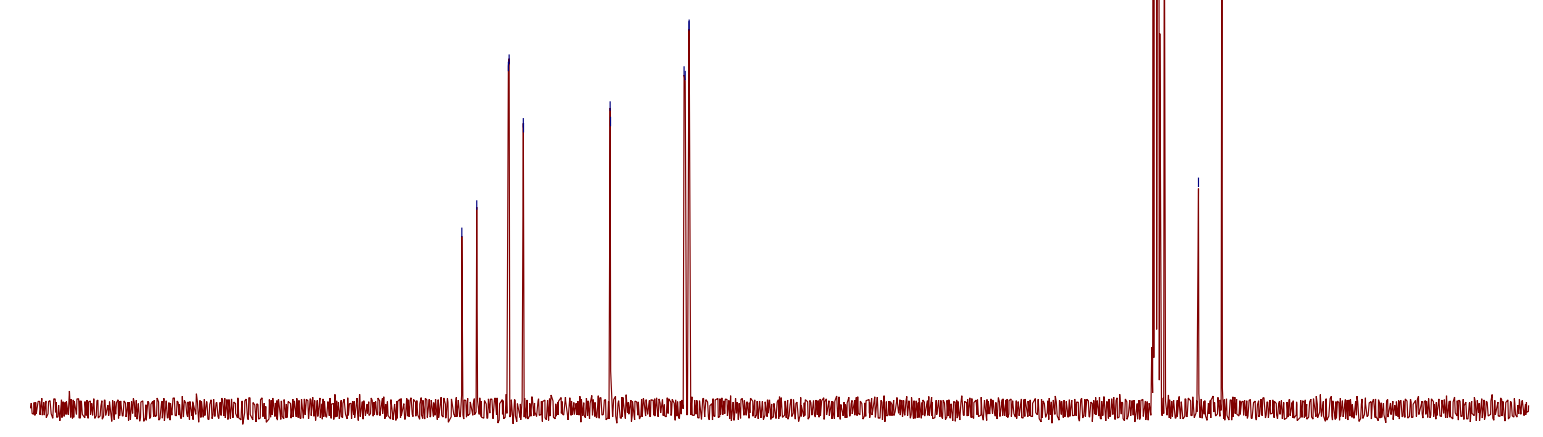

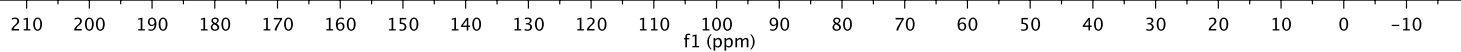




\begin{tabular}{|c|c|}
\hline Origin & Bruker BioSpin GmbH \\
\hline Solvent & DMSO \\
\hline Temperature & 300.0 \\
\hline Pulse Sequence & $\mathrm{zg} 30$ \\
\hline Experiment & 1D \\
\hline Number of Scans & 16 \\
\hline Acquisition Date & 2013-10-16T09:58:00 \\
\hline \multicolumn{2}{|c|}{ Spectrometer Frequency 400.13} \\
\hline Spectral Width & 8223.7 \\
\hline Lowest Frequency & -1638.5 \\
\hline Nucleus & $1 \mathrm{H}$ \\
\hline Acquired Size & 32768 \\
\hline Spectral Size & 65536 \\
\hline
\end{tabular}
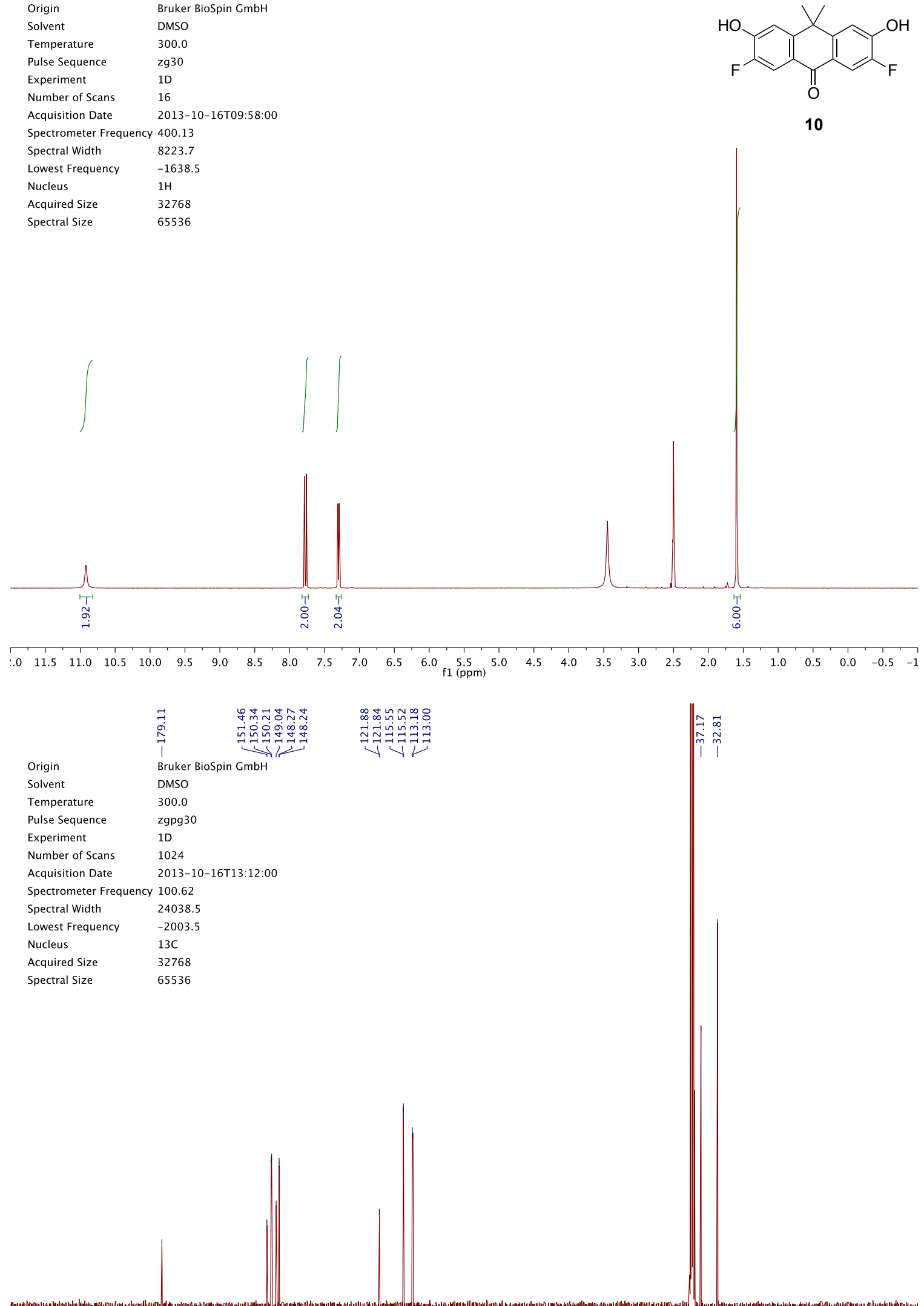

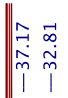

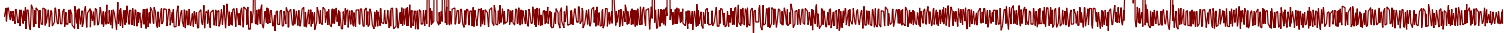

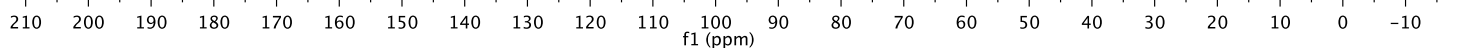



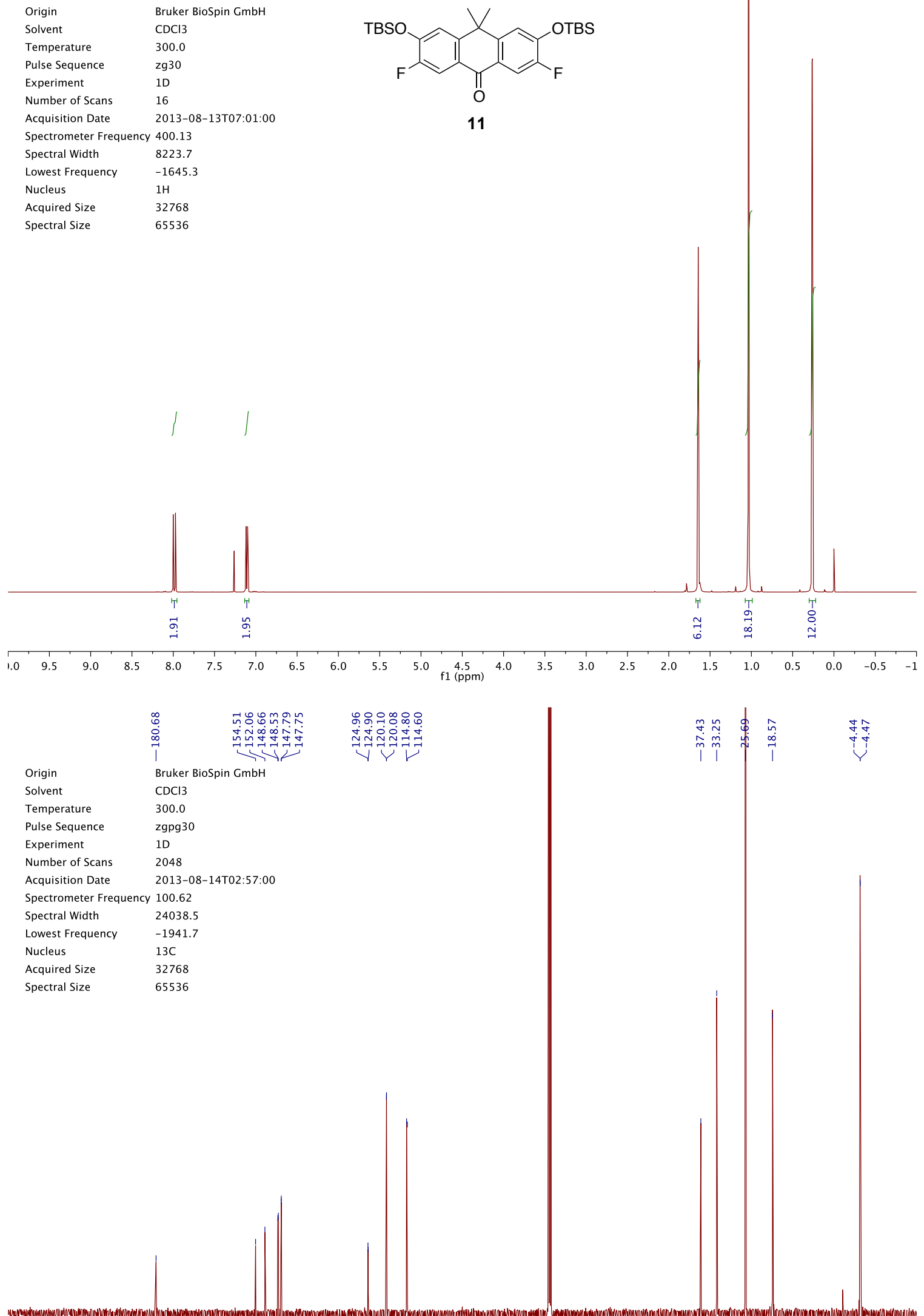

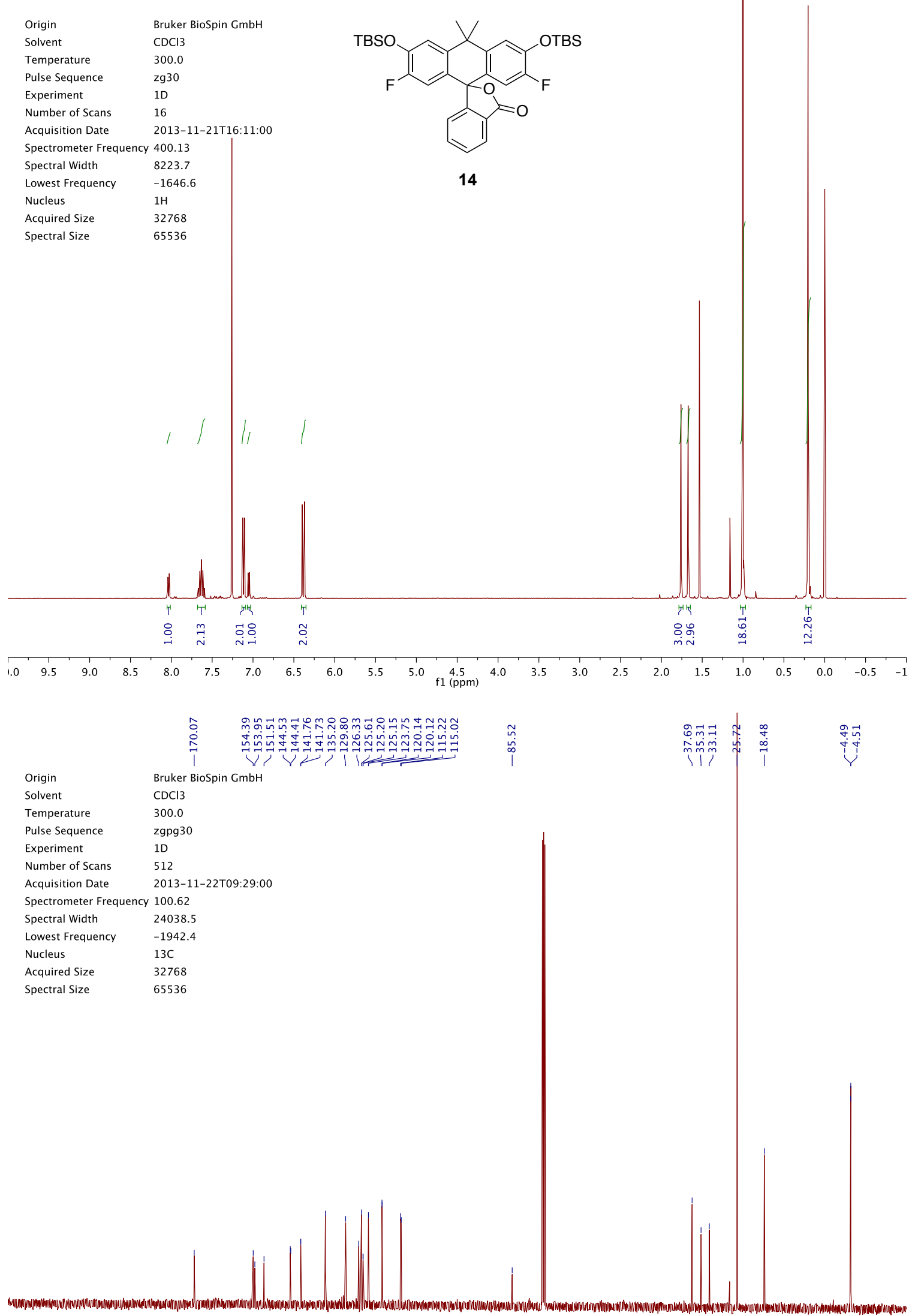

$\begin{array}{llllllllllllllllllllllll}210 & 200 & 190 & 180 & 170 & 160 & 150 & 140 & 130 & 120 & 110 & \begin{array}{c}100 \\ \mathrm{f} 1(\mathrm{ppm})\end{array} & 90 & 80 & 70 & 60 & 50 & 40 & 30 & 20 & 10 & 0 & -10\end{array}$ 


$\begin{array}{ll}\text { Origin } & \text { Bruker BioSpin } \mathrm{GmbH} \\ \text { Solvent } & \mathrm{CDCl} 3 \\ \text { Temperature } & 300.0 \\ \text { Pulse Sequence } & \mathrm{zg} 30 \\ \text { Experiment } & 1 \mathrm{D} \\ \text { Number of Scans } & 16 \\ \text { Acquisition Date } & 2013-12-16 \mathrm{~T} 21: 05: 00 \\ \text { Spectrometer Frequency } & 400.13 \\ \text { Spectral Width } & 8223.7 \\ \text { Lowest Frequency } & -1645.3 \\ \text { Nucleus } & 1 \mathrm{H} \\ \text { Acquired Size } & 32768 \\ \text { Spectral Size } & 65536\end{array}$
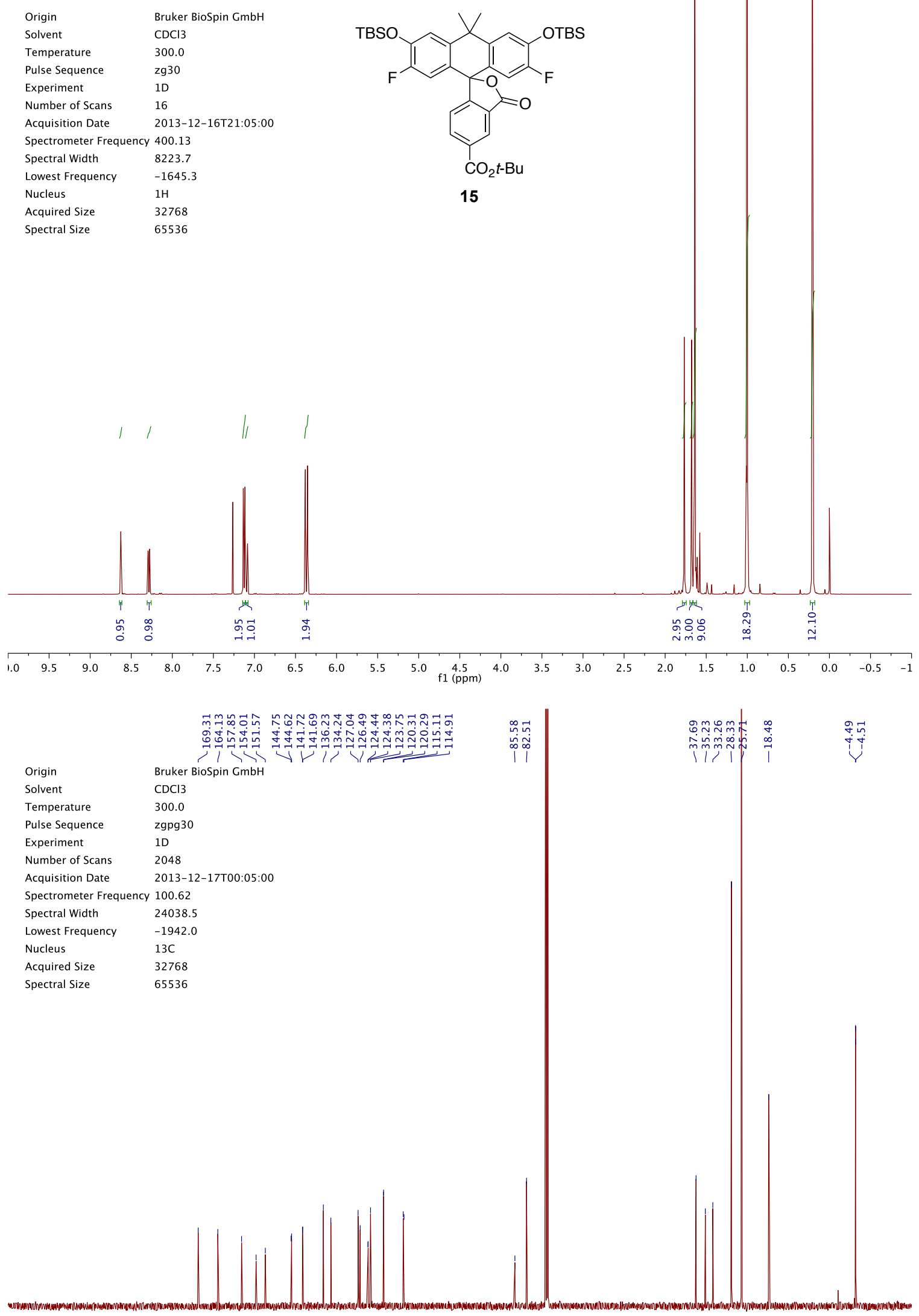

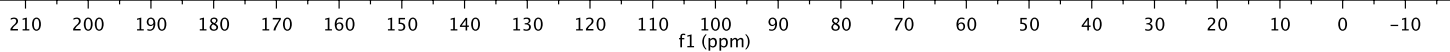




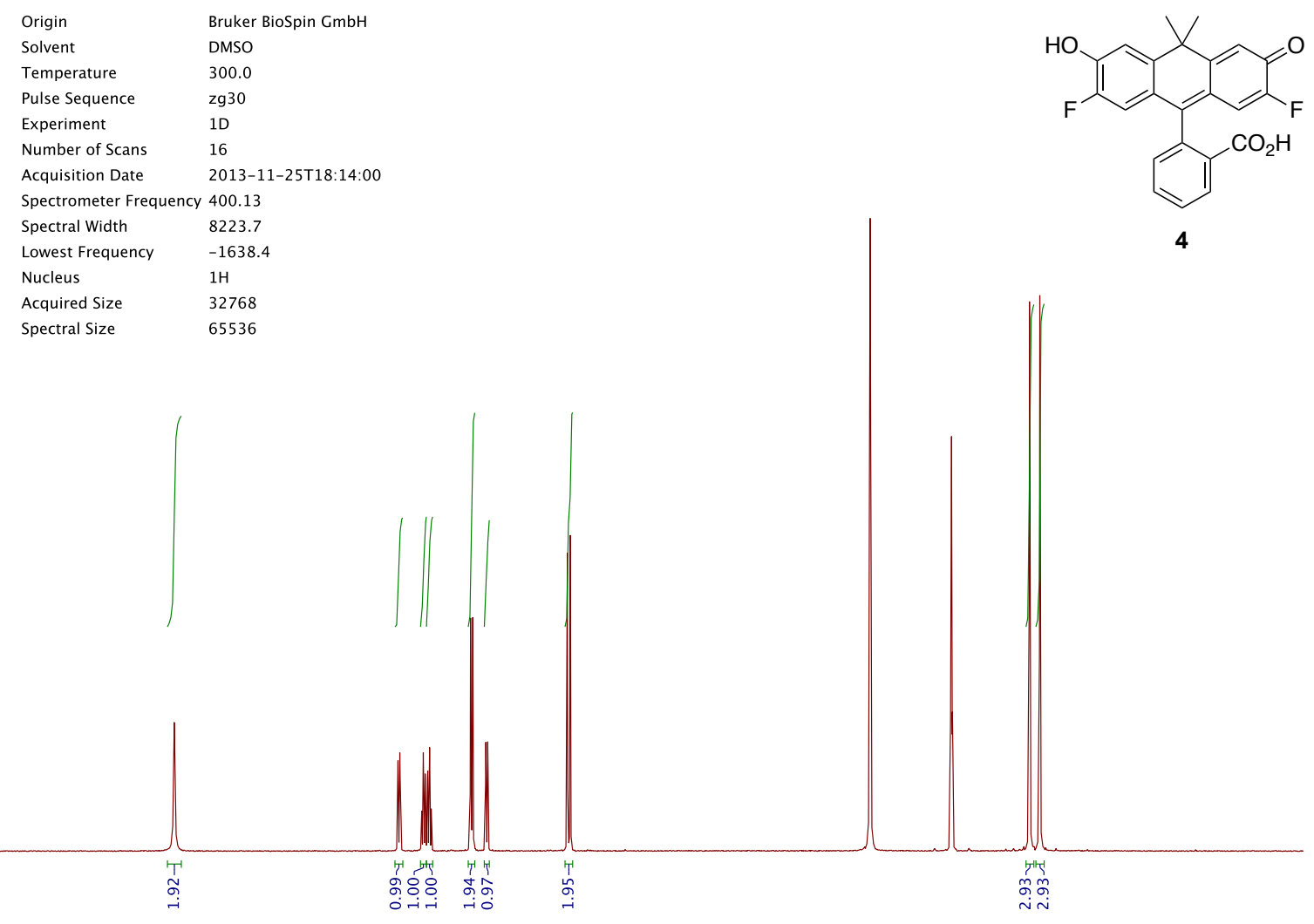

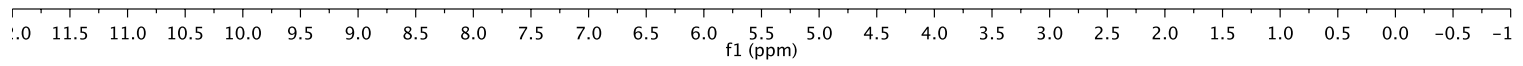
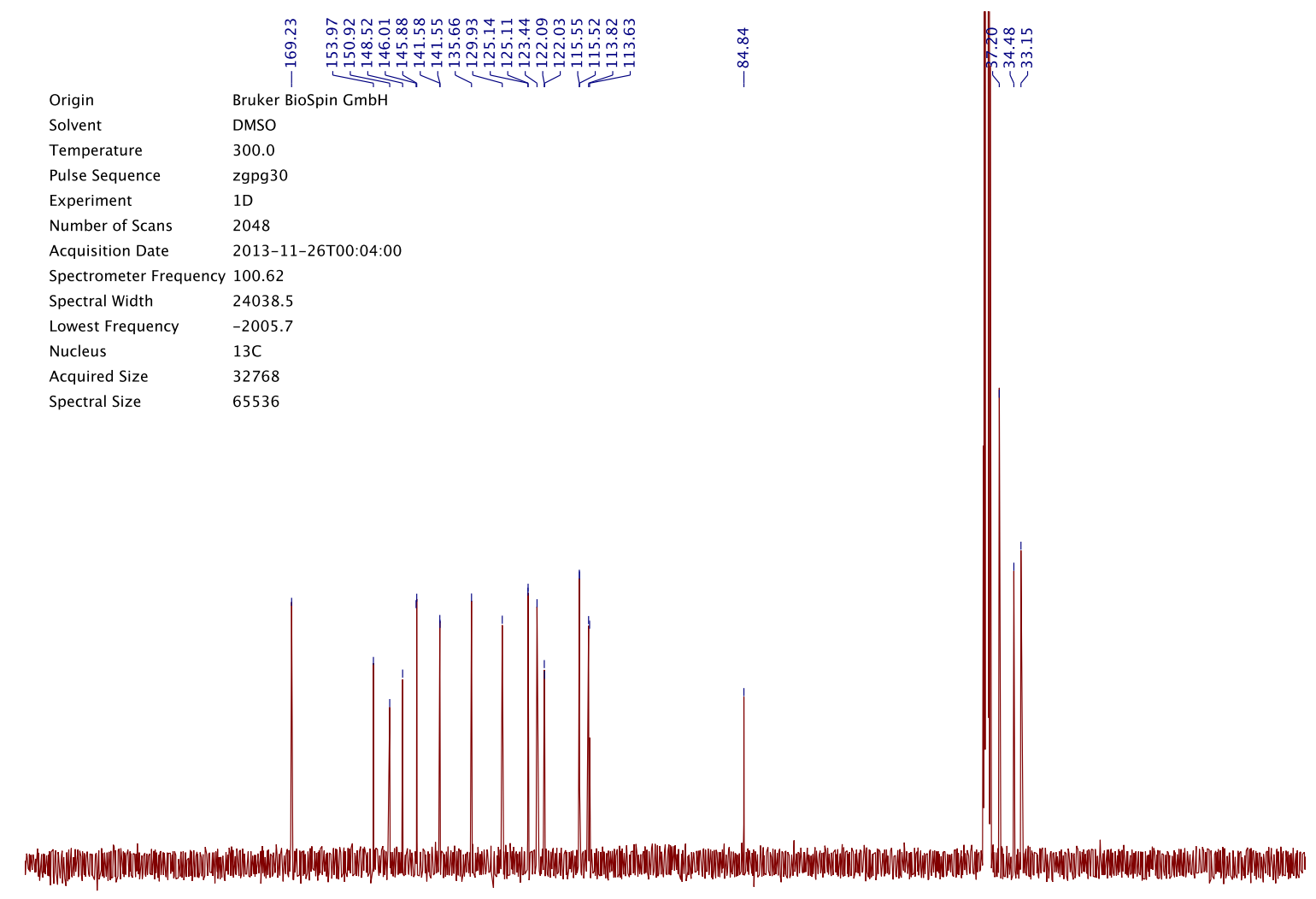

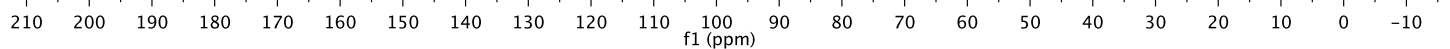




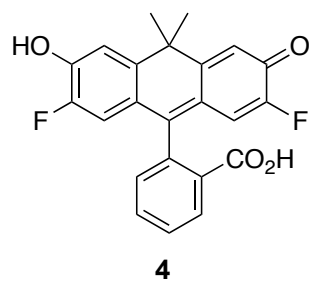

DAD1 A, Sig=254,8 Ref=off (2013_12IDAILYSQUENCE_LC 2013-12-19 13-26-2312013_12000001.D)

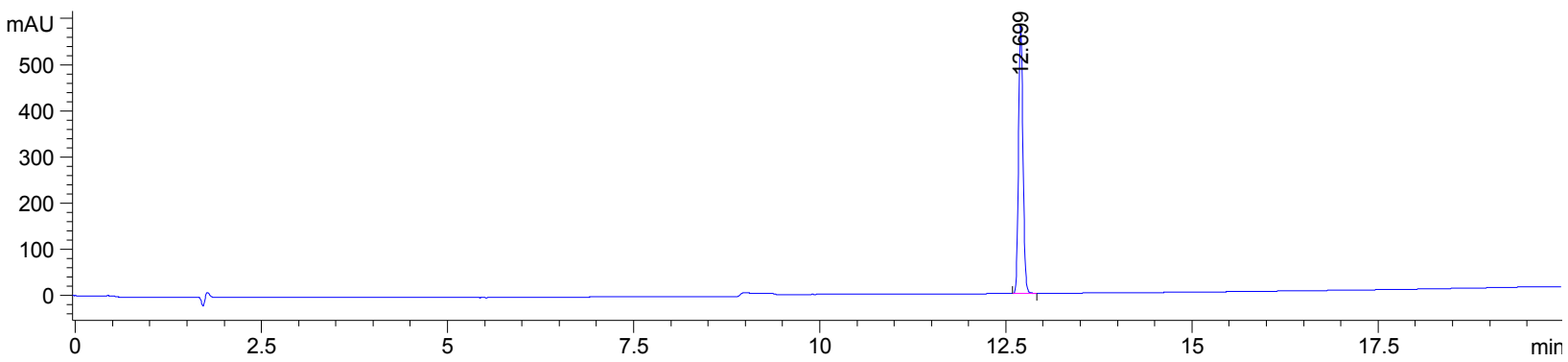

*MSD1 SPC, time=12.691:12.784 of C:ICHEM32I1IDATAI2013_12IDAILYSQUENCE_LC 2013-12-19 13-26-23I2013_12000001.D ES-API

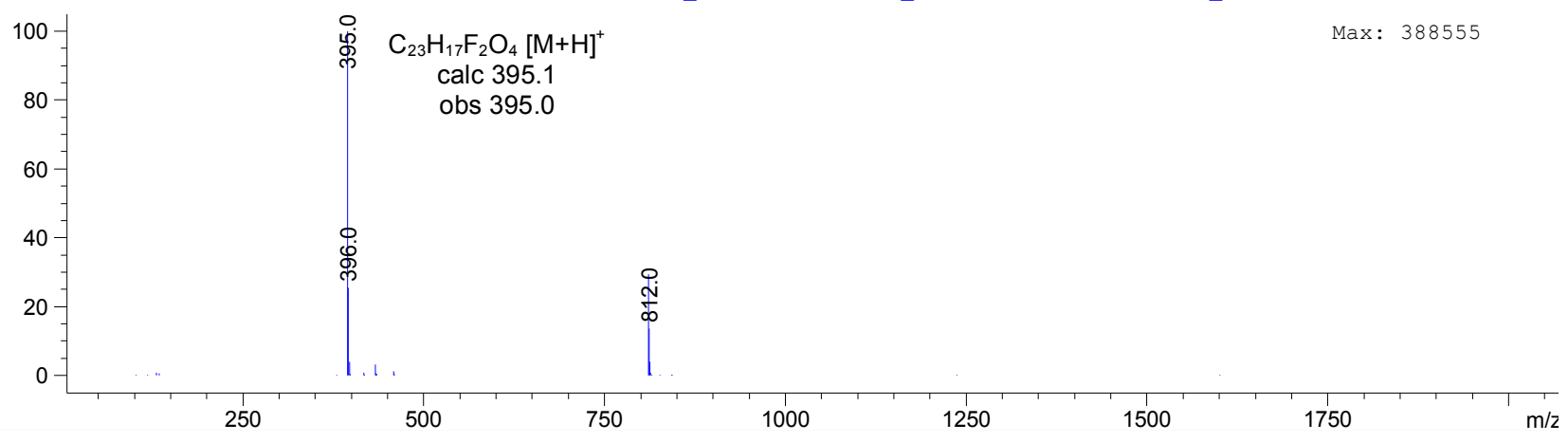




$\begin{array}{ll}\text { Origin } & \text { Bruker BioSpin } \mathrm{GmbH} \\ \text { Solvent } & \text { DMSO } \\ \text { Temperature } & 300.0 \\ \text { Pulse Sequence } & \mathrm{zg} 30 \\ \text { Experiment } & 1 \mathrm{D} \\ \text { Number of Scans } & 16 \\ \text { Acquisition Date } & 2013-12-19 T 09: 36: 00 \\ \text { Spectrometer Frequency } & 400.13 \\ \text { Spectral Width } & 8223.7 \\ \text { Lowest Frequency } & -1638.6 \\ \text { Nucleus } & 1 \mathrm{H} \\ \text { Acquired Size } & 32768 \\ \text { Spectral Size } & 65536\end{array}$<smiles>CC(C)(C)Oc1ccc(C2=C3C=C(F)C(=O)C=C3C(C)(C)c3cc(O)c(F)cc32)c(O)c1</smiles>

16

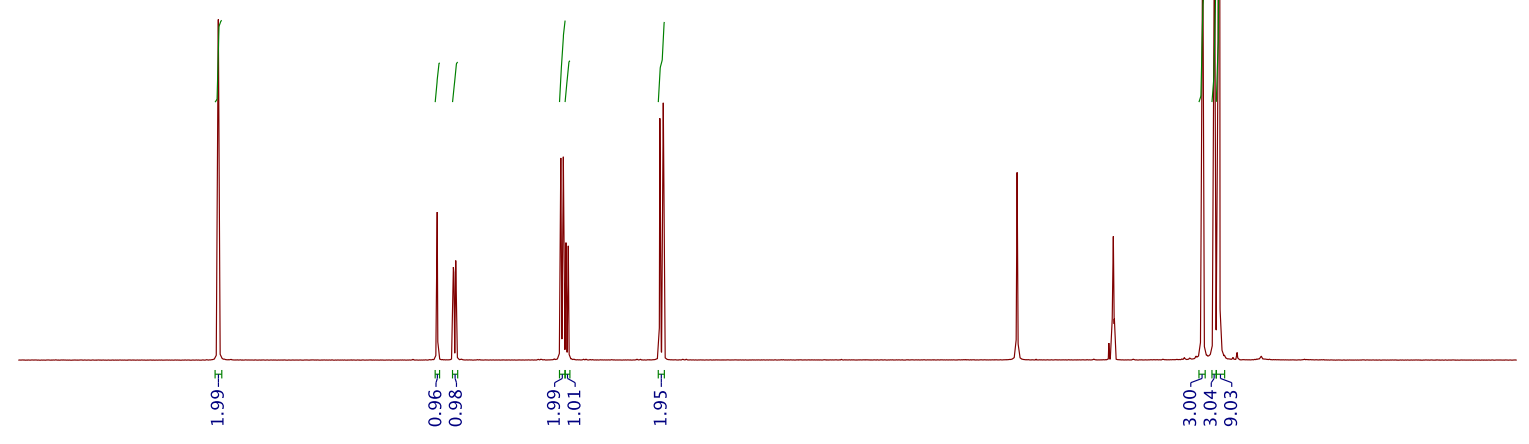

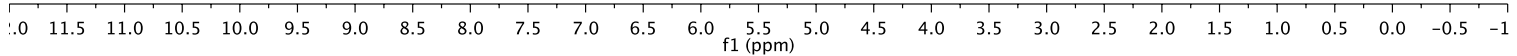
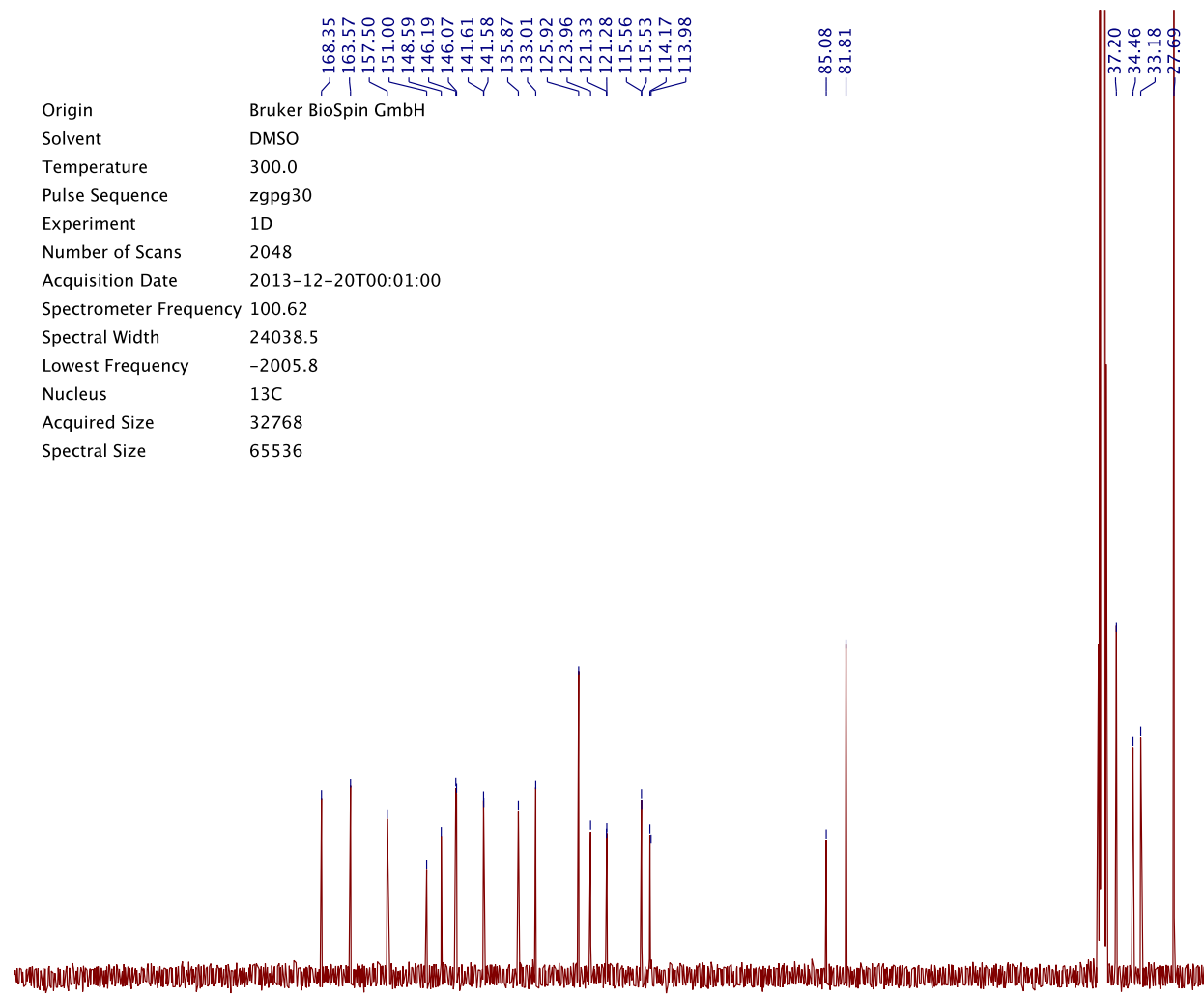

$\begin{array}{llllllllllllllllllllllllll}210 & 200 & 190 & 180 & 170 & 160 & 150 & 140 & 130 & 120 & 110 & \begin{array}{c}100 \\ \mathrm{f} 1(\mathrm{ppm})\end{array} & 90 & 80 & 70 & 60 & 50 & 40 & 30 & 20 & 10 & 0 & -10\end{array}$ 


$\begin{array}{ll}\text { Origin } & \text { Bruker BioSpin } \mathrm{GmbH} \\ \text { Solvent } & \text { MeOD } \\ \text { Temperature } & 300.0 \\ \text { Pulse Sequence } & \mathrm{zg} 30 \\ \text { Experiment } & 1 \mathrm{D} \\ \text { Number of Scans } & 16 \\ \text { Acquisition Date } & 2014-05-28 \mathrm{~T} 16: 01: 00 \\ \text { Spectrometer Frequency } & 400.13 \\ \text { Spectral Width } & 8223.7 \\ \text { Lowest Frequency } & -1644.2 \\ \text { Nucleus } & 1 \mathrm{H} \\ \text { Acquired Size } & 32768 \\ \text { Spectral Size } & 65536\end{array}$

|l| $\mid$
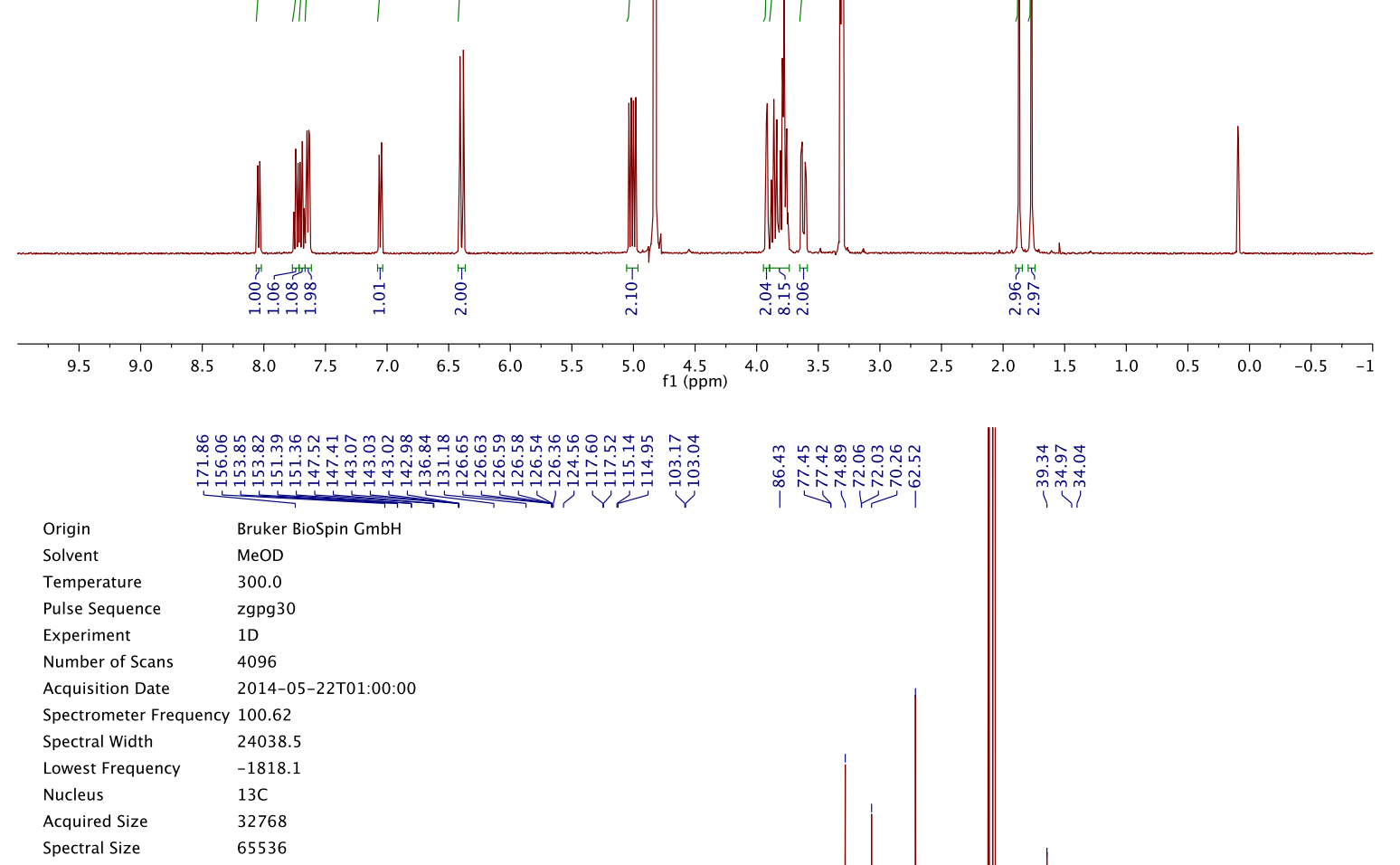

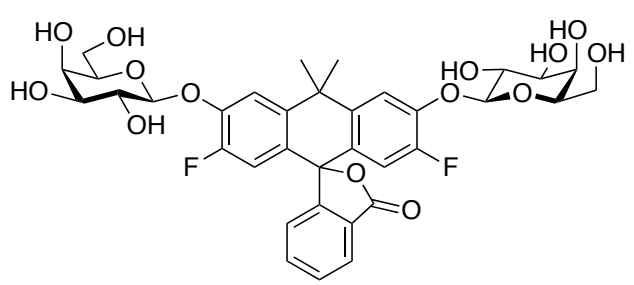

20 


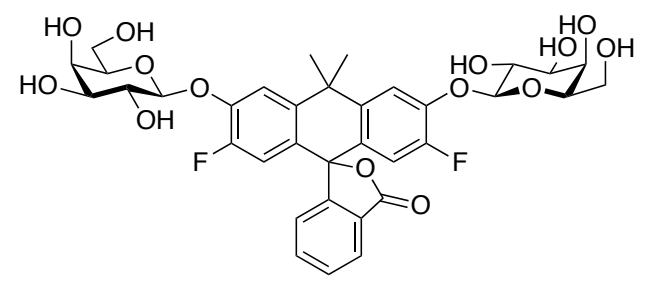

20

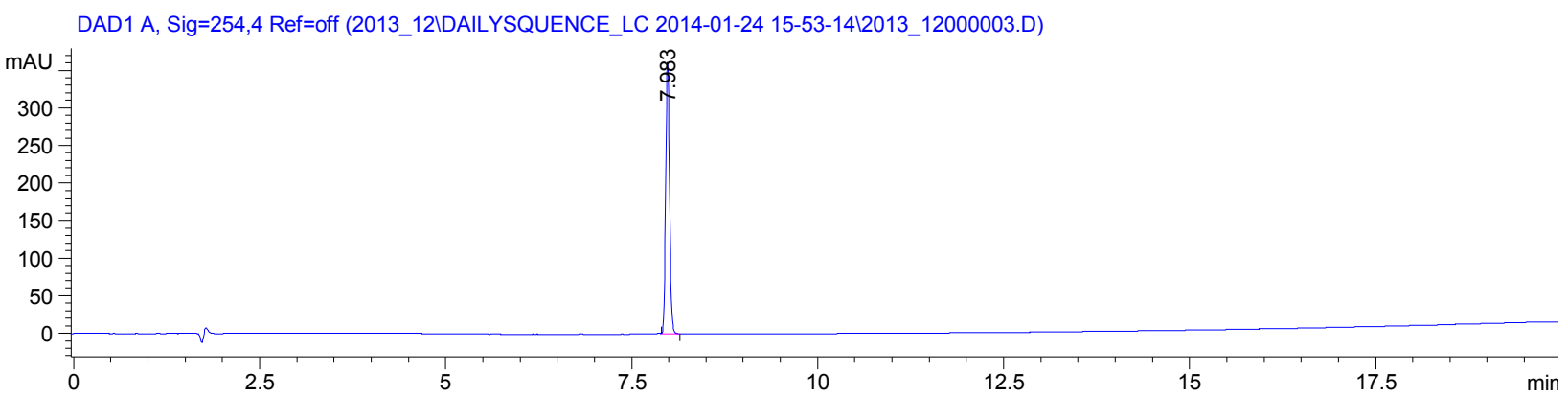

*MSD1 SPC, time=7.980:8.054 of C:ICHEM32I1IDATAI2013_12IDAILYSQUENCE_LC 2014-01-24 15-53-14l2013_12000003.D ES-API,

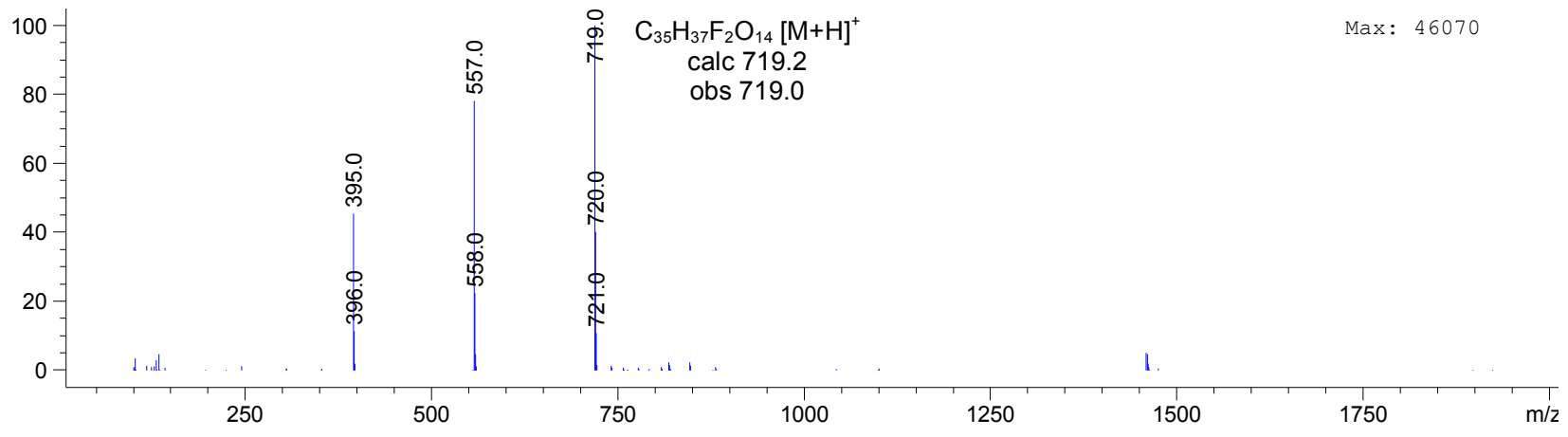




$\begin{array}{ll}\text { Origin } & \text { Bruker BioSpin } \mathrm{GmbH} \\ \text { Solvent } & \text { MeOD } \\ \text { Temperature } & 300.0 \\ \text { Pulse Sequence } & \mathrm{zg} 30 \\ \text { Experiment } & 1 \mathrm{D} \\ \text { Number of Scans } & 16 \\ \text { Acquisition Date } & 2014-05-28 \mathrm{~T} 16: 10: 00 \\ \text { Spectrometer Frequency } & 400.13 \\ \text { Spectral Width } & 8223.7 \\ \text { Lowest Frequency } & -1644.0 \\ \text { Nucleus } & 1 \mathrm{H} \\ \text { Acquired Size } & 32768 \\ \text { Spectral Size } & 65536\end{array}$

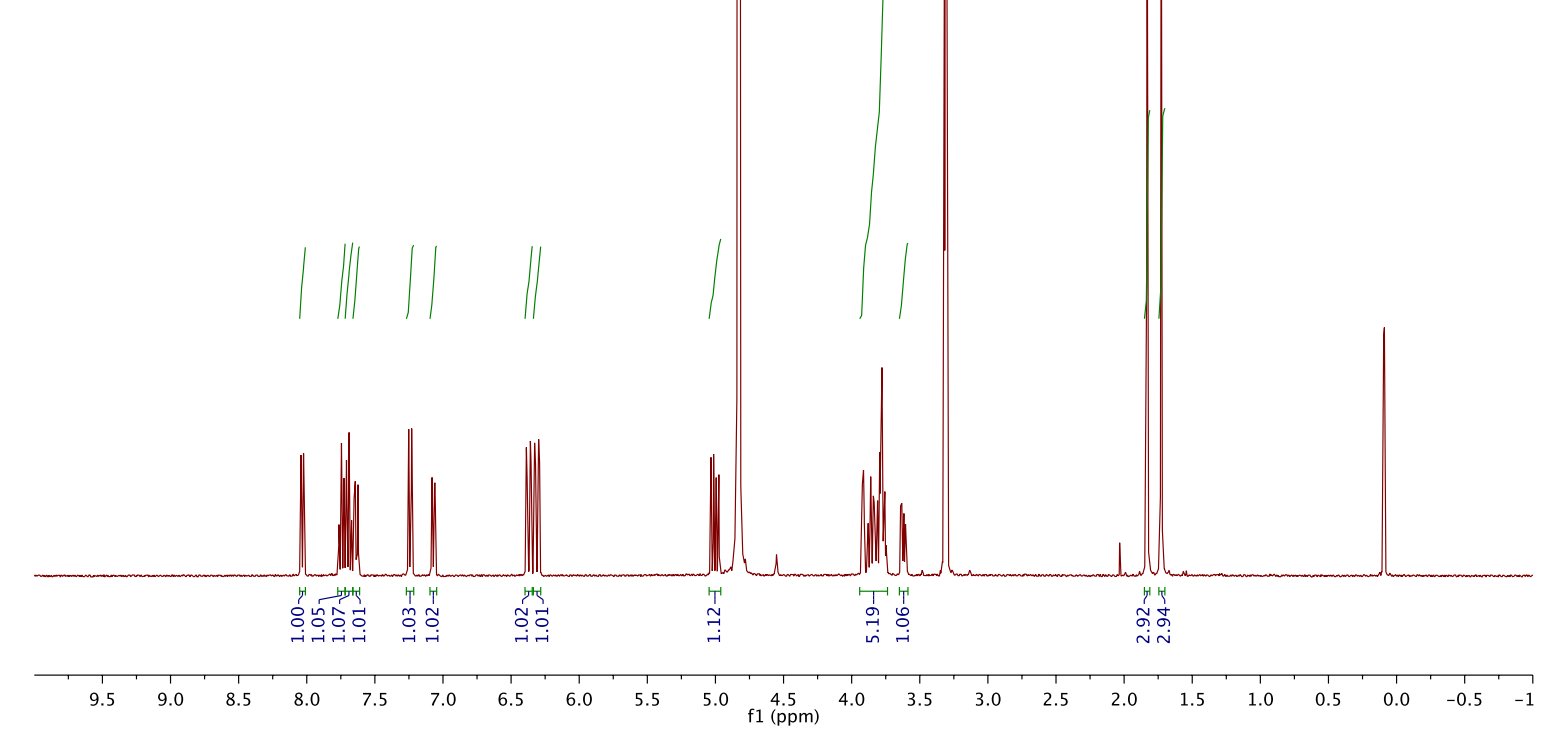

DAD1 A, Sig=254,8 Ref=off (2013_12\DAILYSQUENCE_LC 2014-01-17 16-09-24l2013_12000001.D)

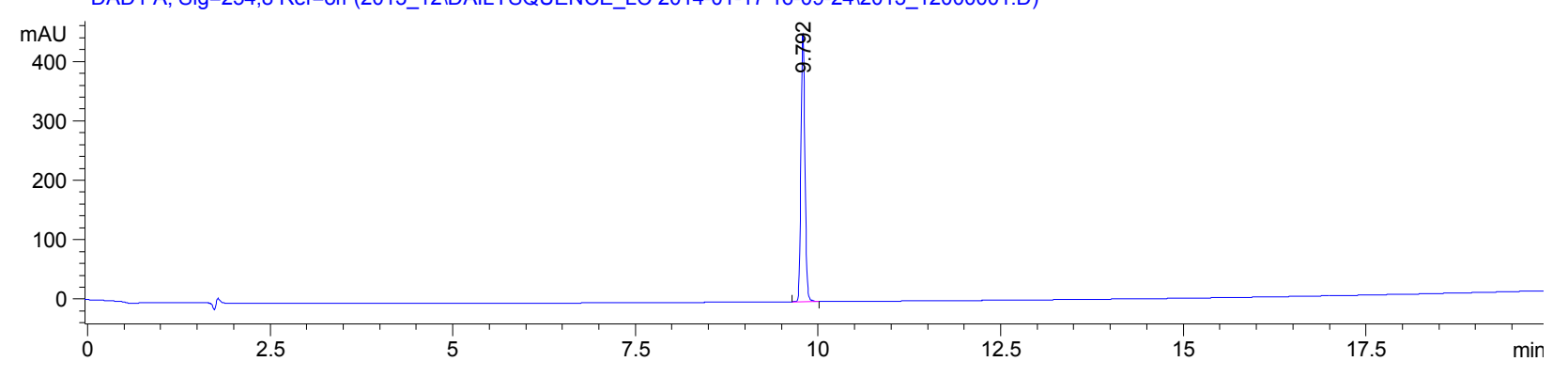

*MSD1 SPC, time=9.791:9.865 of C:ICHEM32/1IDATAI2013_12IDAILYSQUENCE_LC 2014-01-17 16-09-24I2013_12000001.D ES-API,

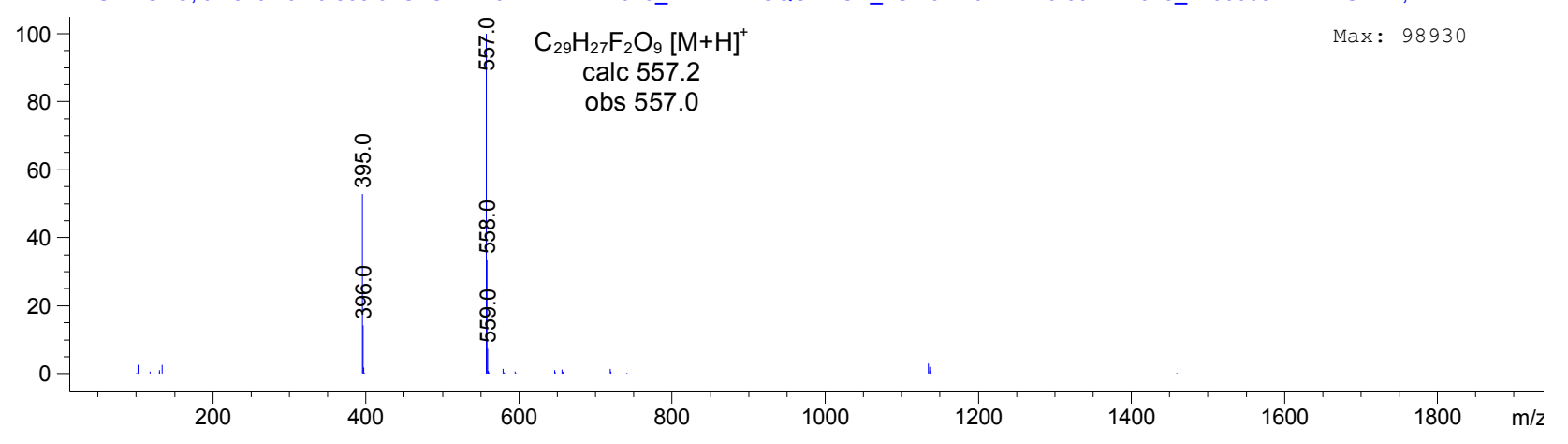



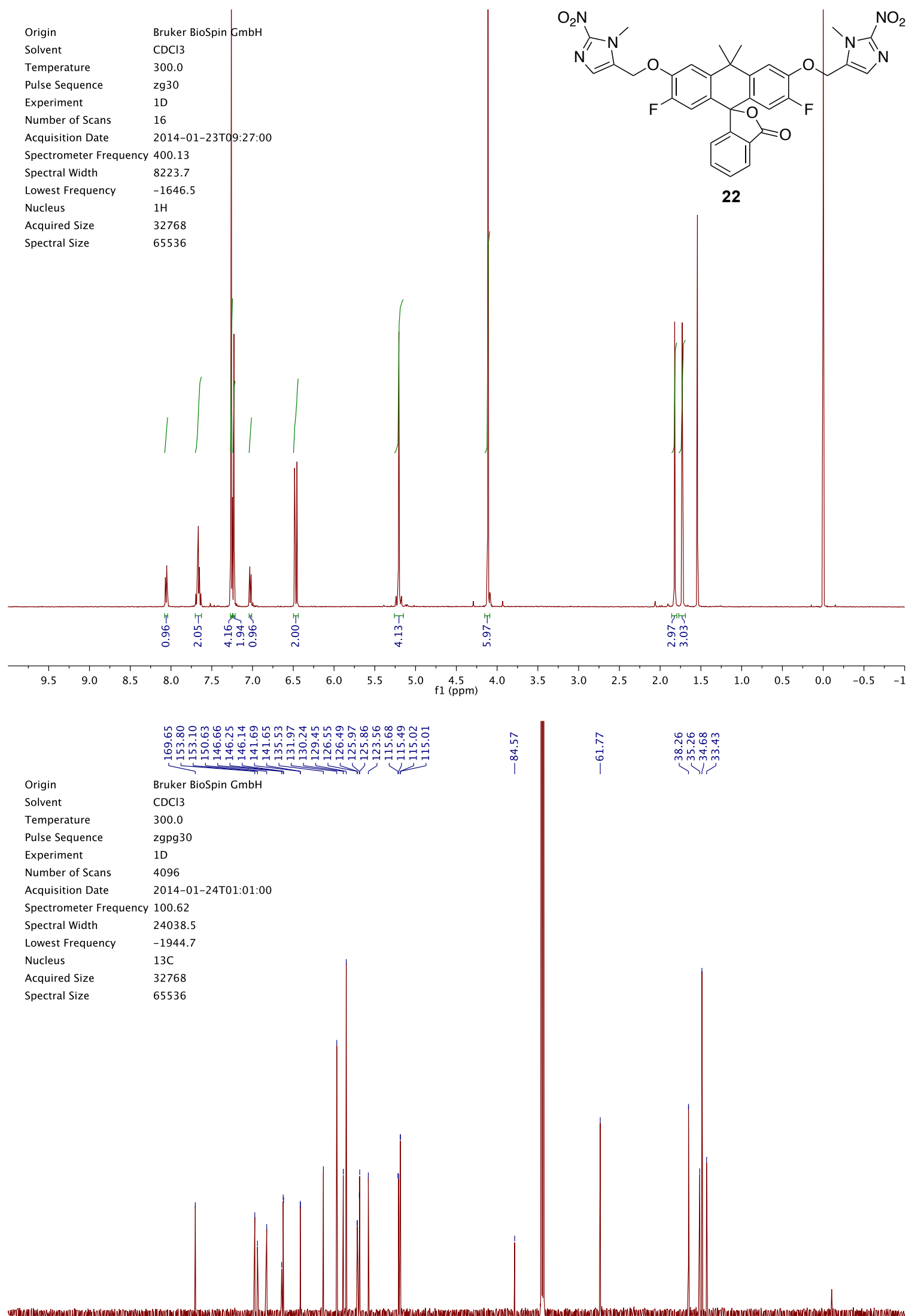

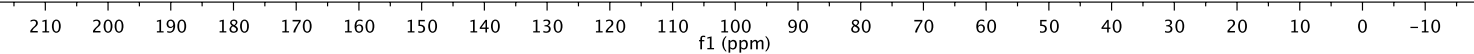




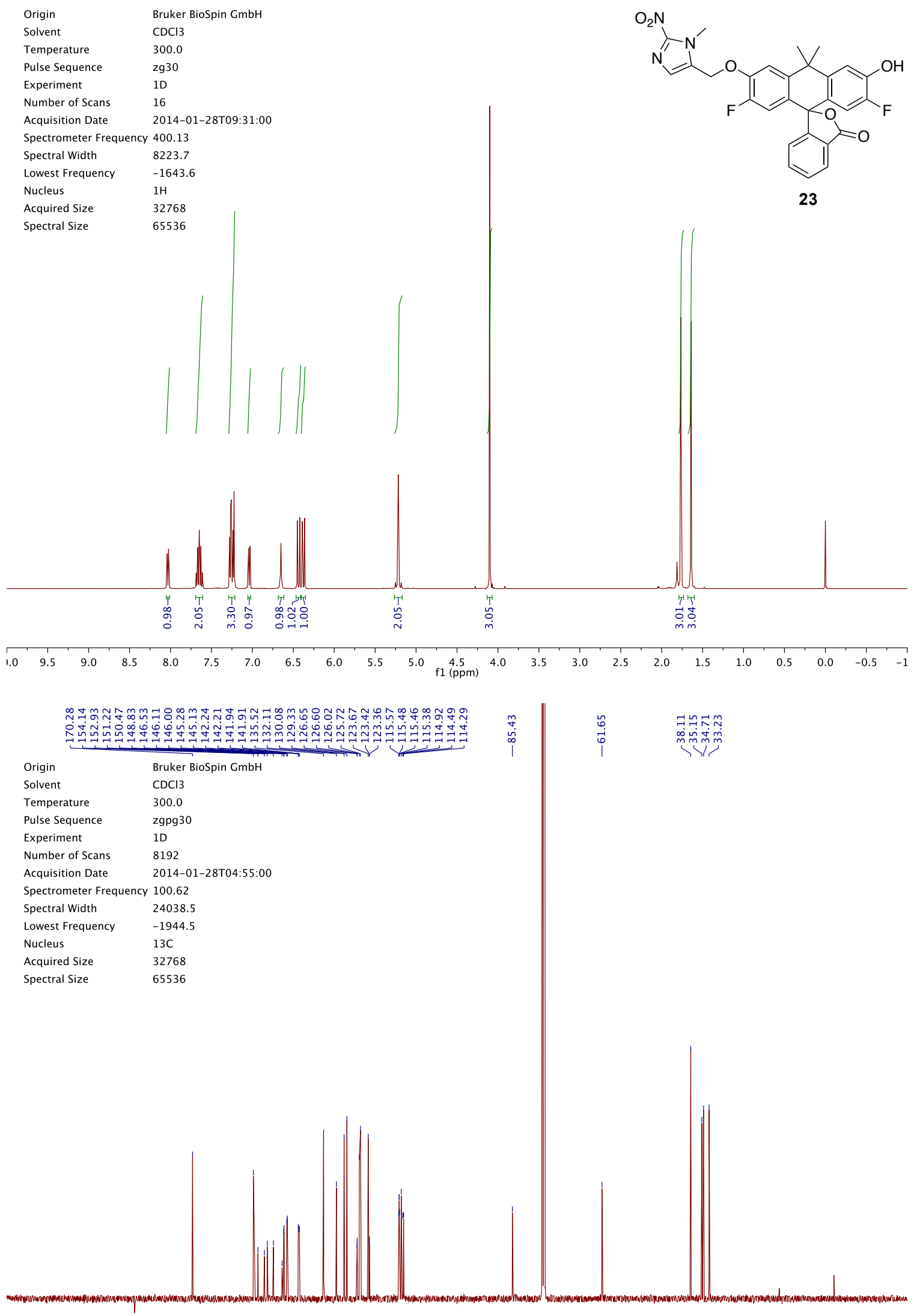

$\begin{array}{lllllllllllllllllllllllll}210 & 200 & 190 & 180 & 170 & 160 & 150 & 140 & 130 & 120 & 110 & \underset{\mathrm{f} 1}{1(\mathrm{ppm})} & 90 & 80 & 70 & 60 & 50 & 40 & 30 & 20 & 10 & 0 & -10\end{array}$ 

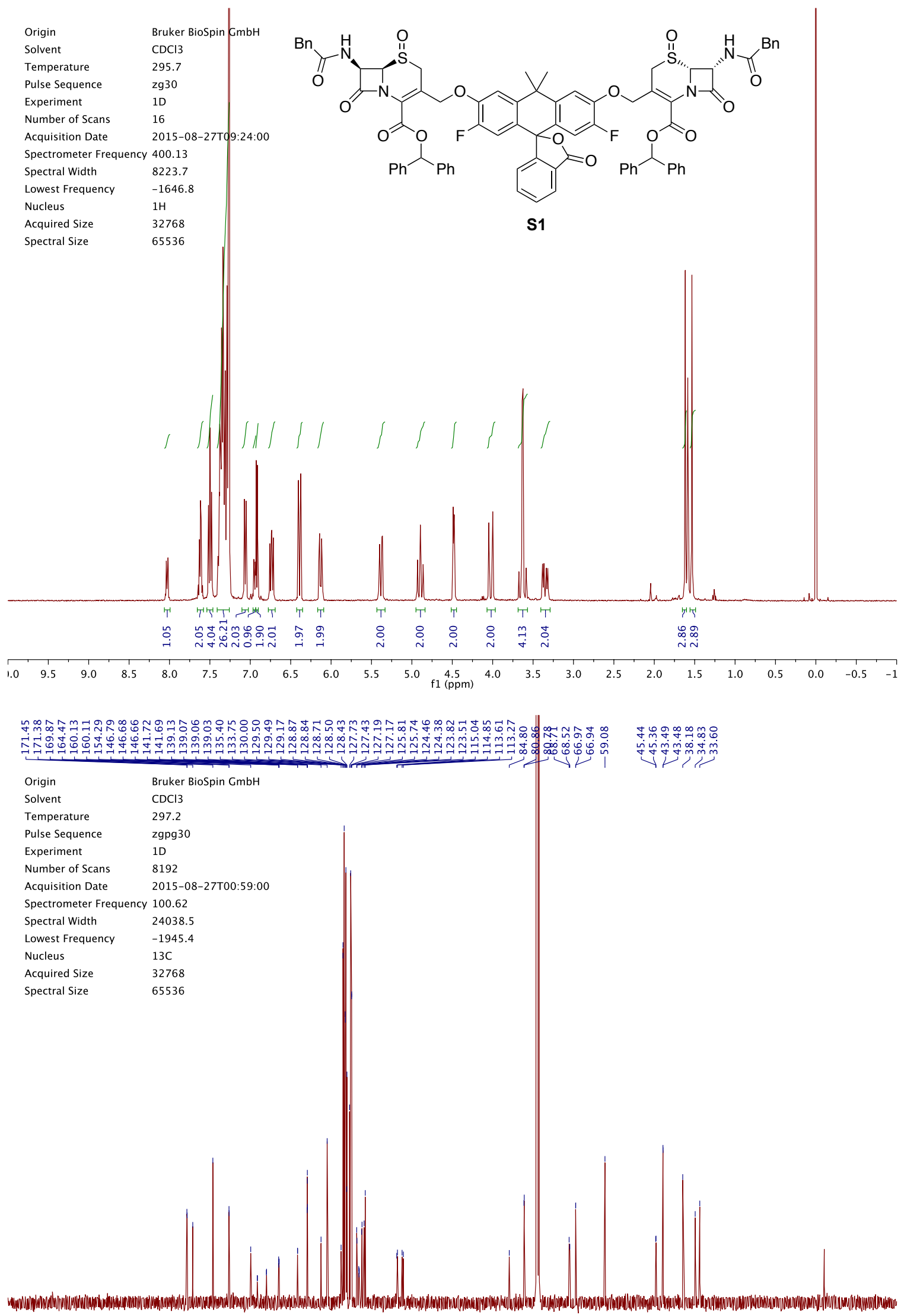

$\begin{array}{llllllllllllllllllllllllll}210 & 200 & 190 & 180 & 170 & 160 & 150 & 140 & 130 & 120 & 110 & \begin{array}{l}100 \\ \mathrm{f} 1(\mathrm{ppm})\end{array} & 90 & 80 & 70 & 60 & 50 & 40 & 30 & 20 & 10 & 0 & -10\end{array}$ 


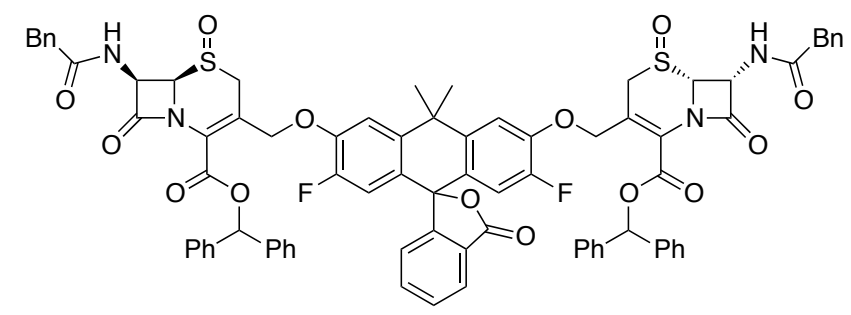

s1

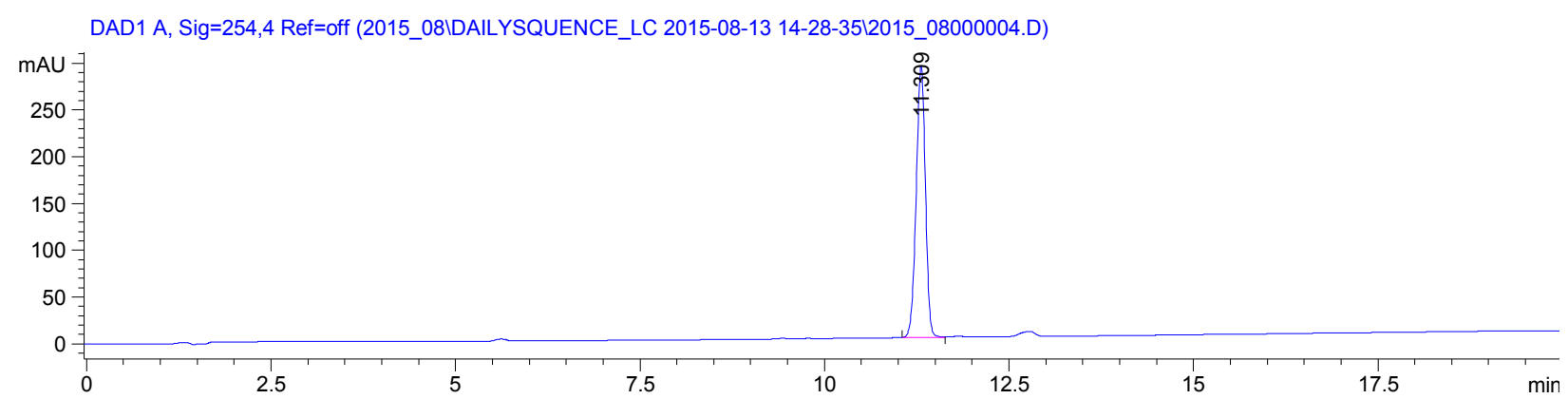

*MSD1 SPC, time=11.213:11.342 of C:ICHEM32I1IDATAI2015 08IDAILYSQUENCE LC 2015-08-13 14-28-35I2015_08000004.D ES-API

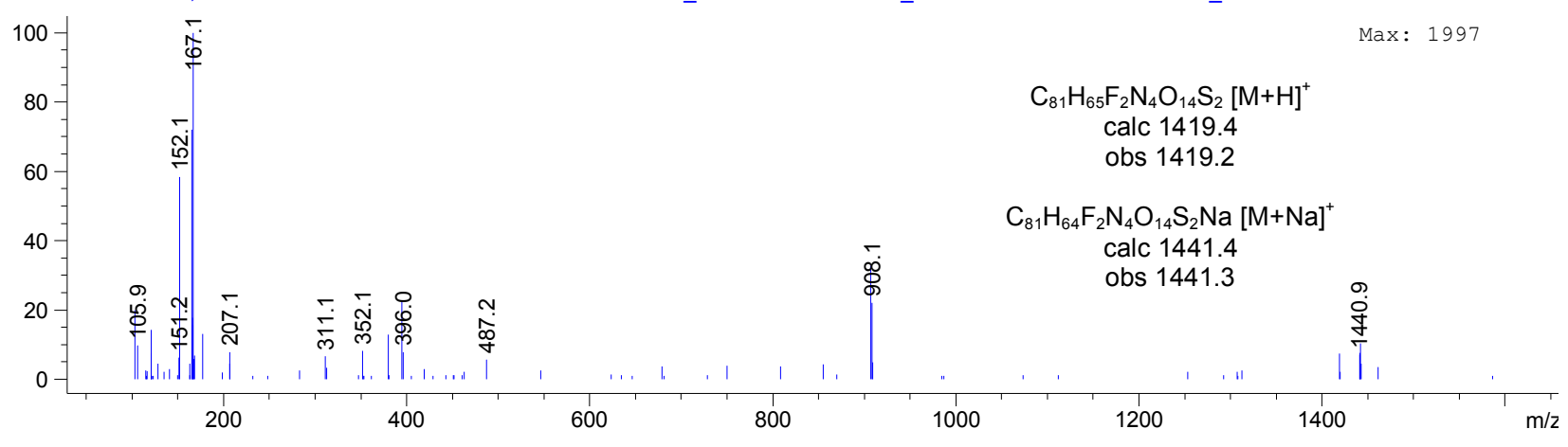




$\begin{array}{ll}\text { Origin } & \text { Bruker BioSpin } \mathrm{GmbH} \\ \text { Solvent } & \text { DMSO } \\ \text { Temperature } & 300.0 \\ \text { Pulse Sequence } & \mathrm{zg} 30 \\ \text { Experiment } & 1 \mathrm{D} \\ \text { Number of Scans } & 16 \\ \text { Acquisition Date } & 2015-04-06 \mathrm{~T} 09: 57: 00 \\ \text { Spectrometer Frequency } & 400.13 \\ \text { Spectral Width } & 8223.7 \\ \text { Lowest Frequency } & -1638.6 \\ \text { Nucleus } & 1 \mathrm{H} \\ \text { Acquired Size } & 32768 \\ \text { Spectral Size } & 65536\end{array}$
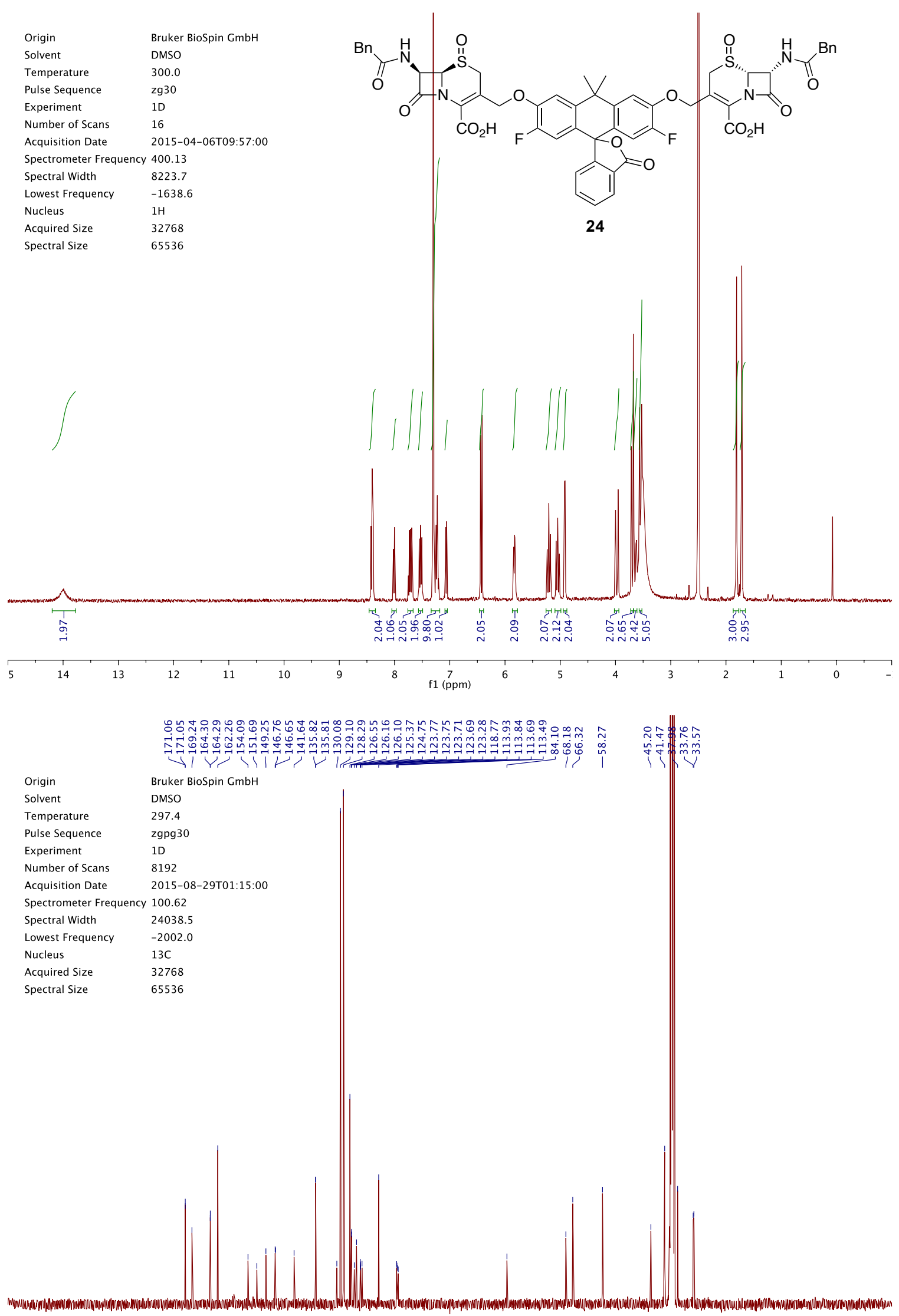

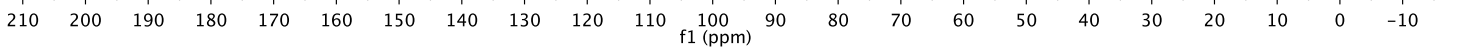




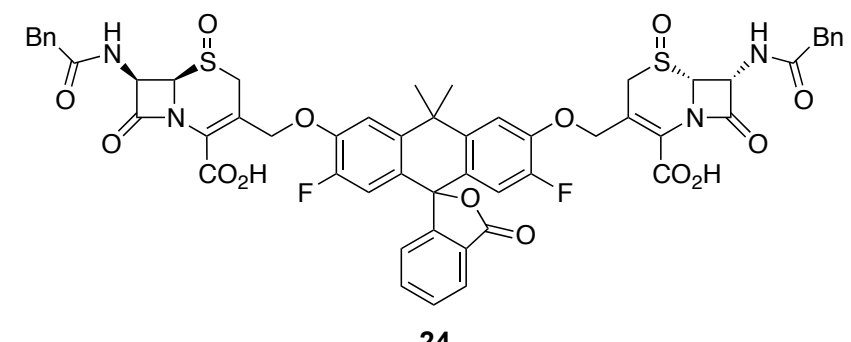

24

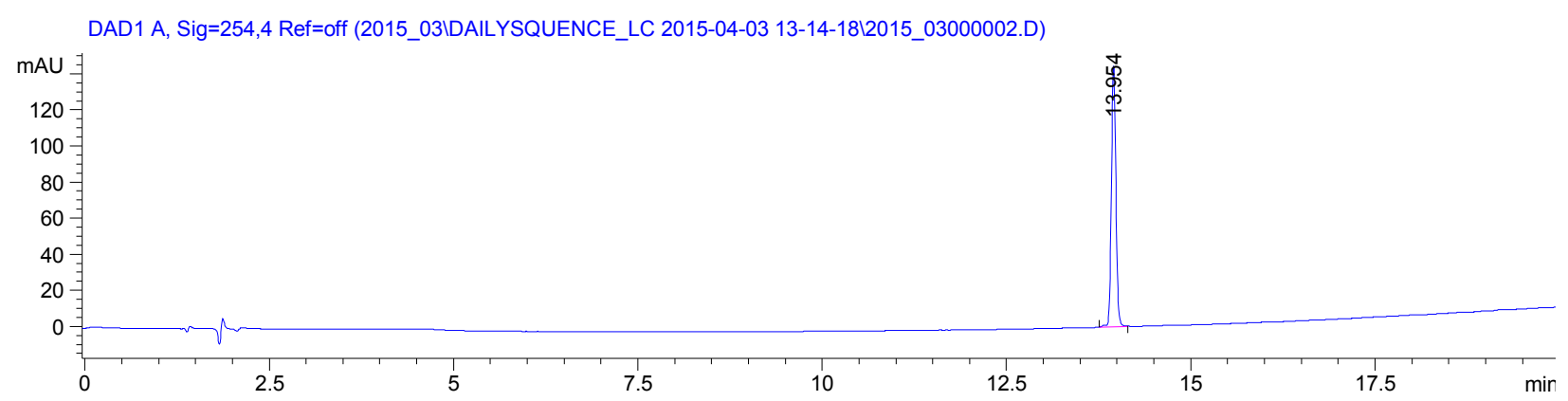

*MSD1 SPC, time=13.925:14.073 of C:ICHEM32I1IDATAI2015_03|DAILYSQUENCE_LC 2015-04-03 13-14-1812015_03000002.D ES-API

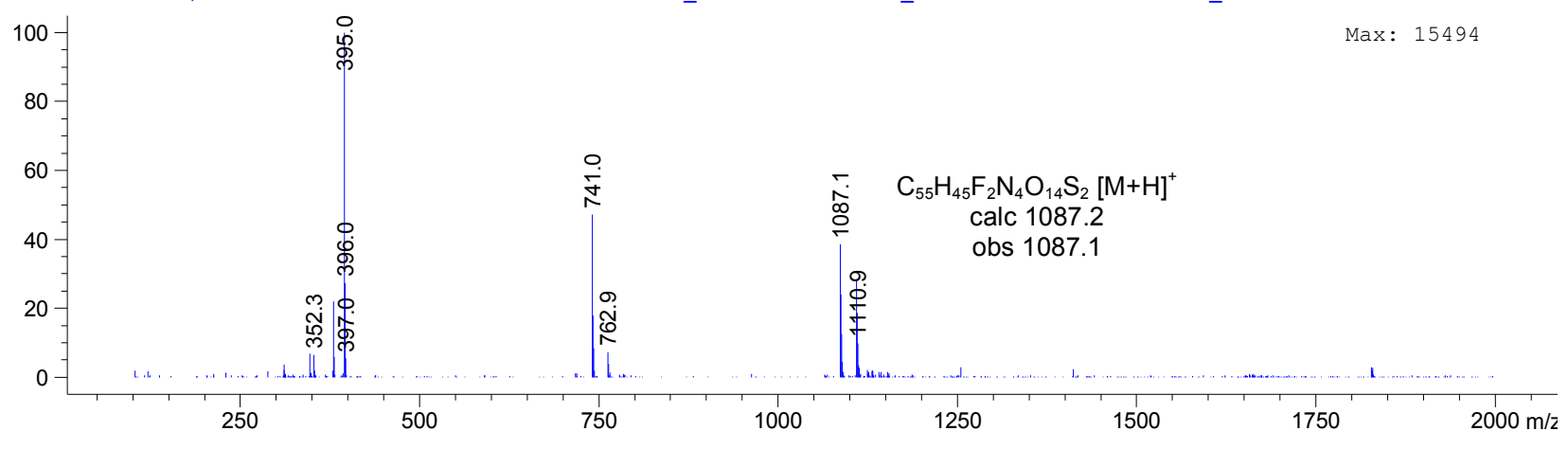




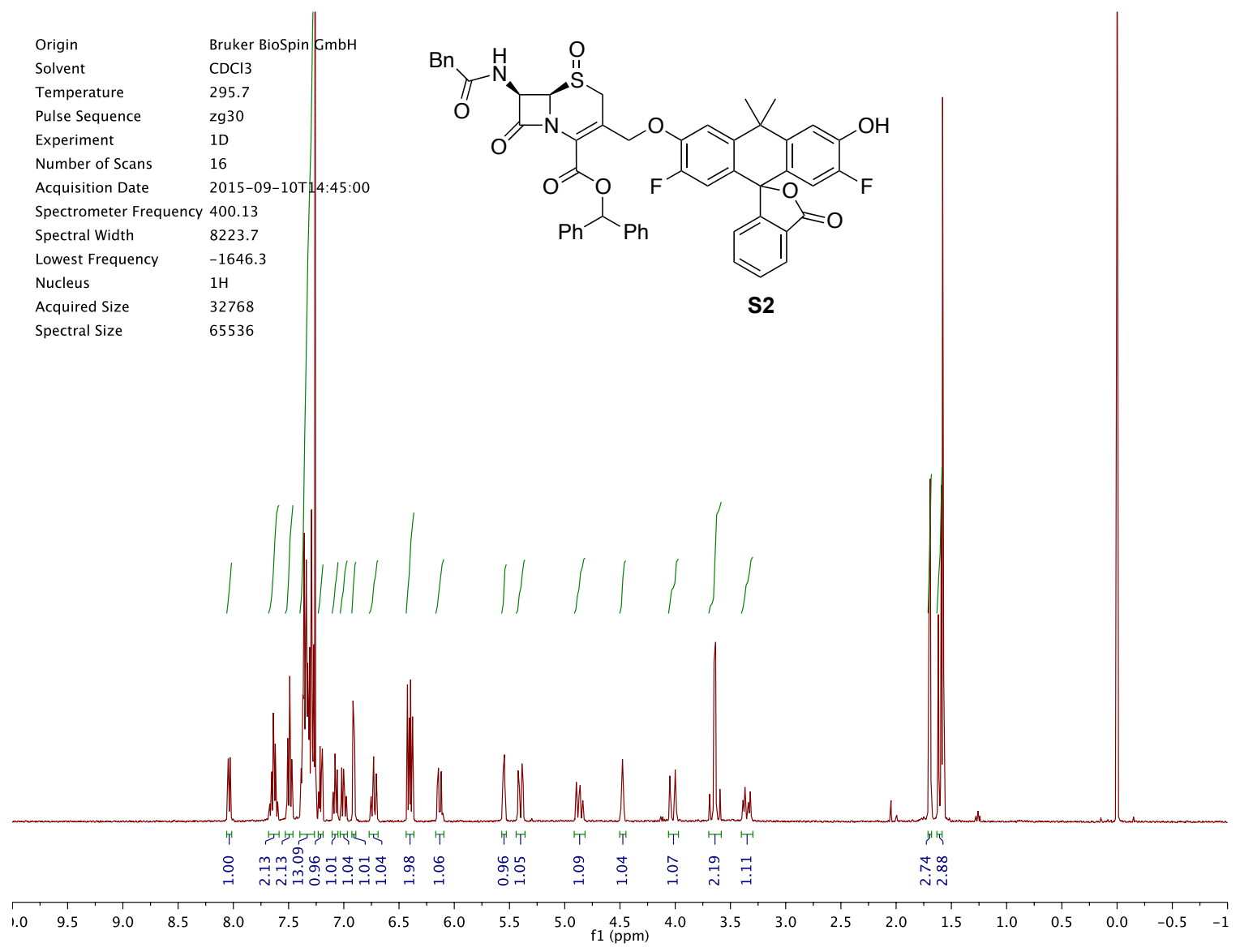

DAD1 A, Sig=254,4 Ref=off (2015_09IDAILYSQUENCE_LC 2015-09-09 16-32-0112015_09000003.D)

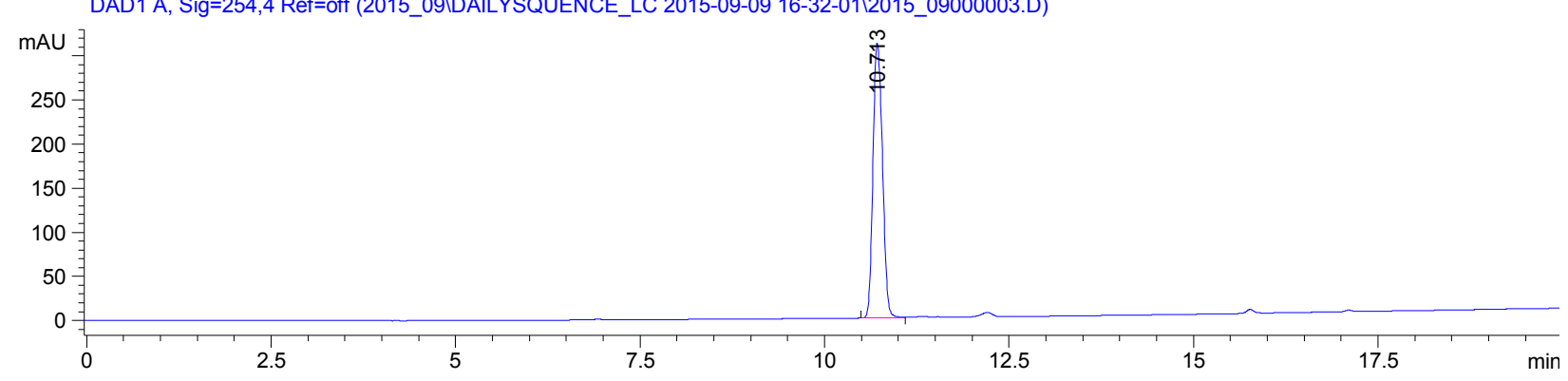

*MSD1 SPC, time=10.637:10.840 of C:ICHEM32\1IDATAI2015_09IDAILYSQUENCE_LC 2015-09-09 16-32-01|2015_09000003.D ES-API

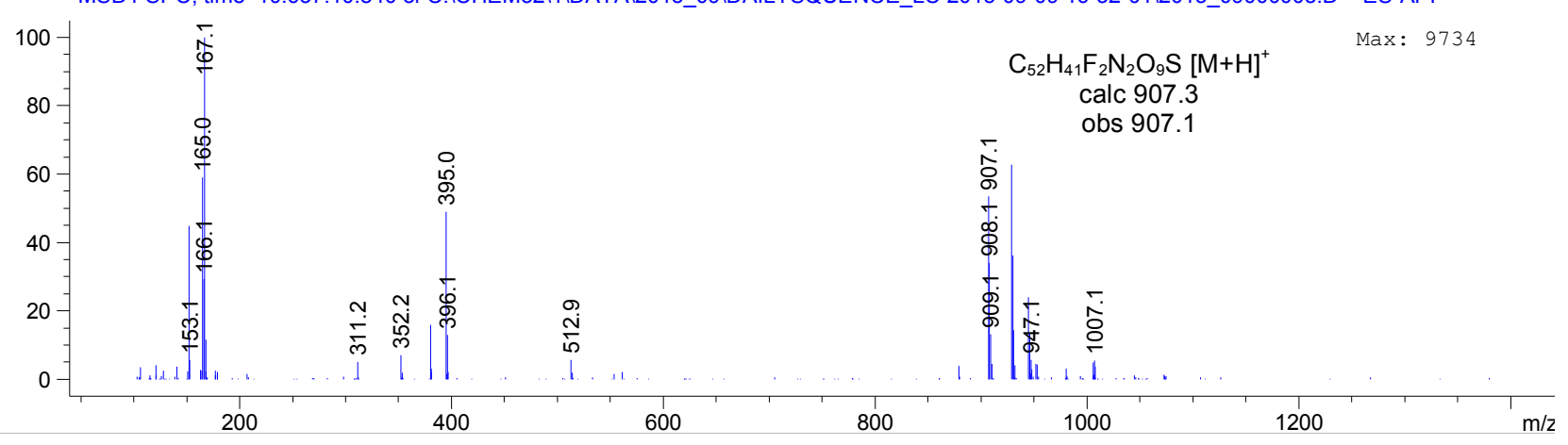




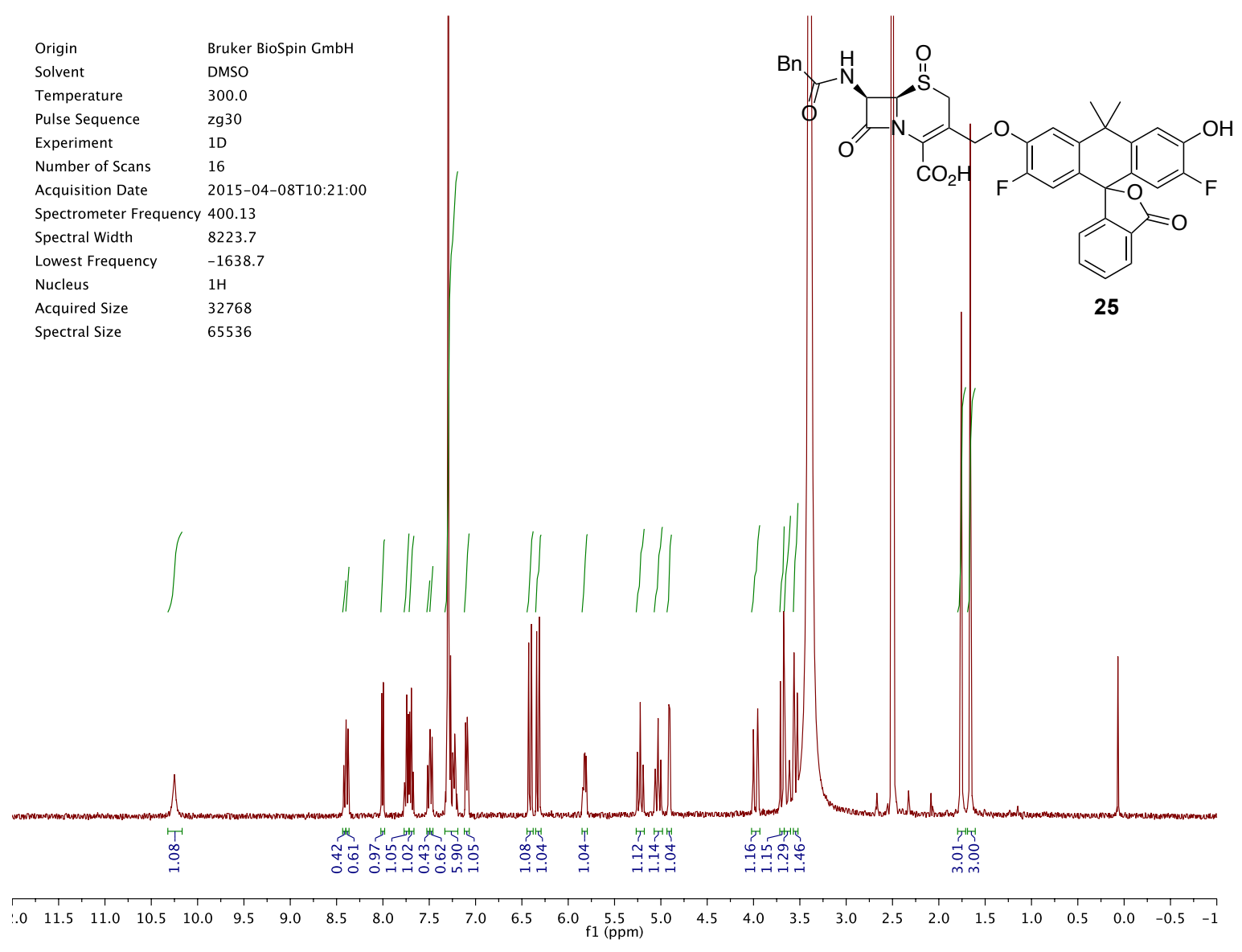

DAD1 A, Sig=254,4 Ref=off (2015_08IDAILYSQUENCE_LC 2015-08-13 14-28-3512015_08000002.D)

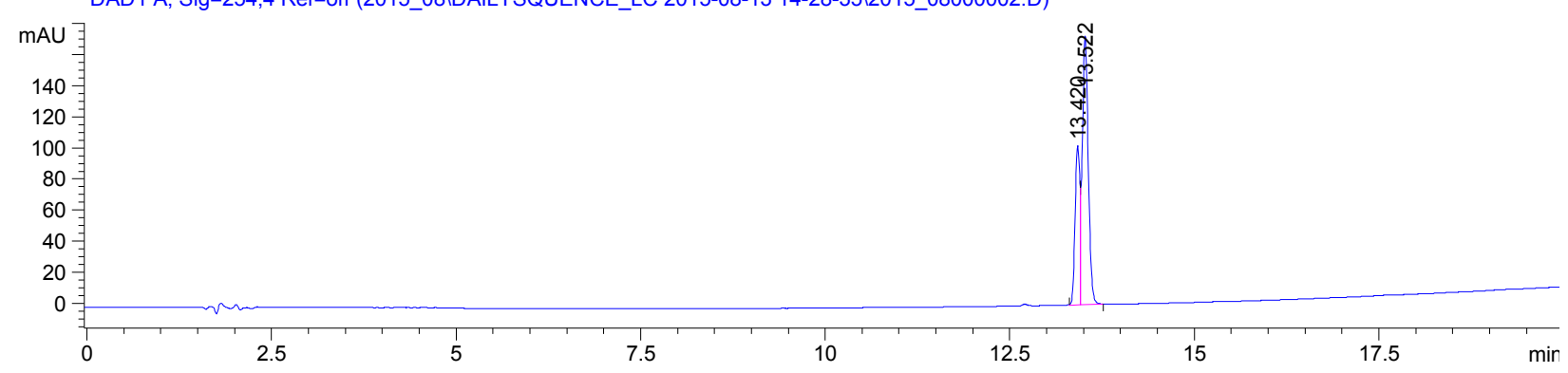

*MSD1 SPC, time=13.371:13.574 of C:ICHEM32\1IDATAI2015_08IDAILYSQUENCE_LC 2015-08-13 14-28-35।2015_08000002.D ES-API

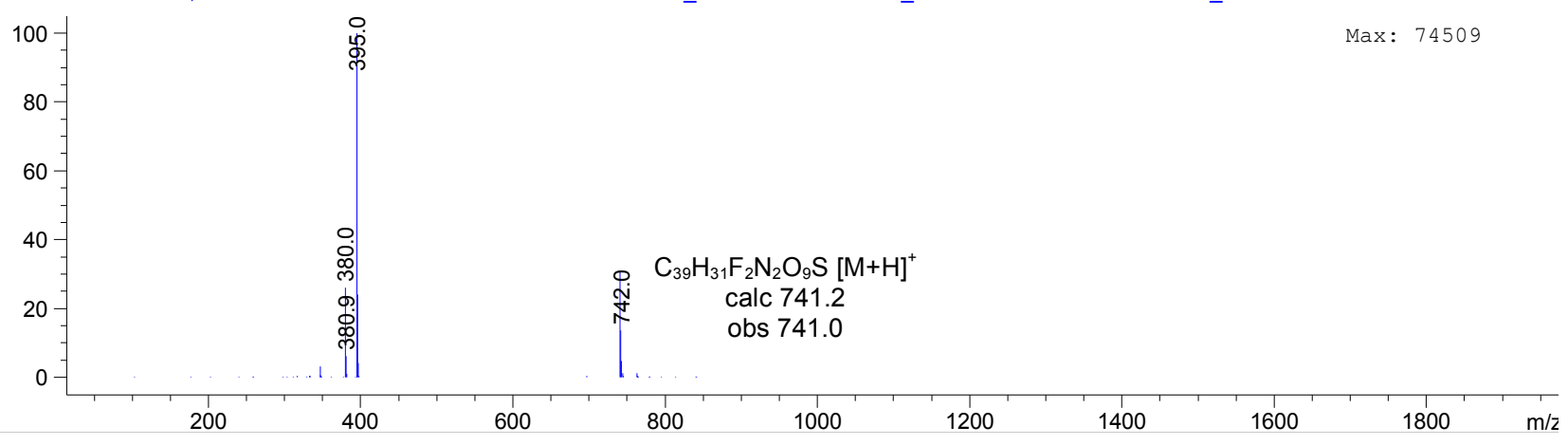




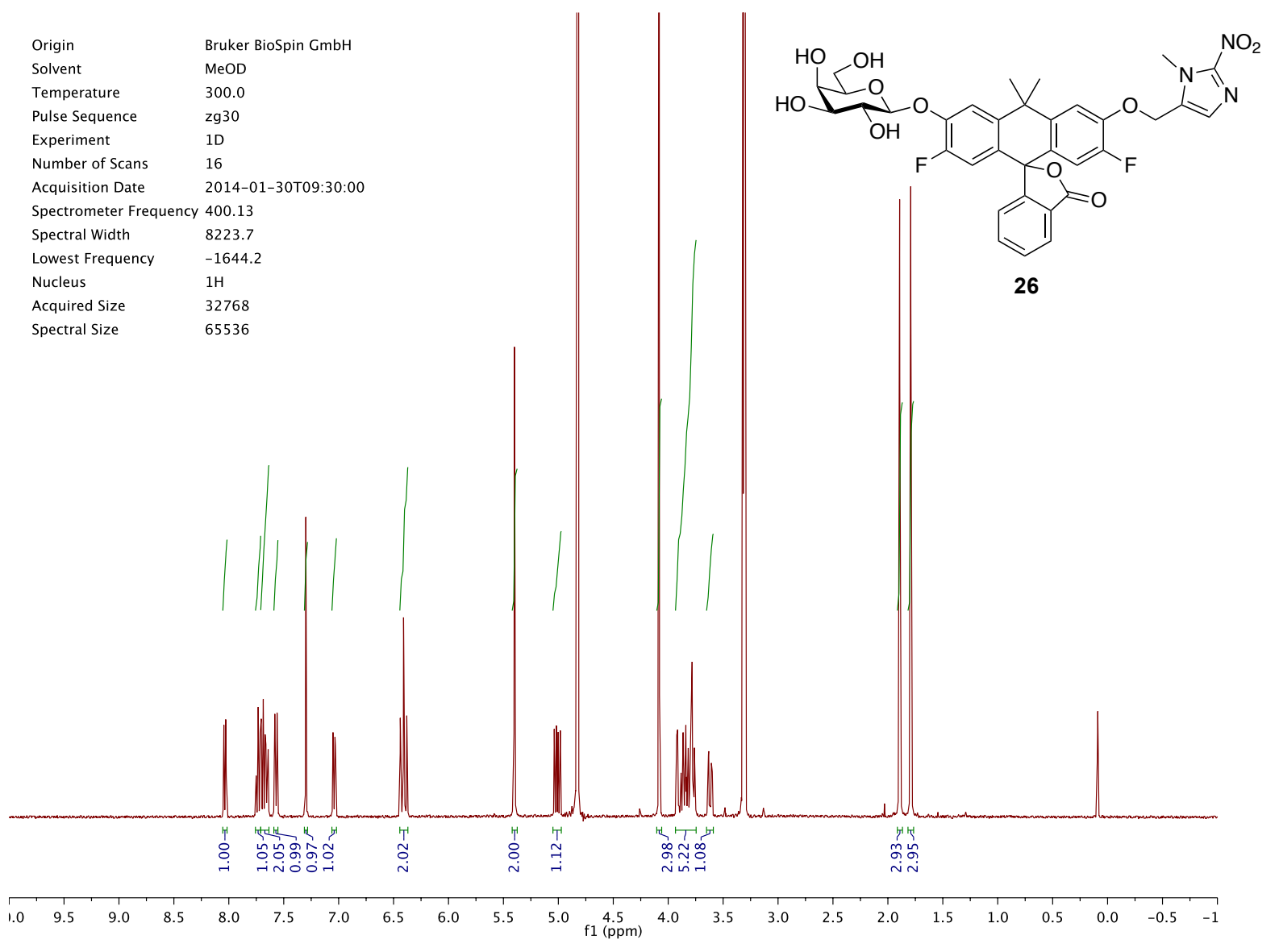

DAD1 A, Sig=254,8 Ref=off (2013_12IDAILYSQUENCE_LC 2014-01-29 15-26-1612013_12000004.D)

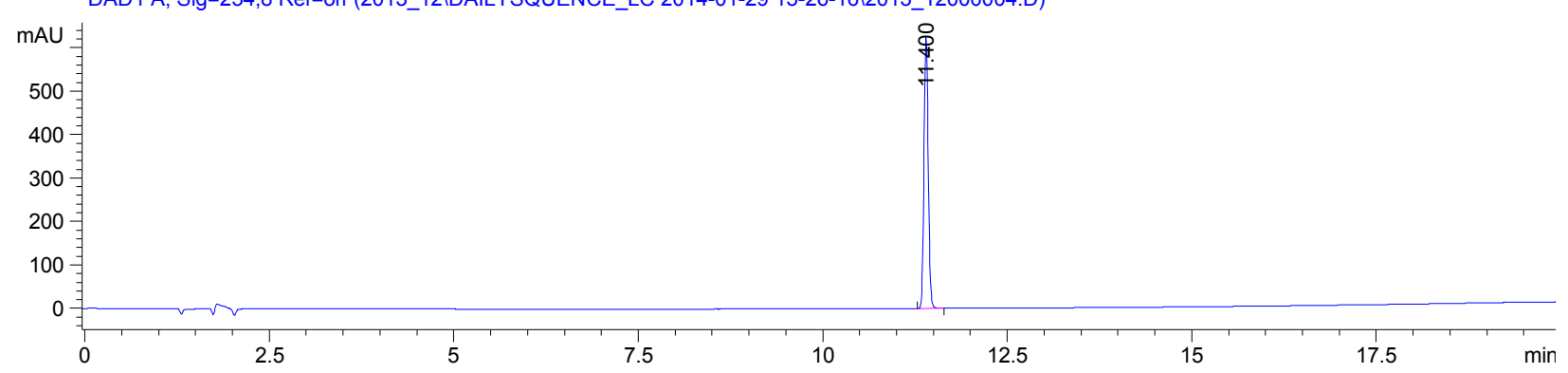

*MSD1 SPC, time=11.380:11.490 of C:ICHEM32I1IDATAI2013_12IDAILYSQUENCE_LC 2014-01-29 15-26-16l2013_12000004.D ES-API

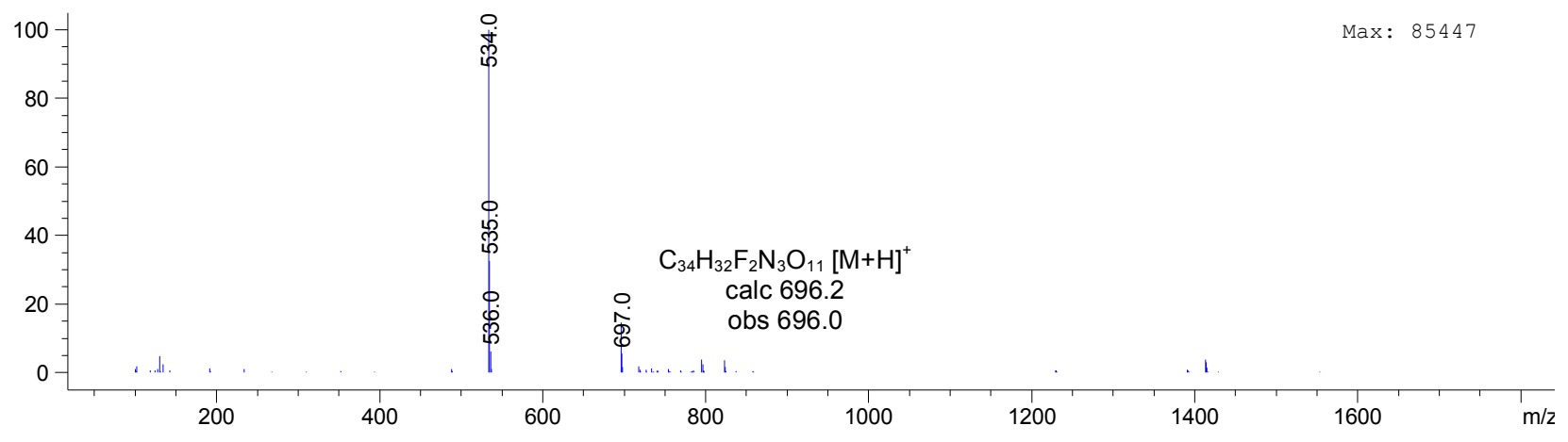




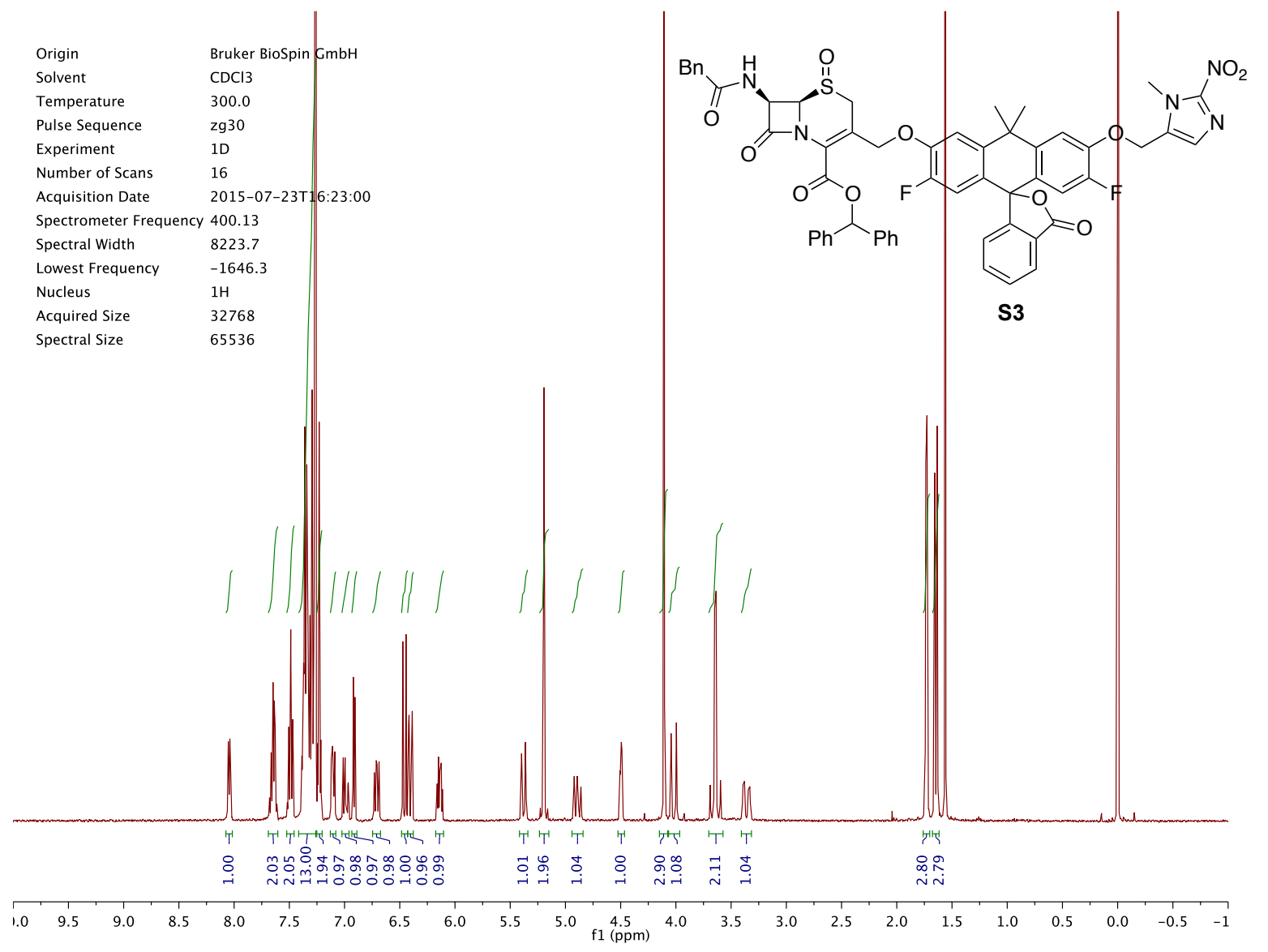

DAD1 A, Sig=254,4 Ref=off (2015_07IDAILYSQUENCE_LC 2015-07-22 15-46-2012015_07000002.D)

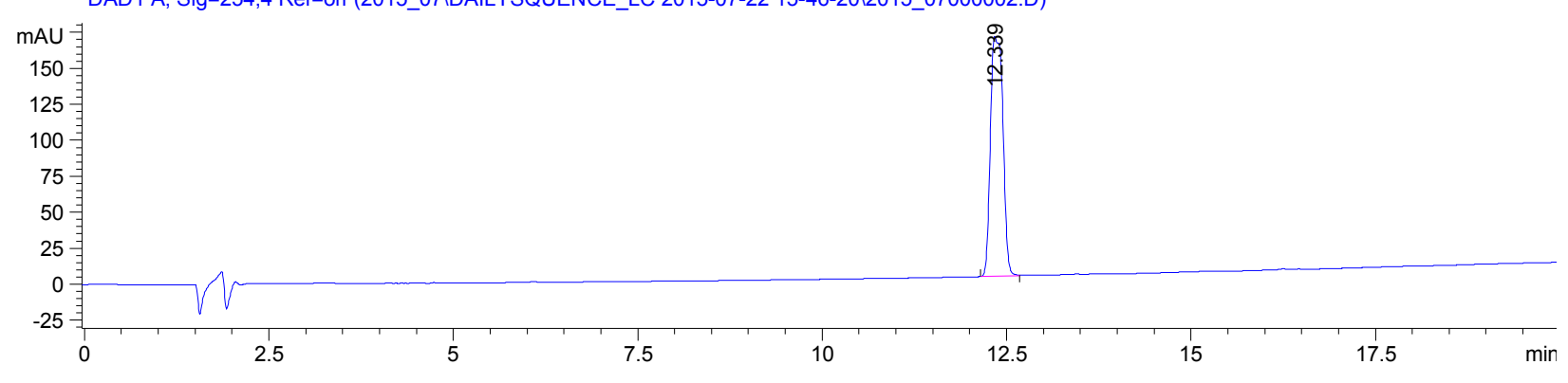

*MSD1 SPC, time=12.285:12.469 of C:ICHEM32\1IDATAI2015_07\DAILYSQUENCE_LC 2015-07-22 15-46-2012015_07000002.D ES-API

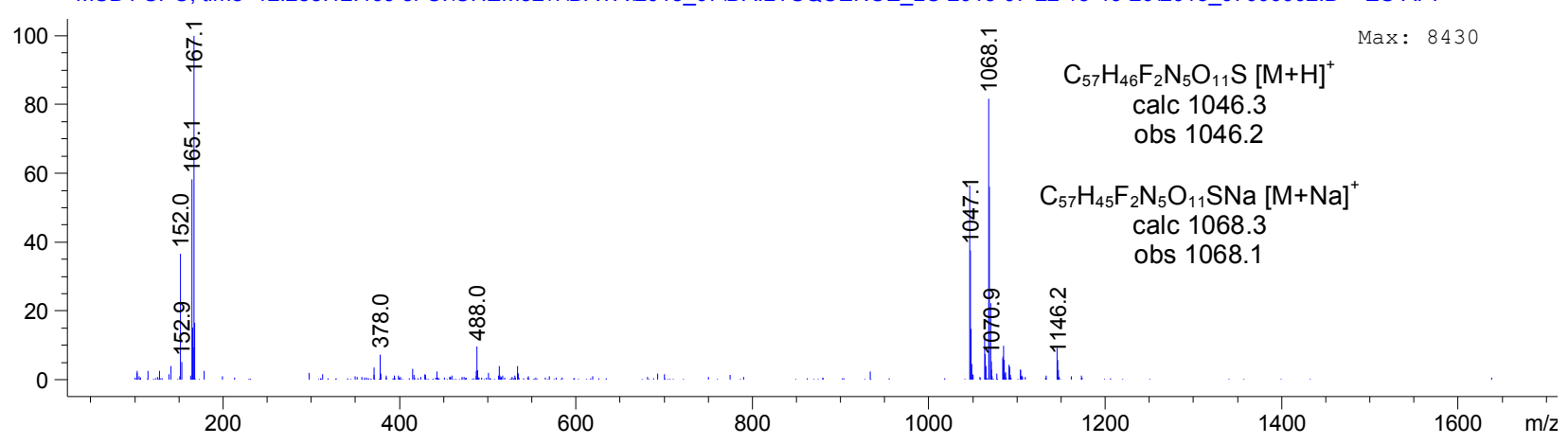




\begin{tabular}{|c|c|}
\hline Origin & Bruker BioSpin GmbH \\
\hline Solvent & DMSO \\
\hline Temperature & 300.0 \\
\hline Pulse Sequence & zg30 \\
\hline Experiment & 1D \\
\hline Number of Scans & 16 \\
\hline Acquisition Date & 2015-07-28T09:00:00 \\
\hline \multicolumn{2}{|c|}{ Spectrometer Frequency 400.13} \\
\hline Spectral Width & 8223.7 \\
\hline Lowest Frequency & -1637.6 \\
\hline Nucleus & $1 \mathrm{H}$ \\
\hline Acquired Size & 32768 \\
\hline Spectral Size & 65536 \\
\hline
\end{tabular}

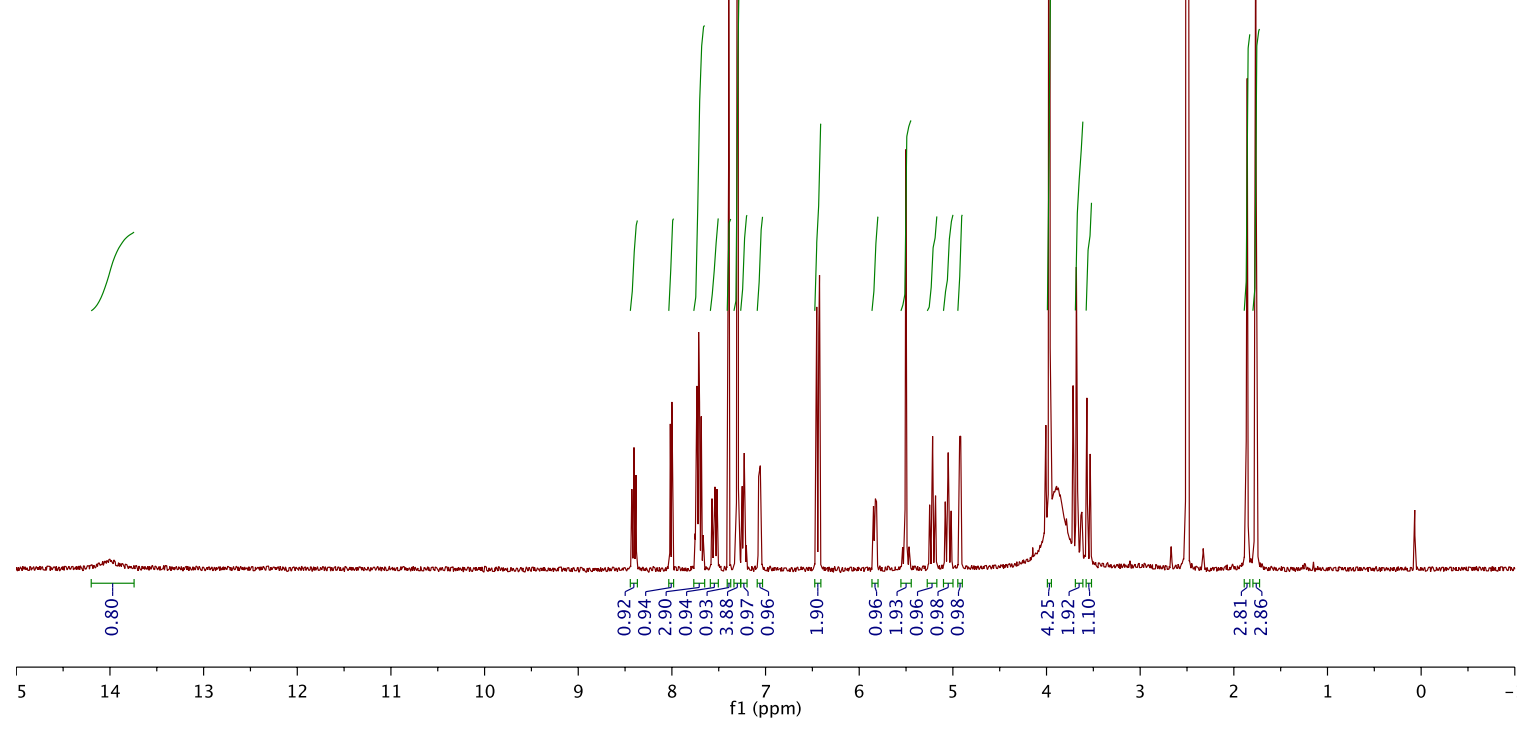

DAD1 A, Sig=254,4 Ref=off (2015_07\DAILYSQUENCE_LC 2015-07-24 13-26-1612015_07000011.D)

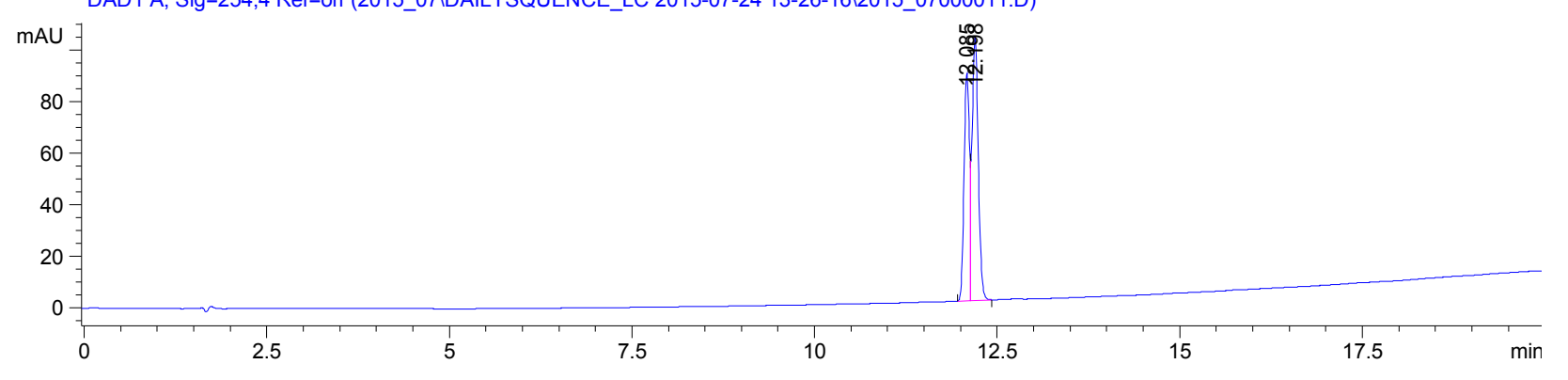

*MSD1 SPC, time=12.022:12.262 of C:ICHEM32I1IDATAI2015_07/DAILYSQUENCE_LC 2015-07-24 13-26-16|2015_07000011.D ES-API

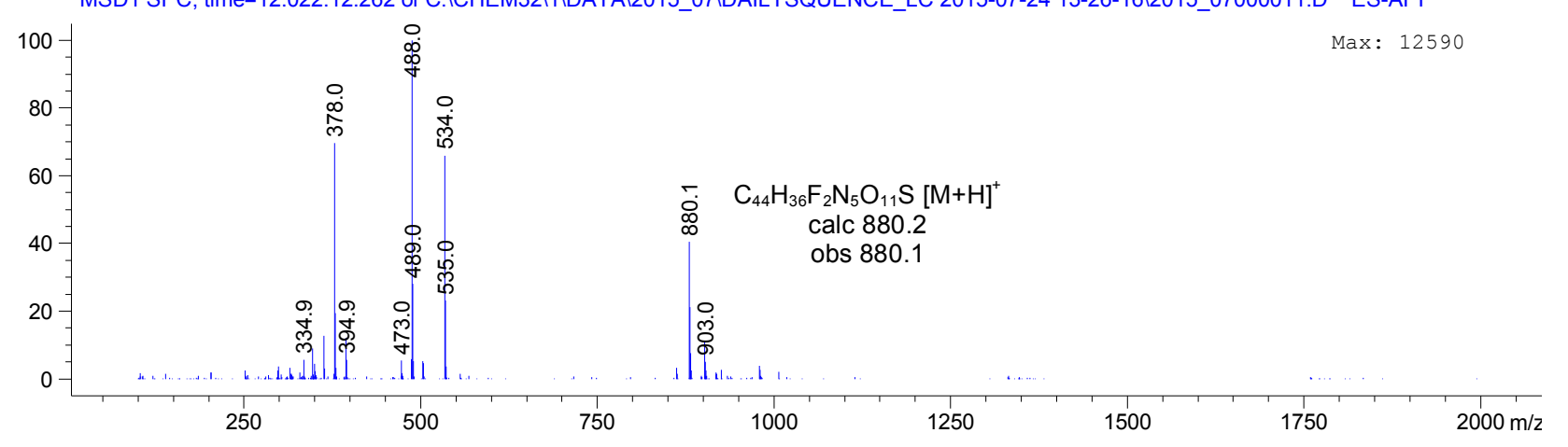



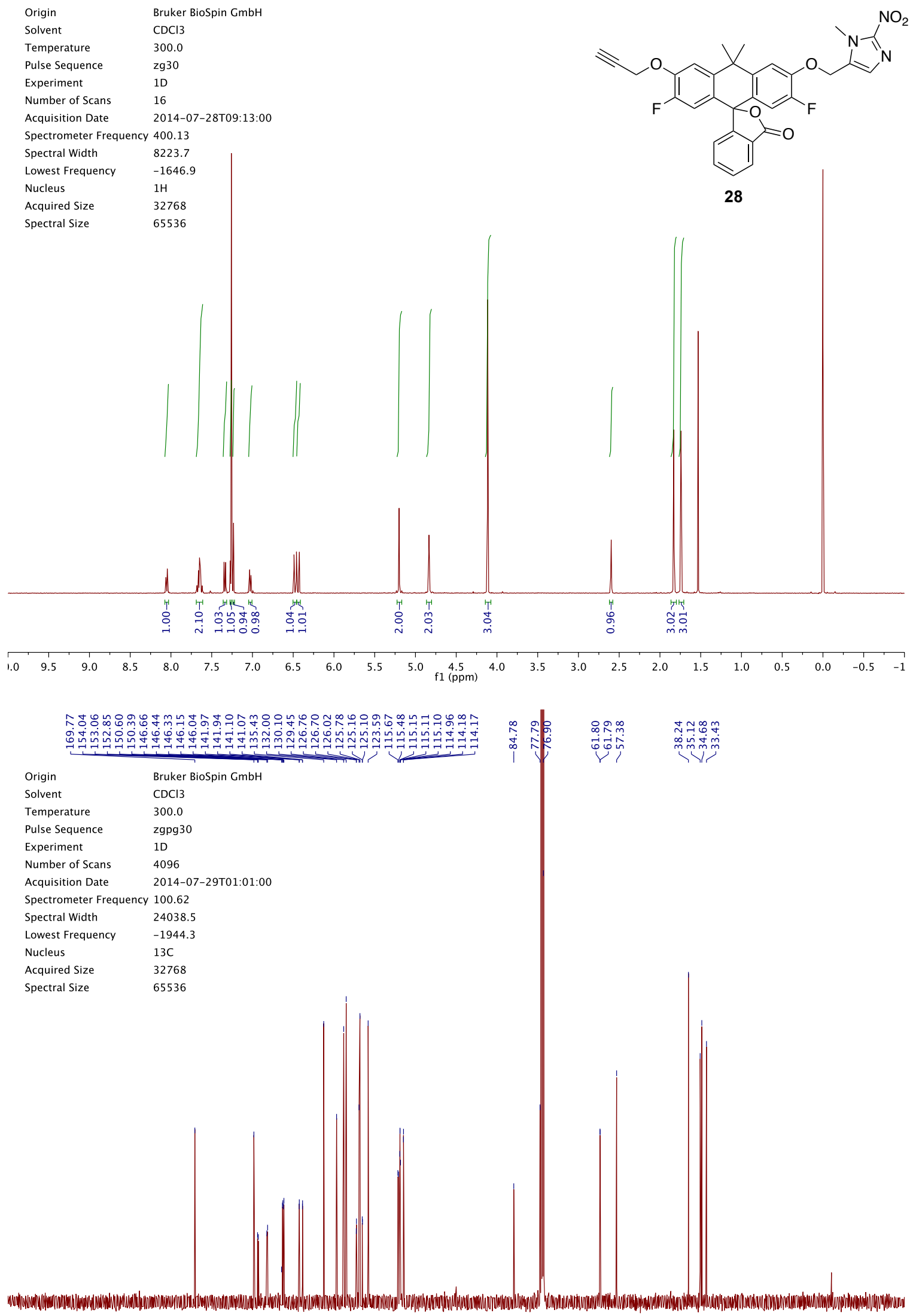

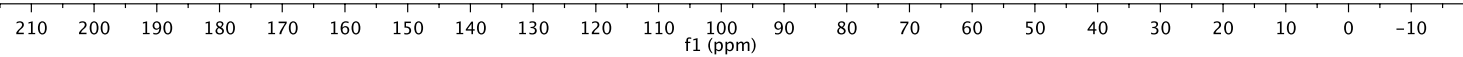




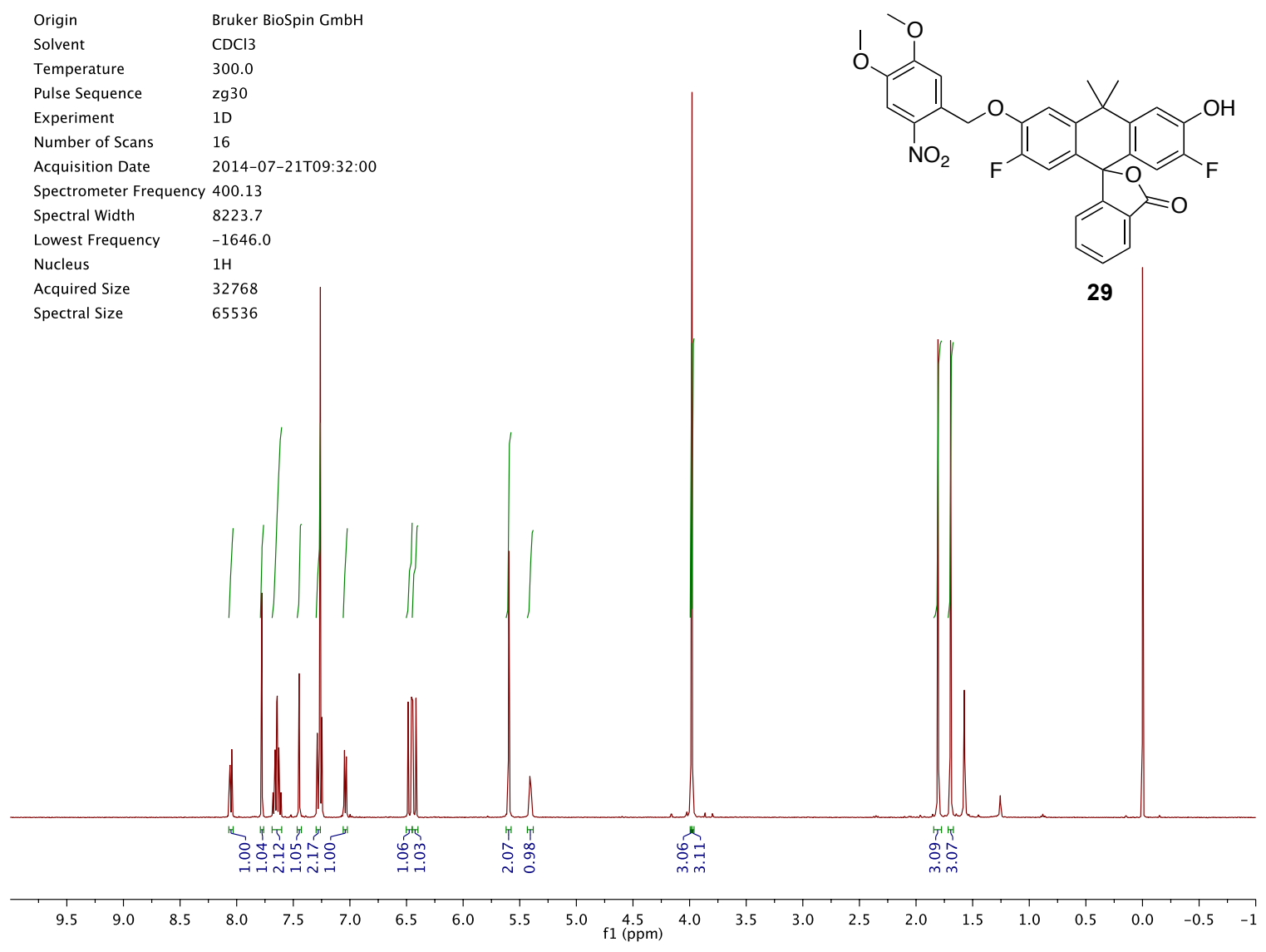

$\begin{array}{ll}\text { Origin } & \text { Bruker BioSpin } \mathrm{GmbH} \\ \text { Solvent } & \mathrm{CDCl} \\ \text { Temperature } & 300.0 \\ \text { Pulse Sequence } & \text { zgpg30 } \\ \text { Experiment } & 1 \mathrm{D} \\ \text { Number of Scans } & 8192 \\ \text { Acquisition Date } & 2014-07-19 \mathrm{~T} 04: 55: 00 \\ \text { Spectrometer Frequency } & 100.62 \\ \text { Spectral Width } & 24038.5 \\ \text { Lowest Frequency } & -1943.7 \\ \text { Nucleus } & 13 \mathrm{C} \\ \text { Acquired Size } & 32768 \\ \text { Spectral Size } & 65536\end{array}$

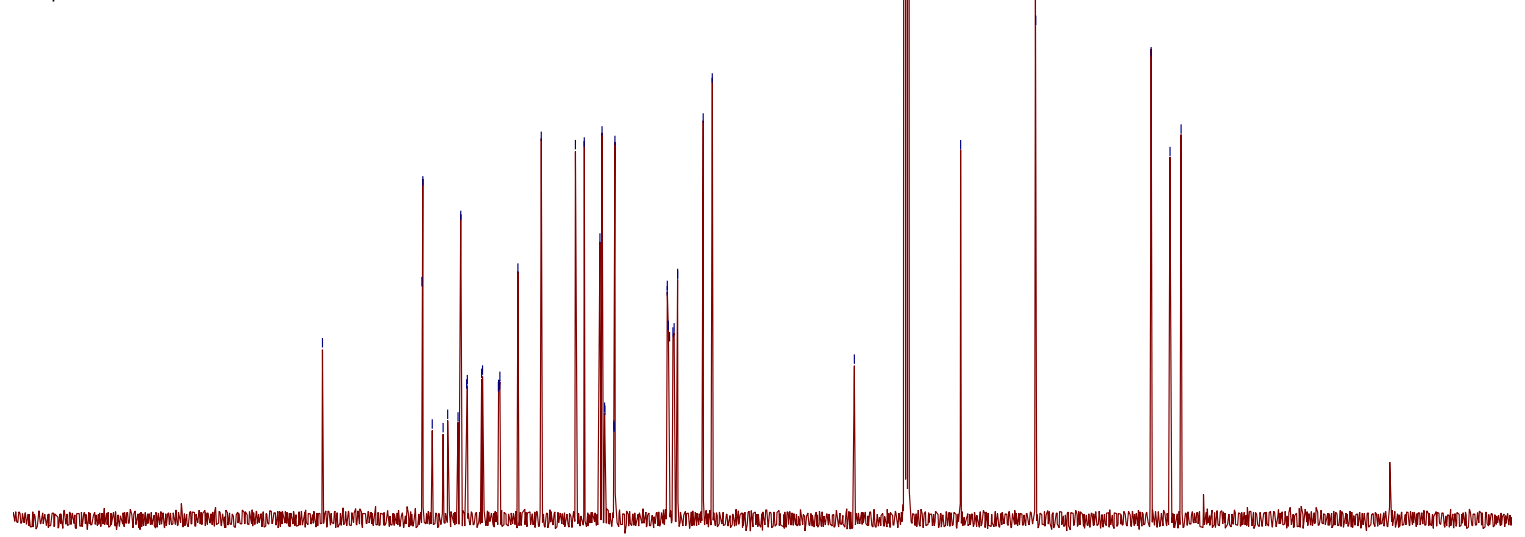

$\begin{array}{lllllllllllllllllllllll}210 & 200 & 190 & 180 & 170 & 160 & 150 & 140 & 130 & 120 & 110 & \underset{\mathrm{f} 1}{100}(\mathrm{ppm}) & 90 & 80 & 70 & 60 & 50 & 40 & 30 & 20 & 10 & 0 & -10\end{array}$ 


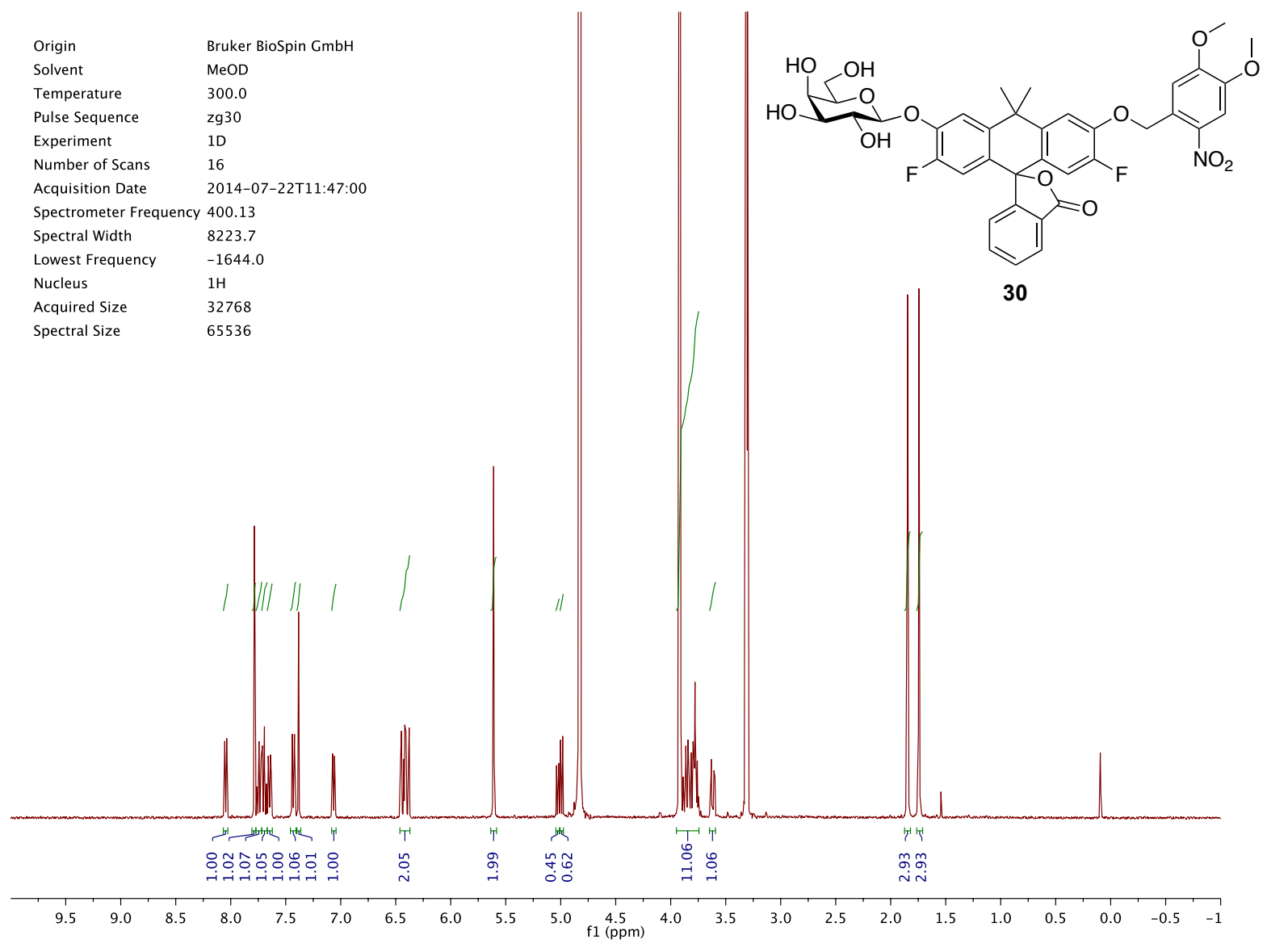

DAD1 A, Sig=254,4 Ref=off (2014_07IDAILYSQUENCE_LC 2014-07-21 10-47-1212014_07000013.D)

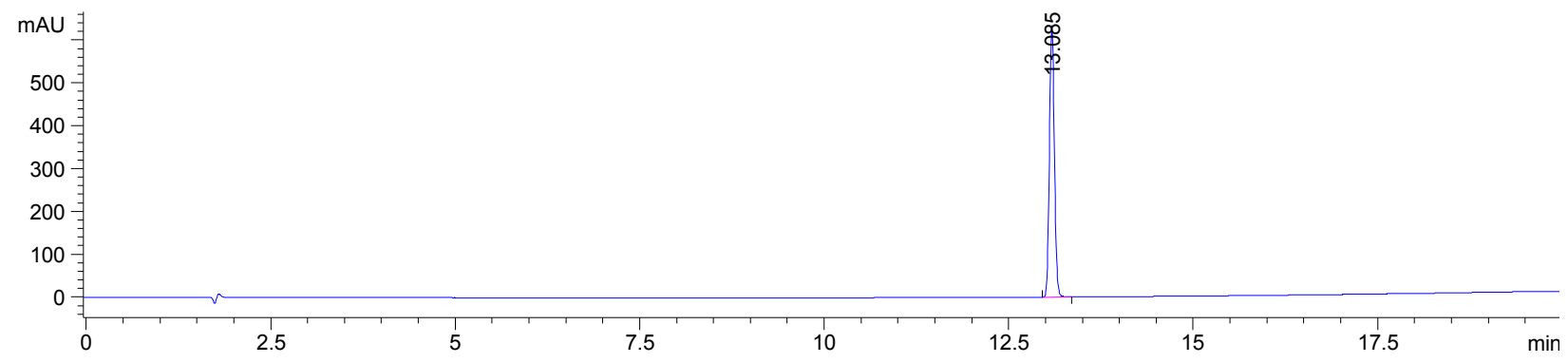

*MSD1 SPC, time=13.061:13.190 of C:ICHEM32।1IDATAI2014_07IDAILYSQUENCE_LC 2014-07-21 10-47-12l2014_07000013.D ES-API

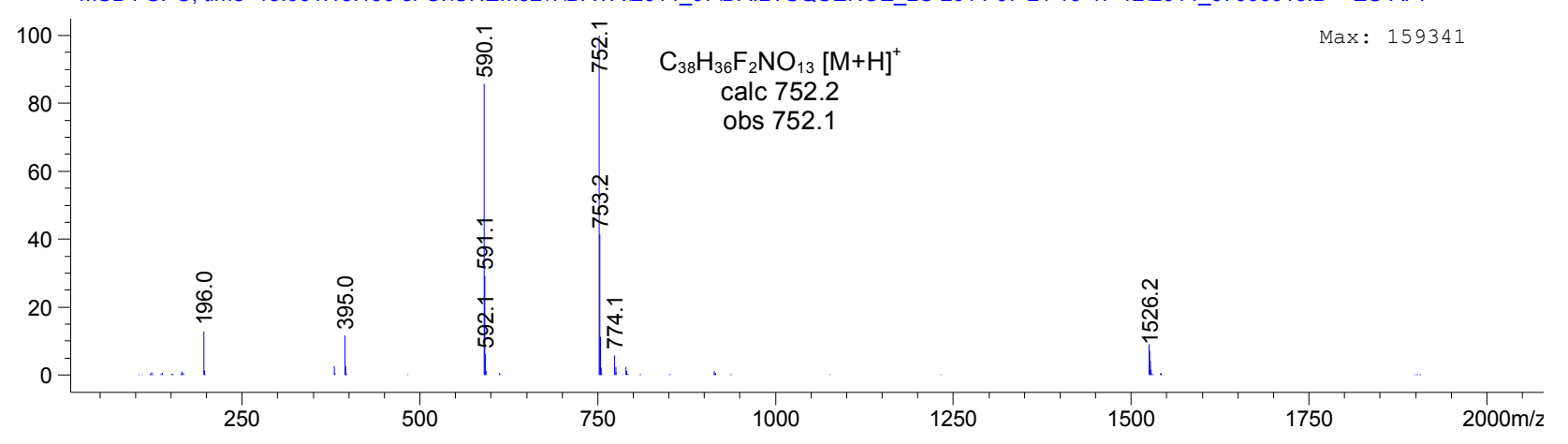



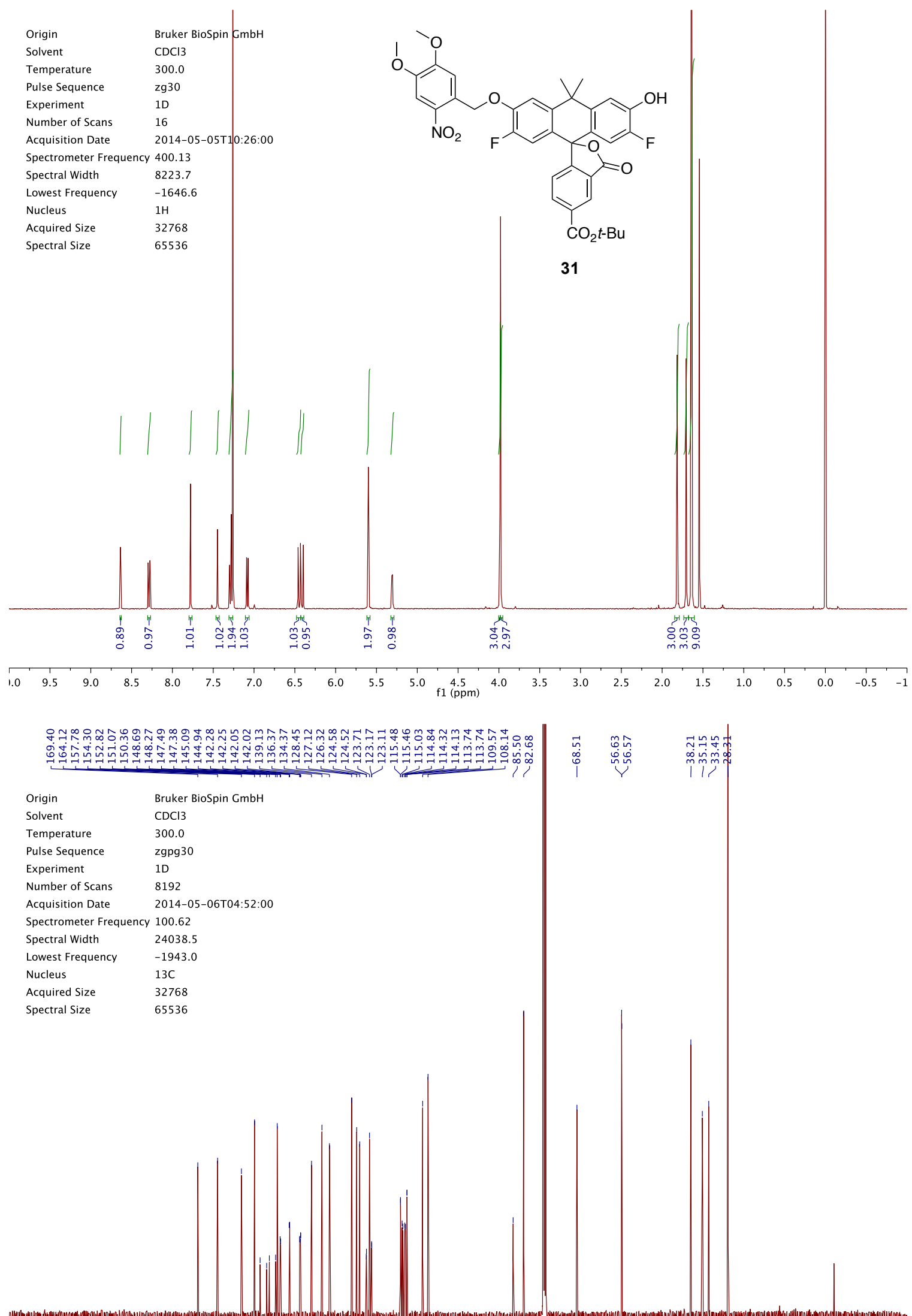

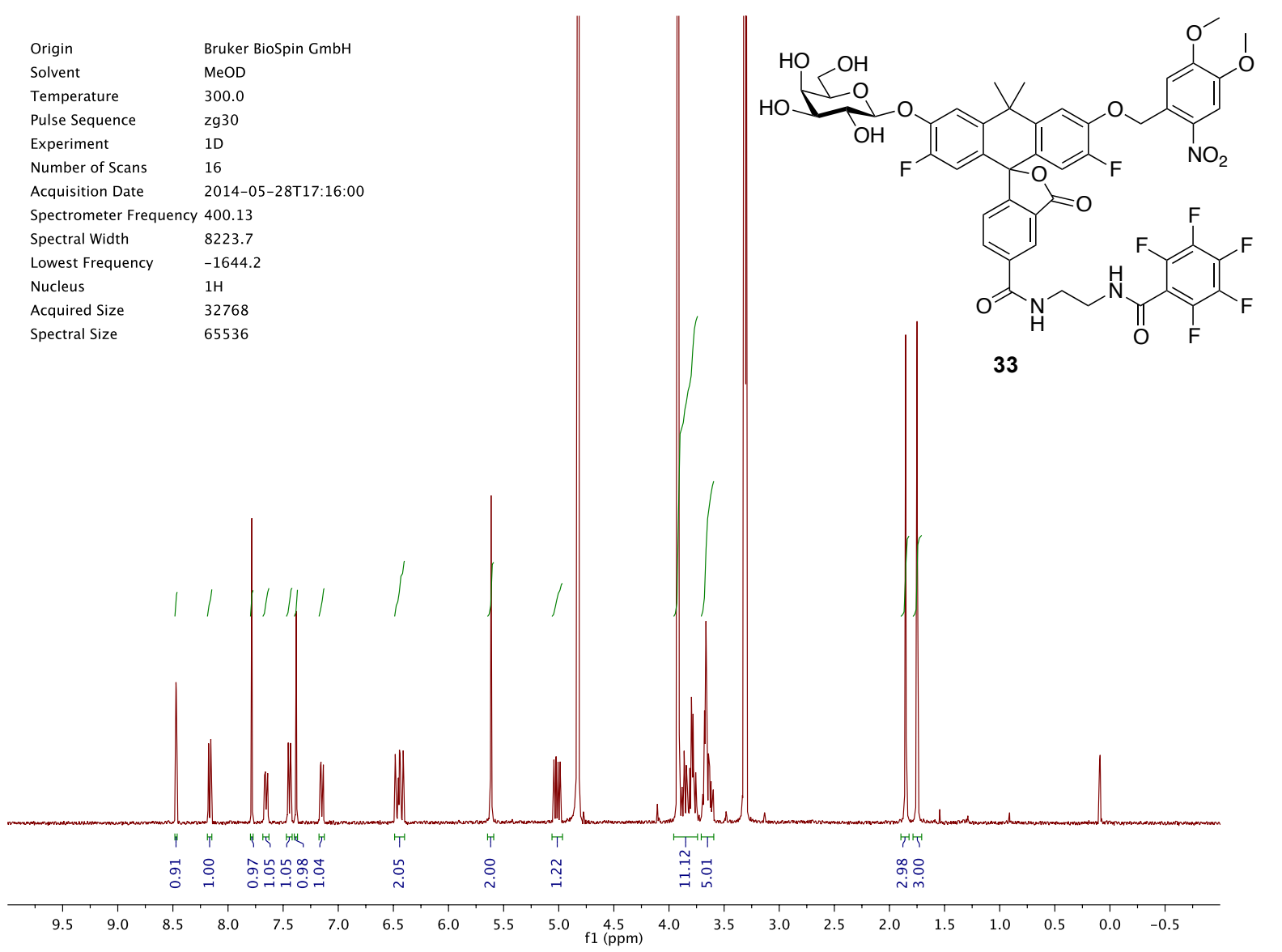

DAD1 A, Sig=254,4 Ref=off (C:ICHEM32O...DATAI2014_05IDAILYSQUENCE_LC 2014-05-27 14-24-45|2014_05000004.D)

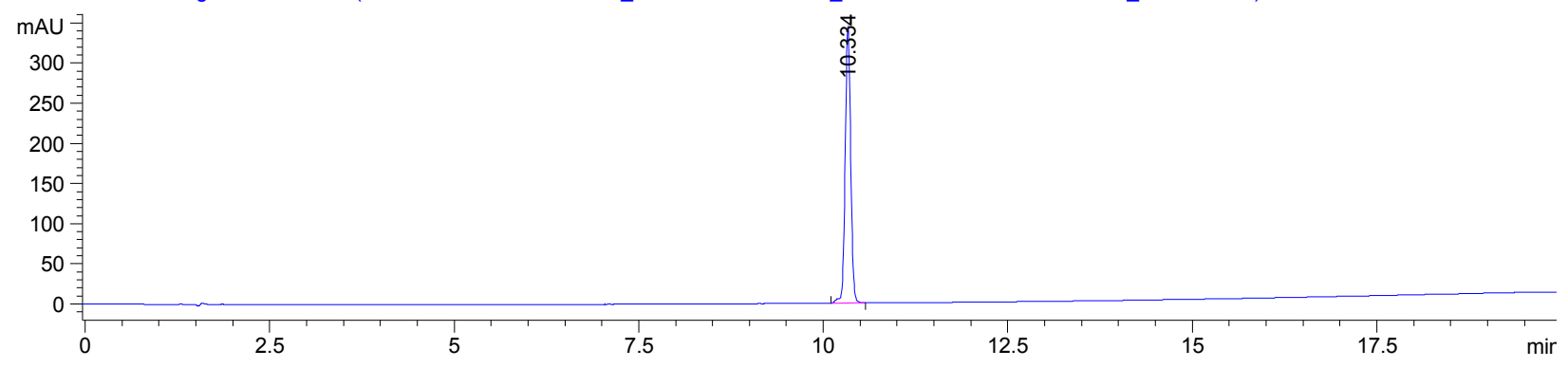

*MSD1 SPC, time=10.304:10.433 of C:ICHEM32OLDI1DATAI2014_05IDAILYSQUENCE_LC 2014-05-27 14-24-45|2014_05000004.D ES-

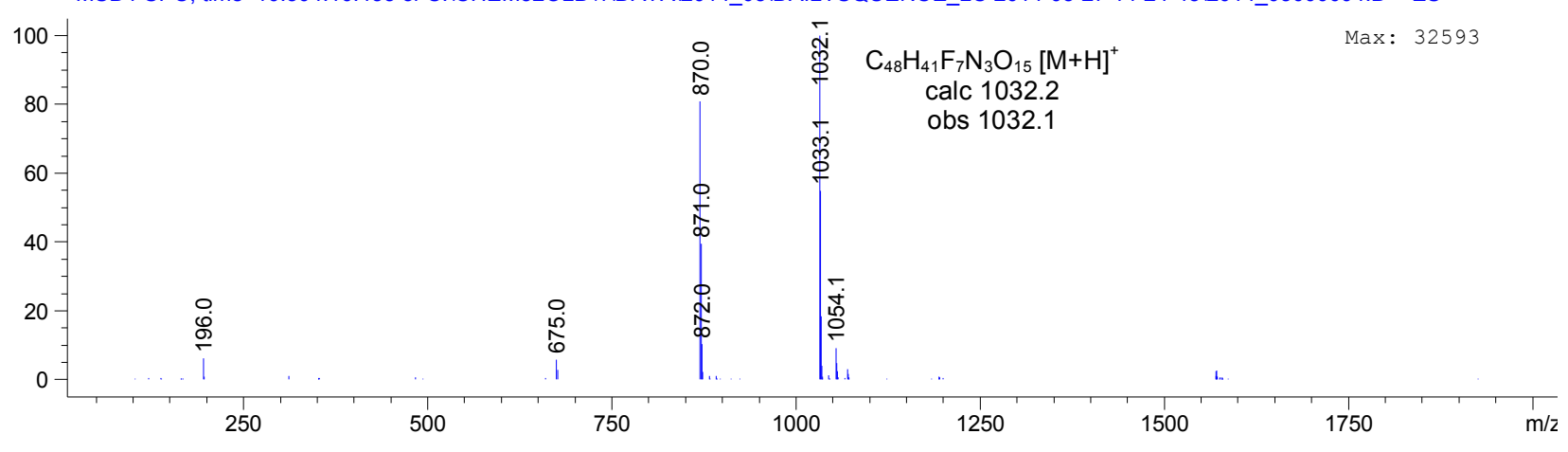

